Florida International University FIU Digital Commons

$11-6-2009$

\title{
Interactions between Endothelin Receptor B and Transcription Factors Sox 10 and Pax3 in the Melanocyte Lineage
}

Marcia Lowenstein

Florida International University, mlowenst@fiu.edu

DOI: 10.25148 /etd.FI09120806

Follow this and additional works at: https:// digitalcommons.fiu.edu/etd

Part of the Biology Commons, Cell and Developmental Biology Commons, and the Genetics Commons

\section{Recommended Citation}

Lowenstein, Marcia, "Interactions between Endothelin Receptor B and Transcription Factors Sox10 and Pax3 in the Melanocyte Lineage" (2009). FIU Electronic Theses and Dissertations. 117.

https://digitalcommons.fiu.edu/etd/117 


\title{
FLORIDA INTERNATIONAL UNIVERSITY
}

\author{
Miami, Florida
}

\section{INTERACTIONS BETWEEN ENDOTHELIN RECEPTOR B AND TRANSCRIPTION FACTORS SOX10 AND PAX3 IN THE MELANOCYTE LINEAGE}

\author{
A dissertation submitted in partial fulfillment of the \\ requirements for the degree of \\ DOCTOR OF PHILOSOPHY \\ in \\ BIOLOGY \\ by \\ Marcia K. Lowenstein
}

2009 
To: Dean Kenneth Furton

College of Arts and Sciences

This dissertation, written by Marcia K. Lowenstein, and entitled Interactions between Endothelin receptor $b$ and Transcription Factors Sox10 and Pax3 in the Melanocyte Lineage, having been approved in respect to style and intellectual content, is referred to you for judgment.

We have read this dissertation and recommend that it be approved.

Opheila I. Weeks

Alejandro Barbieri

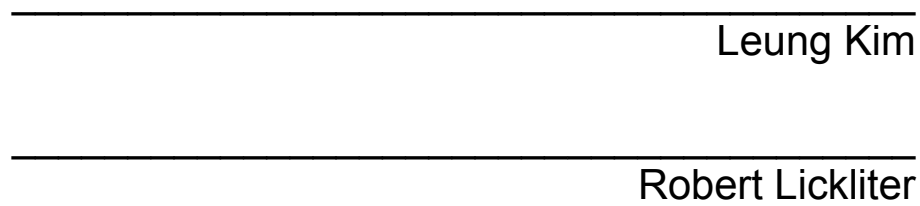

Robert Lickliter

Lidia Kos, Major Professor

Date of Defense: November 6, 2009

The dissertation of Marcia K. Lowenstein is approved.

\begin{tabular}{r} 
Dean Kenneth Furton \\
College of Arts and Sciences \\
\hline Dean George Walker \\
University Graduate School
\end{tabular}

Florida International University, 2009 


\section{DEDICATION}

To my husband, Henry, whose love and support gave me the strength to pursue my dreams,

To my children, Max, Ray, Elan and Aaron, whose love and smiling faces helped carry me through and always re-energized me, And to my parents, Esther and Jack Kravec and Ralph and Bronia Lowenstein, whose love and confidence encouraged me to reach for the stars. 


\section{ACKNOWLEDGMENTS}

I would like to thank Dr. Lidia Kos, my major professor, for taking me in when I was orphaned and letting me grow and flourish into what I have always been at heart: a developmental biologist. Years of intellectual discussions, the space and access to perform my experiments and friendship have made this journey a great one. For all that, I thank you Lidia.

I would also like to thank my committee members, Dr. Ophelia Weeks, Dr. Robert Lickliter, Dr. Alejandro Barbieri and Dr. Leung Kim for their support and guidance along the way. A very special thank you to Dr. Philip Stoddard, who treated me as if I were one of his own students and was always available to help me, and in fact contributed to many aspects of my data analysis and thought process. I would also like to thank Dr. Paulette Johnson who helped with the some of the statistical analyses of my data. To Denisse Diaz, who I met as a young undergraduate when she came to work with me in the lab and who provided much support and help during the busiest times of my research and was a invaluable assistant. I would also like to thank Myron Evans, another undergraduate assistant, who provided significant help with the novel phenotype project among other things. And to all my labmates, past and present, for always being helpful and making our lab a great place to work. Last but not least, I would like to thank Dr. James J. Valdes, Franchesca Ramirez and Barbara Juarez for their help with the novel phenotype project. Finally, I would like to thank the Minority Biomedical Research Support (MBRS; NIH/NIGMS R25 GM061347) for funding my research. 


\section{ABSTRACT OF THE DISSERTATION \\ INTERACTIONS BETWEEN ENDOTHELIN RECEPTOR B AND \\ TRANSCRIPTION FACTORS SOX10 AND PAX3 IN THE MELANOCYTE \\ LINEAGE \\ by}

Marcia K. Lowenstein

Florida International University, 2009

Miami, Florida

Professor Lidia Kos, Major Professor

Genetic interactions that underlie developmental processes such as cell differentiation and pattern formation are complex and difficult to elucidate. Neural Crest (NC) cells and their derivatives offer an optimal system in which to probe for these complex interactions as they acquire different cell fates and constitute a variety of structures. The transcription factors Sox10 and Pax3 as well as the transmembrane receptor Endothelin receptor b (Ednrb) are temporally and spatially co-expressed early in NC cells and mutations in these genes lead to similar hypopigmentation phenotypes due to a reduced number of NC-derived melanocyte precursors, the melanoblasts. The goal of this study was to establish whether Sox10 and Ednrb or Pax3 and Ednrb interact to promote normal murine melanocyte development. Crosses of Sox10 or Pax3 with Ednrb heterozygous mutants showed that the double heterozygous hypopigmentation phenotype was significantly more pronounced than 
phenotypes of single heterozygotes, implying that a synergistic interaction exists between Sox10 and Ednrb and Pax3 and Ednrb.

This interaction was further explored by the attempt to rescue the Sox 10 and Pax3 hypopigmentation phenotypes by the transgenic addition of Ednrb to melanoblasts. Pigmentation was completely restored in the Sox10 and partially restored in the Pax3 mutant mice. The comparison of the number of melanoblasts in transgenic and non-transgenic Sox10 mutant embryos showed that the transgenic rescue occurred as early as E11.5, a critical time for melanoblast population expansion. Cell survival assays indicated that the rescue was not due to an effect of the transgene on melanoblast survival.

A novel phenotype arose when studying the interaction between Ednrb and Pax3. Newborns appeared normal but by 3.5 weeks of age, the affected pups were smaller than normal littermates and developed a dome-shaped head; some also developed thoracic kyphosis. Affected pups were dead by 4 weeks of age: $80 \%$ were $\mathrm{Pax} 3^{\mathrm{Sp} /+}$ and $75 \%$ were female. When compared to normal littermates, affected mice had brains with enlarged $4^{\text {th }}$ ventricles and more glia while skeletal staining showed kyphosis, wider rib cages and pelvic differences. An epistatic interaction resulting from the mixing of genetic backgrounds that is exacerbated in the presence of Pax3 heterozygosity is suspected. 


\section{TABLE OF CONTENTS}

CHAPTER

PAGE

I. INTRODUCTION 1

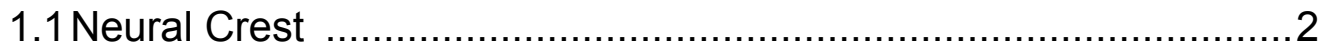

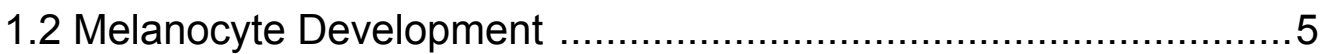

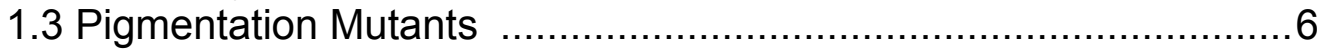

1.4 Genes Governing Murine Melanocyte Development .................... 14

1.5 Genetic Backgrounds and Modifiers ......................................... 16

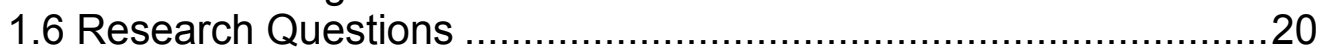

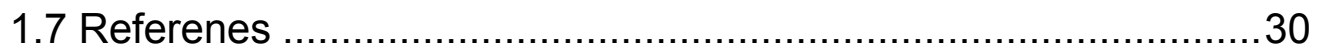

II. INTERACTION BETWEEN THE TRANSCRIPTION FACTORS SOX10 AND PAX3 WITH ENDOTHELIN RECEPTOR B IN THE MELANOCYTE LINEAGE

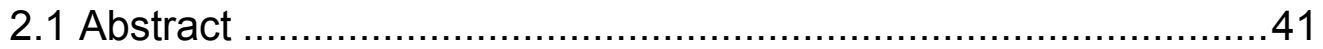

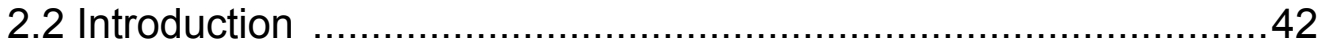

2.3 Materials and Methods ........................................................ 45

2.3.1 Animals and Genotyping ..........................................45

2.3.2 Crosses and Phenotype Analysis ..............................47

2.3.3 Statistical Analysis............................................... 48

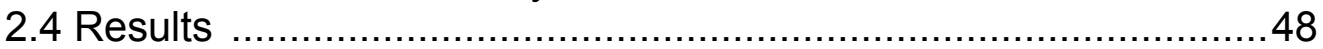

2.4.1 Genetic Interaction between Sox10 and Ednrb .............48

2.4.2 Genetic Interaction between Pax3 and Ednrb ................50

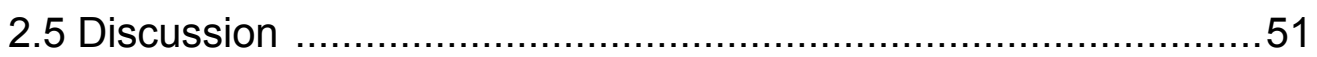

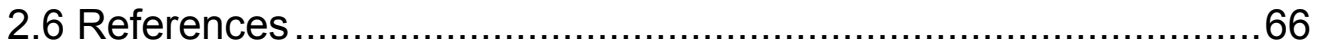

III. TRANSGENIC EXPRESSION OF ENDOTHELIN RECEPTOR B

RESCUES THE HYPOPIGMENTATION PHENOTYPE OF SOX10 AND

PAX3 HETEROZYGOUS MICE

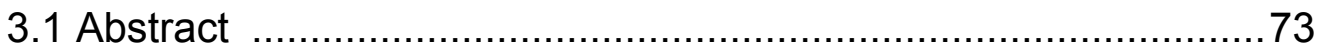

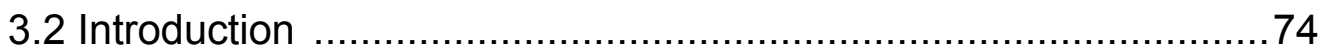

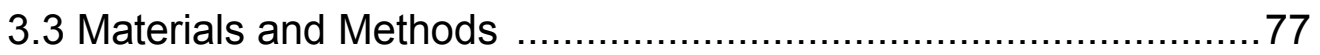

3.3.1 Animals and Genotyping …….................................

3.3.2 Crosses and Phenotype Analysis................................ 79

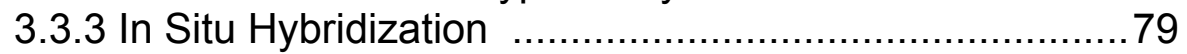

3.3.4 LysoTracker Red and LacZ Staining ...........................82

3.4 Results 83

3.4.1 Dct-Ednrb Transgene Rescues the Sox $10^{\text {LacZ/+ }}$ and Partially Rescues the Pax $3^{\mathrm{Sp} /+}$ Hypopigmentation 


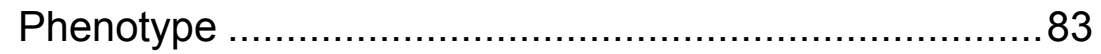

3.4.2 Transgenic Embryos Show Increased Numbers of Melanoblasts

3.4.3 Increased Numbers of Melanoblasts in Transgenic Embryos Cannot Be Accounted for by an Effect on their Survival

3.5 Discussion

3.6 References 101

IV. CROSS BETWEEN Ednrb ${ }^{\mathrm{S}-/ /+}$ AND Pax $3^{\mathrm{Sp} /+}$ RESULTS IN A NOVEL PHENOTYPE: HYDORCEPHALUS AND INTERMITTENT SKELETAL DEFORMITIES 105

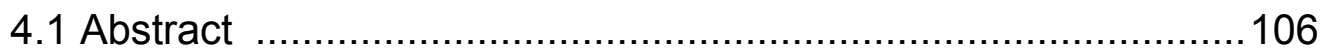

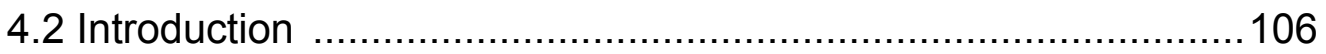

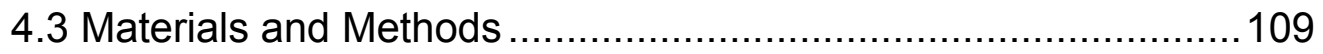

4.3.1 Animals and Genotyping ……..............................109

4.3.2 Crosses and Phenotype Analysis .............................. 110

4.3.3 Skeletal Staining.....................................................110

4.3.4 Brain Dissection ................................................111

4.3.5 Antibody Staining ..............................................112

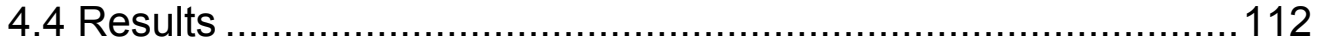

4.4.1 Realization of Novel Phenotype ..............................112

4.4.2 Sample Size and Demographics ............................. 113

4.4.3 Skeletal Abnormalities Seen in Mutant Mice ............... 114

4.4.3 Differences in Brain Morphology ............................... 114

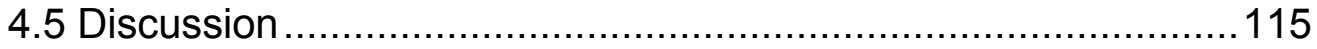

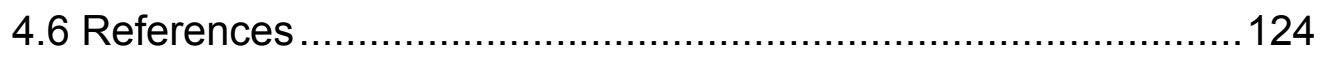

V. CONCLUSIONS, FUTURE DIRECTIONS AND IMPLICATIONS............127

5.1 Conclusions and Future Directions …..................................... 128

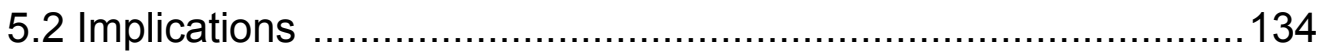

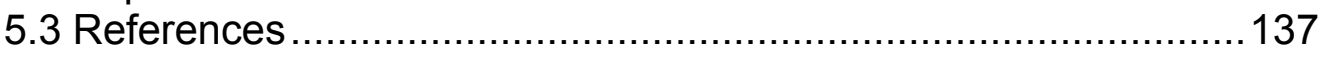

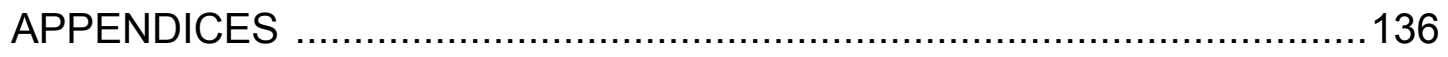

VITA 


\section{LIST OF TABLES}

TABLE

PAGE

CHAPTER II

2.1Sox10 and Ednrb double heterozygosity results in an aggravated phenotype

2.2 Wilcoxon rank sum test of hypopigmentation in Sox10 and Ednrb single heterozygoes versus double heterozygosity

2.3 Sums of Averages

2.4 Pax3 and Ednrb double heterozgosity results in an aggravated phenotype

2.5 Wilcoxon rank sum test of hypopigmentation in Pax3 and Ednrb single heterozygotes versus double heterozygosity

2.6 Sums of Averages

CHAPTER III

3.1 Complete rescue of Sox $10^{\mathrm{LacZ} /+}$ pigmentation by Dct-Ednrb transgene

3.2 Transgenic expression of Ednrb partially rescues the Pax $3^{\mathrm{Sp} /+}$ phenotype 93

3.3 Pmel17 labeled trunk melanoblasts

3.4 Transgenic rescue of Sox10 haploinsufficient cells is not due to an effect on melanoblast survival at E11.5

3.5 Transgenic rescue of Sox 10 haploinsufficient cells is not due to an effect on melanoblast survival at E12.5

\section{CHAPTER IV}

4.1 Distribution of affected progeny according to generation, genotype and gender

4.2 Dimensions of two brains 


\section{LIST OF FIGURES}

FIGURE

PAGE

CHAPTER I

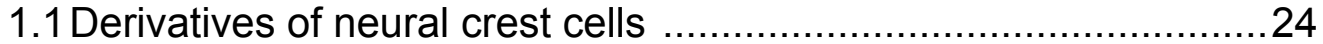

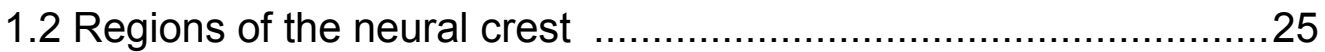

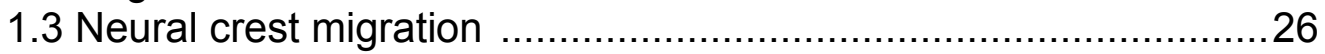

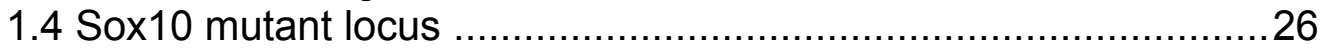

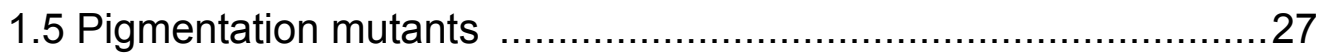

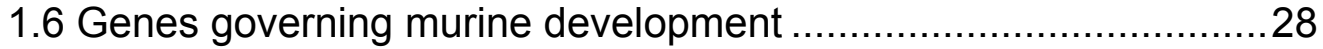

CHAPTER II

2.1 Sox10 and Ednrb double heterozygosity results in an aggravated

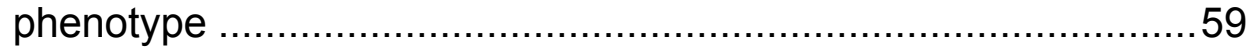

2.2 Double heterozygous progeny of generations 2 and 3 exhibit larger areas of hypopigmentation than single heterozygous animals .....60

2.3 Pax3 and Ednrb double heterozygosity results in an aggravated hypopigmentation phenotype ................................................63

2.4 Double heterozygous progeny of generations 2 and 3 exhibit larger areas of hypopigmentation than single heterozygous animals ....64

\section{CHAPTER III}

3.1 Transgenic rescue of the Sox $10^{\mathrm{LacZ} /+}$ pigmentation phenotype ....91

3.2 Dct-Ednrb transgene partially rescues the $\mathrm{Pax} 3^{\mathrm{Sp} /+}$ pigmentation phenotype

3.3 In situ hybridization with Pmel17 riboprobe shows increased numbers of trunk melanoblasts in transgenic embryos at E11.5 .95

3.4 LacZ staining of E11.5 Sox10 embryos shows transgenic rescue of melanoblasts in Sox10 heterozygotes

3.5 LacZ staining of E12.5 Sox10 embryos shows transgenic rescue of melanoblasts in Sox10 heterozygotes

CHAPTER IV

4.1 Normal and affected littermates 120

4.2 Skeletal staining showing curvature of the spine, rib cage expansion and hydrocephalic head.

4.3 Skull and pelvic differences

4.4 Brain morphology differences.

APPENDICES

A.1 Possible results of gel electrophoresis of mice tail DNA genotyping

A.2 Possible results of gel electrophoresis of mice tail or yolk sac DNA genotyping expansion and hydrocephalic head.... 
A.3 Defining the area for cell counts of Pmel17 positive cells LIST OF ABBREVIATIONS AND ACRONYMS

$\mathrm{BCIP}=5$-Bromo-4-chloro-3-indolyl-phosphate

$\mathrm{bp}=$ base pair

$\mathrm{BS}=$ belly spot

$\mathrm{C}=$ centigrade

cDNA = complimentary DNA

DNA = deoxyribose nucleic acid

Dct = DOPAchrome tautomerase

Dct-Ednrb $=$ transgene that delivers Ednrb to melanoblasts

der $=$ dermis

DMSO $=$ dimethyl sulfoxide

dNTP = deoxynucleotides

$\mathrm{DePC}=$ diethylpyrocarbonate

$\mathrm{E}=$ embryonic day

Edn3 $=$ Endothelin3

Ednrb $=$ Endothelin receptor $b$

$E M T=$ epithelial mesenchymal transition

ep $=$ epidermis

ET-B = avian Endothelin receptor $b$

EDTA = ethylene diaminetetra acetic acid

$\mathrm{EtOH}=$ ethanol

$\mathrm{F} 1=$ filial $1=$ generation 1

$\mathrm{F} 2=$ filial $2=$ generation 2

$\mathrm{F} 3=$ filial $3=$ generation 3

$\mathrm{g}=$ gram

GFAP = Glial Fibrillary Acidic Protein

$\mathrm{H}_{2} \mathrm{O}_{2}=$ hydrogen perioxide

$\mathrm{hD} \beta \mathrm{H}=$ dopamine- $\beta$-hydroxylaze

$\mathrm{hf}=$ hair follicle

$\mathrm{hr}=$ hour

$\mathrm{LB}=$ Luria Broth

$\mathrm{LiCl}=$ lithium chloride

Kitl $=$ Kit ligand

$\mathrm{mM}=$ millimolar

$\mathrm{M}=$ molar

$\mathrm{Mb}=$ melanoblast

$\mathrm{MeOH}=$ methanol

$\min =$ minutes

Mitf $=$ Microphthalmia-associated transcription factor

$\mathrm{ml}=$ milliliter

MSA = Migration Staging Area

$\mathrm{n}=$ sample size

$\mathrm{N}=$ generation produced by backcrossing a progeny with a parent 


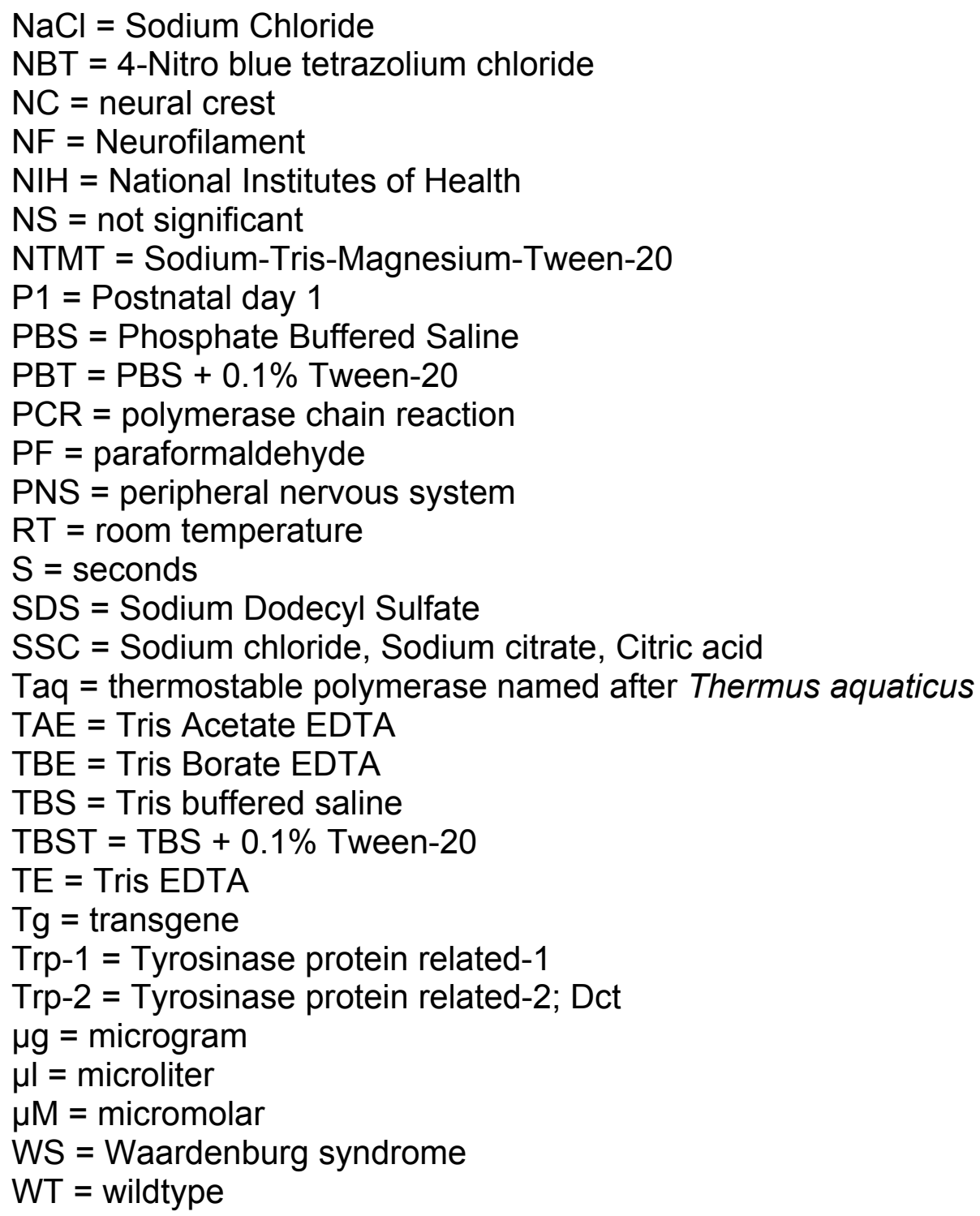


Chapter I.

INTRODUCTION 


\section{INTRODUCTION}

From fertilization to birth, cells undergo a series of changes that results in the transformation of nonspecific cells into a complex living organism that has all the necessary structures in the correct location time and time again. The transformation of cells that look identical into specialized cells with specific functions is the developmental process known as differentiation. As cells differentiate they must also receive signals that dictate the structure into which they will be incorporated; for instance keratinocytes, melanocytes, and fibroblasts need spatial and temporal orientation to become functional skin. These questions of differentiation and pattern formation can be elucidated by studying the genetic networks that control these processes. In vertebrates, the neural crest has served as a good model to study these questions.

\section{Neural Crest}

The neural crest (NC) is an ideal cell type in which to study cell fate and specification. Unique to vertebrates, NC cells arise in the developing neural tube and migrate to the far reaches of the developing organism, all the while differentiating in accordance to environmental signals they encounter along the way. Arising from the epithelium and undergoing mesenchymal transition (Duband et al., 1995), NC cells emigrate from the dorsal aspect of the neural tube. Depending on their migratory path these multipotent progenitor cells differentiate into a variety of cells (Figure 1), including melanocytes, Schwann cells, satellite cells, enteric glia, neurons and facial cartilage and bones (Anderson, 1989; LeDouarin and Kalcheim, 1999). The diversity of structures 
arising from the NC has long intrigued developmental biologists; the central question being, how does a group of cells that appears homogeneous give rise to such diverse structures within the organism (Dupin et al., 2001; Gammill and Bronner-Fraser, 2003; Shah et al., 1994)?

Development of the NC by protochordate ancestors is considered a major evolutionary event in vertebrates and thus appears to be conserved in species ranging from zebrafish to humans (Gammill and Bronner-Fraser, 2003; Gans and Northcutt, 1983), enabling us to study NC cells and their gene networks across species. Specifically the generation of NC cells begins as the ectoderm separates into the neural ectoderm (also known as the neural plate which gives rise to the central nervous system) and the non-neural ectoderm (which will give rise to the epidermis); the border between these two areas will give rise to NC cells (Gammill and Bronner-Fraser, 2003). As neurulation proceeds, a subset of these border cells will begin their emigration (Selleck and BronnerFraser, 1995; Serbedzija et al., 1994) and subsequently populate the entire length of the embryo. This process is exhaustive and once NC cells emerge and migrate, this border known as the neural crest ceases to exist.

Early NC markers include Snail (for mice and fish; Slug for birds) (Locascio et al., 2002), Foxd3 (Kos et al., 2001) and Group E Sox family members Sox9 (Mori-Akiyama et al., 2003) and Sox10 (Southard-Smith et al., 1998). Snail/Slug have been shown in cultured cells to be important for the epithelialmesenchymal transition (Cano et al., 2000) and in vivo for the proper specification (Aybar et al., 2003; LaBonne and Bronner-Fraser, 2000) and 
migration (LaBonne and Bronner-Fraser, 2000; Nieto et al., 1994) of NC progenitor cells. Foxd3 is essential for proper differentiation of NC cells and appears to act in concert with Snail/Slug on downstream targets necessary for neural crest determination (Sasai et al., 2001).

Neural crest cells respond to both cell autonomous and external signals based on spatiotemporal and developmental sensitivities (Le Douarin et al., 2004; Paratore et al., 2002b; Shah and Anderson, 1997). Often referred to as neural crest stem cells (NCSCs), many lineages appear to maintain a stem-like quality throughout life (Dupin et al., 2000; Kim et al., 2003). Stem cells are defined as those cells that remain undifferentiated and multipotent throughout their lives, and generate progeny that can either remain multipotent or have a bias towards terminal differentiation depending on external cues. While embryonic stem cells remain totipotent, many other types of stem cells are partially committed, probably due to the niche they inhabit; in turn, NCSCs give rise only to neural crest derivatives (Le Douarin et al., 2004; Morrison et al., 1997; Sommer, 2001).

In addition to the effects of intrinsic and extrinsic signals, terminal differentiation into specific tissues and structures also depends on the axial level from which the NC cells originate (Figure 2). Cranial NC cells migrate into the branchial arches and the face to form bones and cartilage of the face and neck, cranial nerves and some pigment cells. The vagal and sacral NC cells migrate from different regions in the embryo but both are instrumental in innervating the gastrointestinal tract of vertebrates. The cardiac NC contributes 
to, among other things, the musculoconnective tissue of large arteries of the heart and the septum that permits separation of the aorta and pulmonary artery (Le Douarin, 1982; Le Lievre and Le Douarin, 1975). Avian trunk NC cells migrate in two waves, the first wave migrating ventromedially and ultimately forming the sympathetic nervous system, glia of the peripheral nervous system (PNS) and the dorsal root ganglia while the second wave migrates dorsolaterally and is comprised of melanocyte precursors known as melanoblasts (Henion and Weston, 1997; Le Douarin and Teillet, 1974). Murine trunk NC cells also migrate in a temporally specified manner but vary from avian NC migration in that murine NC cells are seen in the dorsolateral pathway throughout the migratory period and it is those cells that will travel via the ventromedial and ventrolateral pathways that are temporally different (Serbedzija et al., 1994; Serbedzija et al., 1990). As with the avian NC, all NC cells that migrate via the dorsolateral pathway will become melanocytes while cells migrating via ventromedial and ventrolateral pathways will become glia of the PNS and the dorsal root ganglia as well as several other derivatives (LeDouarin and Kalcheim, 1999). The spatial-temporal pattern of NC cell migration may be indicative of some level of predetermination of cell lineage or may help restrict developmental potential as a consequence of timing and migratory path.

\section{Melanocyte Development}

The journey from NC cell to a fully mature pigmented melanocyte begins with the induction of the neural tube and the emergence of the NC. Cell lineage 
experiments show that at approximately E8.5, the first wave of murine NC cells begin their emigration through the dorsolateral and ventromedial pathways; migration down the ventrolateral pathway begins shortly afterwards (Serbedzija et al., 1994). By E11.5, melanoblasts have populated all regions of the murine embryo (Figure 3); as the embryo continues to develop, the melanoblasts cross the basement membrane that divides the dermis from the epidermis and most murine melanoblasts will subsequently take up residence in the hair follicle by E16.5 while the others remain in contact with the basement membrane on the epidermal side (Mayer, 1973). Once in the hair follicle, some melanoblasts will settle into a stem cell niche and remain there undifferentiated until the proper signaling pathway stimulates differentiation (Ohlstein et al., 2004). Other cells will continue differentiating and will begin the process of producing melanin shortly after birth. In addition to populating the hair follicle and the epidermis, melanocytes also provide pigment cells to the stria vascularis of the inner ear, the choroid of the eye, the Harderian gland and the atrioventricular valves of the heart (Brito and Kos, 2008; LeDouarin and Kalcheim, 1999).

\section{Pigmentation Mutants}

Mouse pigmentation mutants have been a source of fascination and interest to people over the ages. In fact, ancient Chinese documents reference mouse pigmentation mutants that include albino and yellow mice. In the 1700 s, mice were popular pets in Europe, China and Japan due to the ease of care and their many variations of coat color. Once Mendel's laws of inheritance were rediscovered in the early 1900's, it was quickly recognized that mice provided a 
situation similar to that of the peas - that genetics could be studied using coat color variation in mice. In this case however the model organism is a mammal and shares $95 \%$ genome homology with humans. In addition, the mouse genome has been extensively characterized and is easily manipulated thereby making the mouse an excellent candidate in which to study genetic interactions and disease (Jackson Laboratory, 2009; National Human Genome Research Institute, 2002).

Given that the NC is so important that it has been deemed the $4^{\text {th }}$ germ layer, melanocyte development - or the lack of - has afforded the opportunity to study the dynamics and specifics of NC specification and differentiation using pigmentation models to track NC cell development. Spontaneous pigmentation mutants such as Piebald lethal, Dom and Splotch have proven to be valuable models for understanding gene regulatory networks involved in the development of NC cells.

The piebald lethal mutation $\left(E d n r b^{\mathrm{S}-1}\right)$ spontaneously arose at Jackson Laboratory in April of 1959 in a second generation cross between a $\mathrm{C} 3 \mathrm{H} / \mathrm{HeJ}$ female mouse with a head blaze and a bellyspot and a wildtype C57BL/6 J male. Almost immediately, it was recognized that this mutation was a recessive allele as most pups were born black with white belly spots while several in each litter were born white with black eyes and a black spot or two around the ears and occasionally a black spot at the base of the tail. In addition to the difference in coat color, the white pups typically died within the neonatal period of a deficiency of myenteric ganglion cells (a decrease in the innervation of the 
lower intestinal tract). The mutant named lethal spotting also exhibited a hypopigmentation phenotype, although less severe than piebald lethal, and the same gastrointestinal lethality (Lane, 1966). Of interest is that the pigment cells (melanocytes) and the enteric neurons, which are responsible for proper innervation of the gastrointestinal tract, are both derived from NC cells (Le Douarin and Kalcheim, 1999).

The gene affected in piebald lethal mice encodes Endothelin receptor $b$ (Ednrb), a G-coupled seven transmembrane receptor (Hosoda et al., 1994), whose human homolog, $E D N R B$, is mutated in approximately $5 \%$ of cases of Hirschsprung disease (Chakravarti, 1996; Puffenberger et al., 1994). The Ednrb mutation has also been identified at the spotting lethal locus in the rat (Ceccherini et al., 1995; Gariepy et al., 1996; Shin et al., 1997) and in horses with the lethal white foal syndrome (Santschi et al., 1998).

The murine lethal spotting locus $\left(E d n 3^{/ s}\right)$ encodes the Ednrb ligand, Endothelin 3 (Edn3) (Baynash et al., 1994). Endothelin 3 is a member of a group of three related peptides, Edn1, Edn2 and Edn3, each encoded by a separate gene. The peptides are produced as inactive preproendothelins that undergo successive proteolytic cleavages to generate the 22 amino acid active endothelins.

The developmental expression patterns of Ednrb and Edn3 have been analyzed in avian and murine embryos. These studies showed that Edn3 is expressed in the environment through which NC cells migrate while Ednrb is expressed by the NC cells themselves (Hou et al., 2004; Nataf et al., 1998; 
Nataf et al., 1996). Avian cells giving rise to melanocytes, however, express not Ednrb but a closely related receptor, Ednrb2 (Lecoin et al., 1998; Stone et al., 1997).

In mice homozygous for Ednrb, there is a drastic reduction in the number of melanocyte precursors from the time they can be detected by the expression of the DOPAchrome tautomerase marker ( $D c t$, also referred to as tyrosinase related protein-2, Trp2). DOPAchrome tautomerase is first detected at E10.5 as melanocyte precursors have already undertaken the dorsolateral pathway. This suggested that the expression of functional Ednrb is important for the proper migration of melanocytes before or just before E10.5 (Pavan and Tilghman, 1994). Ednrb was then expressed at different stages of embryogenesis under the control of the tetracycline inducible system and confirmed that Ednrb expression is required from E10.5-12.5 (Shin et al., 1999). Broad expression of Ednrb is seen throughout the developing embryo; the Ednrb/Edn3 signaling pathway appears to be critically important at E10.5-12.5 for the migration of melanoblasts and enteric neuron precursors (Lee et al., 2003; Shin et al., 1999).

In vitro studies in the quail showed that Edn3 markedly increases the proliferation of pluripotent NC cells and eventually stimulates dramatic increases in the number of melanocytes (Lahav et al., 1996; Stone et al., 1997). In primary mouse NC cultures, Edn3 also increases the number of melanocyte precursors (Reid et al., 1996). These observations are consistent with the genetic data of Ednrb mutations and the previous demonstration that 
melanocyte precursors in vitro have binding sites for radio labeled Edn1, which binds to Ednrb (as well as to a second murine Endothelin receptor - EdnrA) (Reid et al., 1996).

In an attempt to rescue the mutant phenotype (spotting and enteric aganglionosis) of the lethal spotting rat in which functional expression of Ednrb is abolished, a transgenic rat expressing Ednrb under the control of the human dopamine- $\beta$-hydroxylase $(\mathrm{hD} \beta \mathrm{H})$ promoter was created (Gariepy et al., 1998). Rescue of the enteric aganglionosis phenotype was obtained in the progeny resulting from the cross of the spotting lethal rat and the $\mathrm{hD} \beta \mathrm{H}-E d n r b$ transgenic rat. However, the pigmentation phenotype was not rescued. This partial rescue can be attributed to the fact that in the rat, the $\mathrm{hD \beta H}$ promoter directs expression only to a subset of central nervous system and PNS precursor cells, not to melanocytes or their precursors. Expression is driven in vagal NC cells (precursors of enteric neurons) from the stage at which they begin to colonize the foregut but not during their migratory steps (Kapur et al., 1991). The $\mathrm{hD} \beta \mathrm{H}-E d n r b$ transgene's ability to prevent enteric aganglionosis shows that the critical time for the action of Ednrb during the development of enteric neurons occurs after the divergence from the melanocytic lineage and after they have reached the gut.

The Dominant megacolon (Sox $10^{\text {Dom }}$ ) mutant also arose spontaneously in a hybrid stock carrying bouncy (B6C3Fe $a / a-b c$ ) at N12 in 1979. Heterozygous animals are characterized by variable white spotting and aganglionic megacolon. Homozygous animals are embryonic lethal and die around E13.5 
depending on the genetic background. These phenotypes result from the synthesis of a C-terminus truncated Sox10 (Sry-like high mobility box 10) protein due to a point mutation that introduces a premature termination codon in the Sox10 gene (Kuhlbrodt et al.,1998; Southard-Smith et al., 1998). Sox10 belongs to a class of transcription factors of the high mobility group (HMG) showing HMG domain homology to the testis-determining factor SRY. It has been proposed that the truncated Sox10 allele may exert its phenotypic effect by acting in a dominant negative manner (Potterf et al., 2000).

Sox10 has been implicated in regulation of cell survival, proliferation and cell specification (Schepers et al., 2002; Wegner, 1999). The heterozygous mutation in humans results in neurocristopathies, the best known being Waardenburg syndrome type II or type IV (Bondurand et al., 2007; Herbarth et al., 1998; Paratore et al., 2002a; Pusch et al., 1998). A mouse mutant was created in which LacZ was inserted into the Sox10 locus. The mutant displays the same phenotype as Sox ${ }^{\text {Dom }}$ (Figure 5); apart from being important in the development of melanocytes and enteric ganglia, Sox10 is also critical for the proper differentiation of Schwann cells (Britsch et al., 2001) In addition, it has been reported that Sox10 deficient mice lack an adrenal medulla as a result of inappropriate specification of NC cells at the onset of migration and subsequent cell death (Reiprich et al., 2008).

Sox proteins are found in all tissues and cells that have been analyzed thus far, and not surprisingly, the individual Sox proteins have very precise speciesspecific patterns and locations (Carney et al., 2006; Hou et al., 2006; Wegner, 
1999). An additional feature of Sox proteins is that, depending on the cellular context, they partner exclusively with other proteins in order to activate downstream targets, as in the case of Sox10 and the transcription factor Pax3 for downstream activation of Mitf, a master melanocyte regulatory transcription factor (Bondurand et al., 2000; Kuhlbrodt et al., 1998). In the case of Sox10 and Pax3, activation of Mitf varies from 500-fold with Sox10 to 10 -fold with Pax3 to $>1500$-fold with Sox10 and Pax3 (Bondurand et al., 2000).

Cell survival, proliferation and specification are the first roles played by Sox10 in the melanocyte lineage (Lee et al., 2000; Mollaaghababa and Pavan, 2003). Neural crest cells initially appear normal in the absence of Sox10 and even begin migration; it is shortly after, in the post-migratory NC population that abnormalities begin: cells become apoptotic and homozygous embryos start dying shortly afterward (Kapur, 1999; Southard-Smith et al., 1998). During specification of melanocytes, Sox10 has been shown to activate Mitf, and together they activate DOPAchrome tautomerase $(D c t)$. Dct functions in the biosynthetic pathway of eumelanin (black pigment), initiating melanogenesis (Ludwig et al., 2004; Tsukamoto et al., 1992).

Splotch $\left(P a x 3^{S P}\right)$ is another spontaneous mouse mutant that displays a spotting phenotype. Splotch is a point mutation within intron 3 of the paired homeobox $3(\operatorname{Pax} 3)$ gene that partners with Sox10. The mutation interferes with normal splicing of intron 3 and results in 4 aberrantly spliced mRNAs with exon 4 deleted. The $\mathrm{Pax}^{\mathrm{SP}}$ mutation also disrupts the homodimerization of the protein, a function associated with the octapeptide-encoding central segment of 
the gene (Epstein et al., 1993) that partners with Sox10. Pax3 is a member of the paired class homeodomain family of transcription factors and first appears in the murine embryo at E8.5 precisely at the dorsal part of the neural tube just before closure (Goulding et al., 1991). It is subsequently found in the developing brain, the dermomyotome of the developing somites, in the limb buds and some craniofacial structures. Mice heterozygous for Pax3 mutations display belly spotting, with occasional dorsal spotting on the back or tail. Pax3, like Sox10, is essential for life and homozygous mutants fail to develop many structures determined by the NC and are embryonic lethal by E13.5. Homozygous embryos display limb abnormalities, exencephaly, heart defects, open neural tube (spina bifida) and abnormal tail morphology. In humans, heterozygous loss of function PAX3 mutations cause Waardenburg Syndrome I and III (WSI,III). WSI phenotypes include abnormal placement of the inner canthus of the eye resulting in a wide nasal bridge formation, skin hypopigmentation, heterochromia iridis and deafness. WSIII phenotypes include skeletal abnormalities and cardiopulmonary defects together with the phenotypes observed in WSI.

Pax3 is crucial for survival of melanocyte progenitors until they reach the migrating staging area (MSA; in chick) where they stay for 24 hours before continuing their migration (Hornyak et al., 2001). Required for the expansion of the progenitor population, one of the most interesting of Pax3's functions is its promotion of melanocyte development while simultaneously inhibiting terminal differentiation. This is accomplished by Pax3 activating Mitf while competing 
with Mitf for binding sites on the Dct promoter (Corry and Underhill, 2005; Hornyak et al., 2001; Lang et al., 2005).

\section{Genes Governing Murine Melanocyte Development}

The identification of the genes mutated in $E d n r b^{S-1}$, Sox $10^{D o m}, P a x 3^{S p}$ as well as other spontaneous pigmentation mutants including Dominant white $\left(K_{i t}{ }^{W-v}\right)$, Slaty $\left(D c t^{s l t}\right)$, Silver $\left(P m e / 17^{s i}\right)$, Belted $\left(\right.$ Adamts20 $\left.{ }^{b t-2 J}\right)$ coupled to genetics and developmental biology studies on insertional and targeted mutants has allowed for the delineation of the molecular sequence of events involved in the process of skin melanocyte development (Figure 6). Premigratory NC cells express transcription factors such as Snail/Slug, Sox10 and Pax3 that do not impose a particular fate until certain signaling molecules change the patterns of gene expression (Bondurand et al., 2000; Locascio et al., 2002). It appears that the members of the Wnt family, Wnt1 and Wnt3, are required for these cells to commit to the melanocytic lineage (Bronner-Fraser, 2004; Dunn et al., 2000; Hari et al., 2002). The Wnt pathway transcriptionally regulates the expression of Mitf by the activation of $\beta$-catenin and Lef1 (Takeda et al., 2000). At this point, those NC cells that left the neural tube and took the dorsolateral pathway have undergone their first commitment step to becoming a melanoblast. The Kitt/Kit pathway is required for the proliferation and survival of these cells by activating Mitf at the protein level (Nishikawa et al., 1991; Opdecamp et al., 1997; Yoshida et al., 1996). During this first commitment step, Sox10 and Mitf cooperatively activate the expression of dopachrome tautomerase (Dct) (Jiao et al., 2004; Ludwig et al., 2004; Potterf et al., 2000). 
$D c t$ is a melanogenic enzyme and it is not clear why it is expressed at this early stage since melanin is only produced at the end of the process of differentiation, about six days later. Another specification marker expressed at this time is the melanosomal protein Pmel17 (Baxter and Pavan, 2003). Kit//Kit signaling is no longer required, and the Edn3/Ednrb pathway takes over controlling the expansion of the committed melanoblast population and, most likely, allowing these cells to migrate further and reach the prospective skin (Shin et al., 1999; Yoshida et al., 1996). Edn3/Ednrb signaling regulates the expression of Mitf both at the transcriptional and translational level, guaranteeing melanoblast survival and regulation of the melanogenic proteins Dct, Trp1, and Pmel17 (Sato-Jin et al., 2008). While traveling along the dermis, extracellular matrix proteins and metaloproteases such as Adamts20, are not only required for their proper migration but also for their survival (Silver et al., 2008). As melanoblasts cross the dermal/epidermal junction they undergo final differentiation by expressing tyrosinase, the rate limiting enzyme for melanin production. While Edn3/Ednrb signaling is not necessary for those melanoblasts that have reached the epidermis, it is still capable of regulating the expression of tyrosinase both transcriptionally and translationally (Sato-Jin et al., 2008). In the epidermis, Kit//Kit signaling becomes critical one more time allowing for the survival of fully committed melanocytes (Yoshida et al., 1996). Those melanocytes that reach the hair follicles remain, and some dedifferentiate to become the melanocyte stem cells that generate new transition 
cells at each hair cycle stage. No differentiated melanocytes remain in the epidermis.

\section{Genetic Backgrounds and Modifiers}

Epistatic relationships between genes is a concept that dates back more than half a century (Haldane, 1941). More recently, definitions describing this concept have emerged with the majority opinion converging on the explanation that a modifier is a gene that alters the expression of another gene, typically at another loci (Futuyma, 1998; Suzuki et al., 2004). As the complexities of genetic interactions come into focus, there is more and more interest from both scientists and medical clinicians to investigate modifier genes: from the standpoint of understanding underlying genetic networks to being able to treat both monogenic and multigenic diseases that present with varying levels of expressivity and penetrance in human patients. An example of a disease state in which gene expression and penetrance of severity can vary between families but also within families is Waardenburg Syndrome (WS). Waardenburg syndrome is a neurocristopathy (disease of the NC) in which one of several melanogenic genes are responsible for the majority of the cases in which the genetics have been elucidated. Mutations in the genes SOX10, PAX3, MITF, $S N A / 2, E D N 3$ and $E D N R B$ have been identified in variant forms of WS and associated with particular signs and symptoms which can include white forelock, cochlear deafness, craniofacial anomalies, aganglionosis and skeletal deformities of the upper limbs (Bondurand et al., 2007; Puffenberger et al., 1994; Sanchez-Martin et al., 2002; Tassabehji et al., 1994; Tassabehji et al., 
1992). Fortuitously, mice carrying similar mutations of the aforementioned genes are good models for the study of WS in humans (Tachibana et al., 2003).

Studying modifier genes in WS or other diseases turns out to be complicated and results are difficult to interpret due to the multitude of unknown factors that may potentially affect any aspect of gene expression. Not only is the type of mutation important, but expressivity and penetrance may also be influenced by the position of the mutation (i.e., which exon carries the mutation) or whether the mutation is in a cis or trans position. In addition, mutations of the same gene may have pleiotropic effects on phenotypic expression (Genin et al., 2008; Goldfarb et al., 1992; Gouya et al., 2006).

One study that looked at epidermal growth factor receptor $\left(E g f r^{t m / M a g}\right)$ during embryonic development identified that the timing of the interaction was dictated by the background in which the mouse was bred and that these background strains significantly influenced the timing of homozygous lethality (Strunk et al., 2004). Depending on the background, the critical time for epistatic influence on the known genetic mutation varied in distinct windows of time: from E4.5-9.5, E10.5-13.5 and E14.5-18.5. Over 15 different in-bred background strains were analyzed but of particular interest to the current study were that embryos on a C57BL/6J background died in mid-gestation while those embryos on a $\mathrm{C} 3 \mathrm{H}$ background died in late gestation. Strunk and colleagues (2004) concluded that modifiers were present in all backgrounds yet function varied according to varying temporal programs. And while the Egfr homozygous condition was consistently embryonic lethal in all background strains, the study provided a 
view into the temporal window of epistatic connections and that what may appear as stochastic in nature is not.

In another study, a mutation that interferes with cardiac formation actually proceeded to different stages of development depending on the background strain of the mouse (Astrof et al., 2007). Mice with the $F N$-null mutation (absence of fibronectin) die very early during embryonic development; embryos on the 129S4 background die of cardia bifida while those embryos on a C57BL/6J background develop a central looped heart and die at a later embryonic age. To identify novel gene candidates for modifiers of cardiac development, F2 intercrosses between 129S4 and C57BL/6J strains were used for genetic mapping and haplotype analysis. These analyses revealed a $1 \mathrm{Mbp}$ interval on mouse chromosome 4 that contains a modifier of cardiogenesis in FN-null mice. Microarray analysis on wildtype, heterozygous and homozygous FN embryos identified 21 candidate genes, 5 of which had differential expression between the two background strains.

Neural crest development appears to be influenced by modifiers in background strains as well. As previously discussed, NC progenitors destined for the enteric nervous system are modulated by the interaction between Sox10 and Ednrb; their mutations also appear to be modulated by modifiers present in the $\mathrm{C} 57 \mathrm{BL} / 6 \mathrm{~J}$ and $\mathrm{C} 3 \mathrm{H}$ backgrounds. The $\mathrm{C} 57 \mathrm{BL} / 6 \mathrm{~J}$ background aggravated the aganglionosis phenotype and decreased hypopigmentation while the $\mathrm{C} 3 \mathrm{H}$ background produced the opposite effects. In fact, the effects on aganglionosis penetrance were so significant that only $15 \%$ of pups on the C57BL/6J 
background survived compared to $78 \%$ of pups on the $\mathrm{C} 3 \mathrm{H}$ background (Cantrell et al., 2004).

Another set of intrasubspecific crosses of $E d n r b^{s}$ mice (Mayer Ednrb ${ }^{s}$ IEdnrb $b^{s}$ and $\mathrm{C} 3 \mathrm{HeB} / \mathrm{FeJ} E d n r b^{s} / E d n r b^{s}$ ) has identified mast cell growth factor (MGF, now known as Kitl) as a modifier for the patterning of hypopigmentation displayed by Ednrb mutants (Rhim et al., 2000) This study suggested that alterations of Kitl expression in $\mathrm{C} 3 \mathrm{H}$ mice may be responsible for the appearance of white forelock hypopigmentation phenotype characteristic of Waardenburg syndrome. Recent studies employing crosses between Ednrb and Kit mutant as well as the transgenic addition of Edn3 to Kit mutants have corroborated the existence of a synergistic interaction between the endothelin and Kitl and signaling pathways in melanocyte development (Aoki et al., 2005; Garcia et al., 2008)

A mutagenesis screen to expose modifiers responsible for the difference in severity in Sox10 heterozygous WS identified 3 modifiers of Sox10, one of which is on the GLI-Kruppel family member 3 (Gli3; a component of the hedgehog signaling pathway) which exacerbates the pigmentation defect of Sox10 heterozygosity (Matera et al., 2008). Finally, a detailed analysis of the expression of various melanogenic genes and melanocyte viability on different in-bred background strains revealed different numbers of melanoblasts among the 8 parts of the embryo according to background strain (Loftus et al., 2009). 


\section{Research questions}

Investigations into whether Ednrb/Edn3, Sox10 and Pax3 interact genetically sprung from their spatiotemporal patterns of expression in early embryogenesis. Based on these patterns of co-expression and similarity of phenotypes in mutants, it is likely that Sox10 and/or Pax3 interact with Ednrb and possibly regulate its expression. Interactions between Sox10 and Ednrb have been shown to modulate the development of enteric neurons (Cantrell et al., 2004; Zhu et al., 2004), and an Ednrb enhancer that is activated specifically in enteric neuron precursors has been identified that contains multiple binding sites for Sox10 (Zhu et al., 2004). Recently, in human melanocytes, Sox10 has been shown to directly regulate Ednrb at the transcriptional level through two different promoters (Yokoyama et al., 2006). Given that Sox10 and Pax3 transactivate downstream targets in melanocyte development and that both transcription factors are essential for survival and/or proliferation of melanocyte progenitors, my research questions directly addressed whether or not these transcription factors interact with Ednrb in the melanocyte lineage.

Question \#1: Does Sox10 interact with Ednrb at the genetic level?

The analysis of the phenotype of Ednrb/Sox10 compound heterozygote mouse mutants will allow us to establish whether Sox10 interacts with Ednrb in an additive, diminishing or synergistic manner. Crosses between Ednrb ${ }^{\mathrm{S}-/ /+}$ and Sox $10^{\text {LacZ/+ }}$ mice over 3 generations were examined and hypopigmentation of resulting single mutants were compared to the hypopigmentation of double 
mutants. An aggravated phenotype beyond the additive expectation will imply a genetic interaction.

Question \#2: Does Pax3 interact with Ednrb at the genetic level?

The analysis of the phenotype of Ednrb/Pax3 compound heterozygote mouse mutants allowed us to establish whether Pax3 interacts with Ednrb in an additive, diminishing or synergistic manner. Crosses between Ednrb ${ }^{S-/ /+}$ and $\mathrm{Pax}^{\mathrm{Sp} / \mathrm{+}}$ mice over 3 generations were examined and hypopigmentation of resulting single mutants compared to the hypopigmentation of double mutants. An aggravated phenotype beyond the additive expectation will imply a genetic interaction.

Question \#3: Can the transgenic delivery of Ednrb to Sox10 haploinsufficient melanocyte progenitor cells rescue the hypopigmentation phenotype of Sox10 mutant mice?

Sox $10^{L a c Z /+}$ mice were crossed with transgenic mice that express Ednrb under the control of the Dct promoter (Ittah, Ph.D. dissertation, Florida International Univ., 2006) and any differences in pigmentation between the Sox10 heterozygote and the Sox10 heterozygote with the transgene were evaluated. A normal coat color will imply that the additional Ednrb supplied early on in development was sufficient to rescue the emerging melanoblasts and restore coat color.

Question \#4: Can the transgenic delivery of Ednrb to Pax3 haploinsufficient melanocyte progenitor cells rescue the hypopigmentation phenotype?

$\mathrm{Pax}^{\mathrm{Sp} / \mathrm{+}}$ mice were crossed with transgenic Dct-Ednrb mice to evaluate any differences in pigmentation between the Sox10 heterozygote and the Sox10 
heterozygote with the transgene. A normal coat color will imply that the additional Ednrb supplied early on in development was sufficient to rescue the emerging melanoblasts and restore coat color.

Question \#5: How early can the transgenic delivery of Ednrb to the Sox10 heterozygote mutant rescue its spotting phenotype?

Sox $10^{L a c Z /+}$ mice were crossed with the transgenic Dct-Ednrb mice. Thus, Sox10 heterozygous mice carrying the transgene expressed additional levels of Ednrb in their melanocyte precursors. Embryos from the cross Sox $10^{\mathrm{LacZ} /+}$ and Dct-Ednrb were harvested at E11.5 and analyzed via in situ hybridization using the Pmel17 riboprobe. If a qualitative difference emerges in the number of melanocyte precursors between Sox10 heterozygotes with and without the transgene, it will imply that the transgene is acting prior to E11.5 and is involved in the expansion of the melanocyte precursor population.

Question \#6: Does the transgenic delivery of Ednrb rescue melanoblasts in the Sox10 heterozygote from an untimely death by apoptosis?

Sox $10^{L a c Z /+}$ mice were crossed with the transgenic Dct-Ednrb mice. Thus, Sox10 heterozygous mice carrying the transgene expressed additional levels of Ednrb in their melanocyte precursors. Embryos from the cross Sox $10^{\mathrm{LacZ} /+}$ and Dct-Ednrb were harvested at E11.5 and E12.5 and analyzed using LacZ and LysoTracker Red double staining to elucidate whether or not the melanoblasts are dying at either E11.5 or E12.5. An increase in the number of double stained cells traveling along the dorsolateral pathway will imply that there is a decrease in the number of melanoblasts that make it to their final destination, resulting in hypopigmentation. 
Question \#7: What are the characteristics of the novel phenotype that arose from the Ednr $b^{S-/ /+}$ cross with $P a x 3^{S p /+}$ ?

A novel phenotype arose from crossing $E d n r b^{S-1 /+}$ with $P a x 3^{S p /+}$. The most obvious and striking characteristics were the development of hydrocephaly during the $3^{\text {rd }}$ and $4^{\text {th }}$ weeks of life, $100 \%$ lethality and skeletal deformity. Gross brain morphology was assessed with the aid of antibody staining to determine if an increase in astrocytes (as a response to stress) was visible. In addition, skeletal staining to describe skeletal differences between normal and mutant littermates was attempted. 


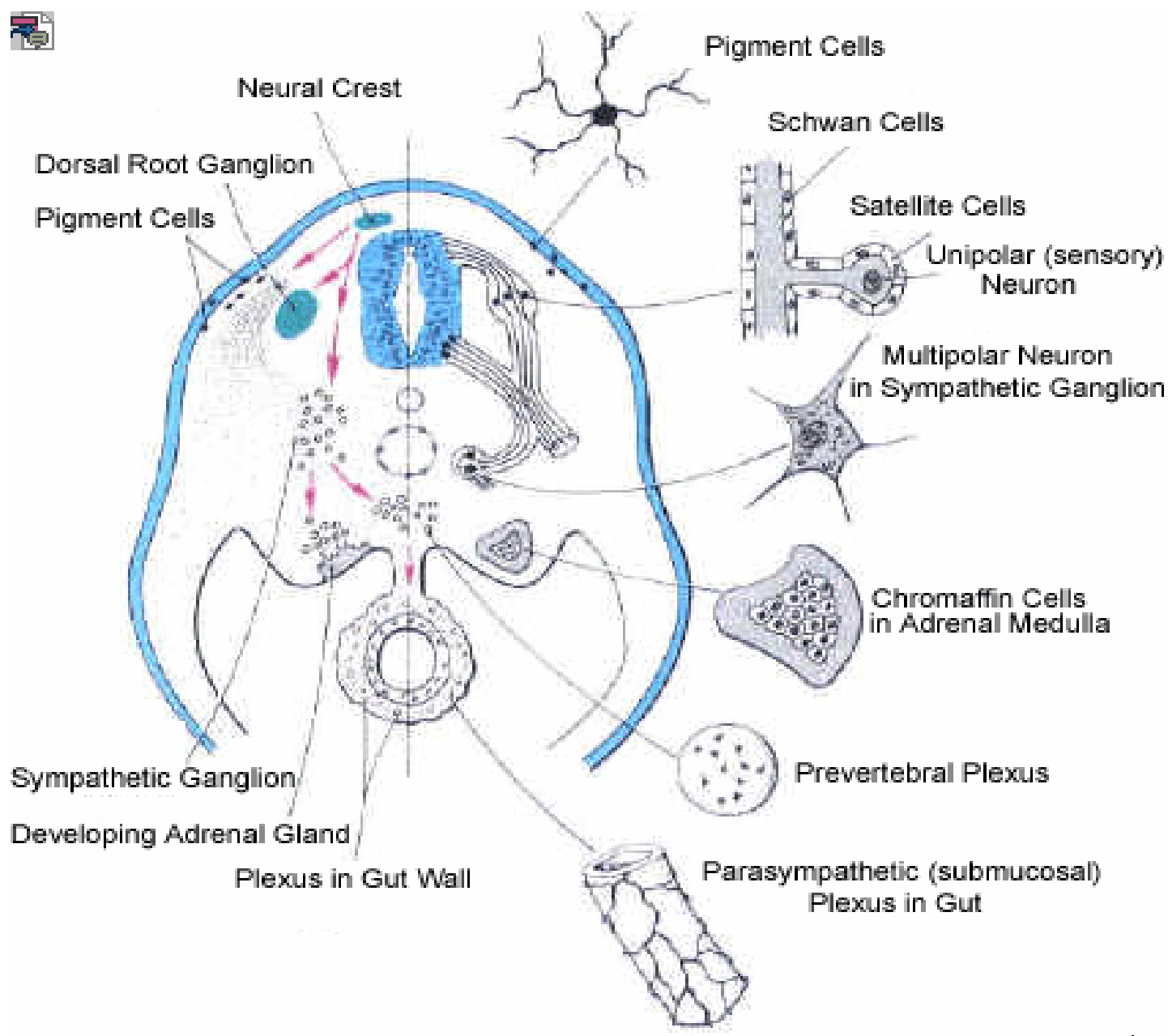

Figure 1.1 Derivatives of neural crest cells (Alberts et al., 2002). 


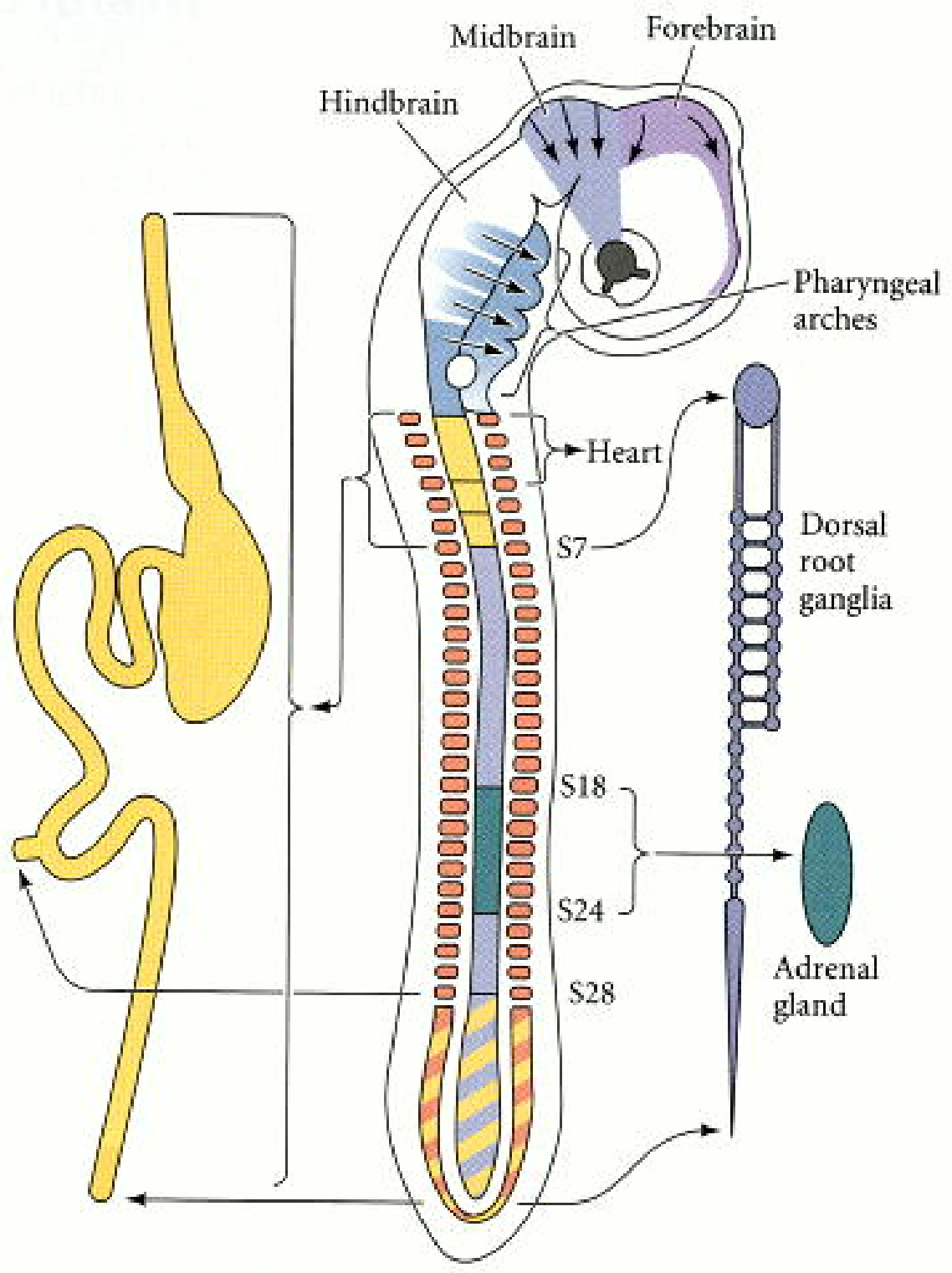

Figure 1.2 Regions of the neural crest. Regions include the cranial NC, vagal NC (near somites 1-7), cardiac NC (somites 1-3), trunk NC (about somite 6 to the tail) and the sacral NC posterior to somite 28 (Gilbert, 2003). 


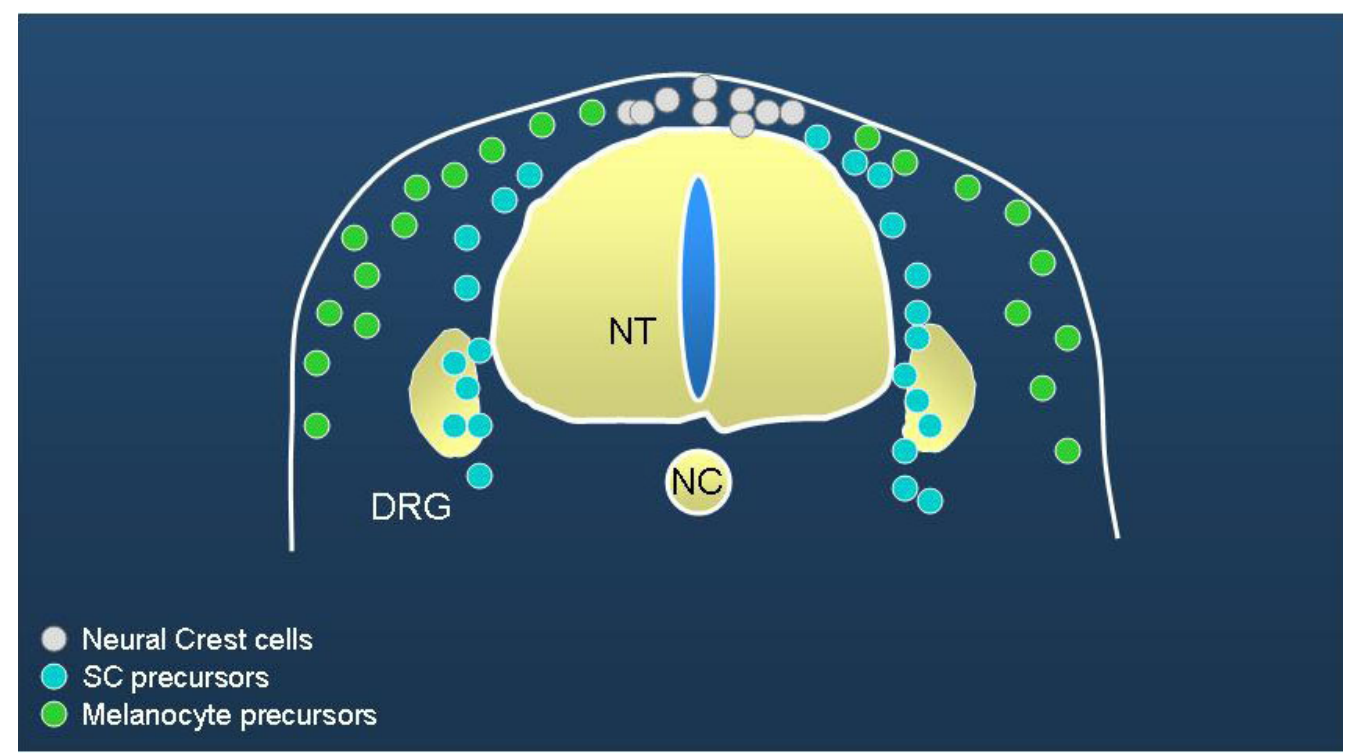

Figure 1.3 Neural crest cell migration. Neural crest cells delaminate from the dorsal aspect of the neural tube. As migration progresses, Neural crest cells traveling via the ventromedial pathway begin to take on the characteristics of Schwann cell precursors (among other phenotypes). Neural crest cells that migrate via the dorsolateral pathway exhibit melanocyte precursor traits. This cartoon depicts the murine neural tube at E11.5. NT = neural tube; NC = Notochord; DRG = dorsal root ganglia.

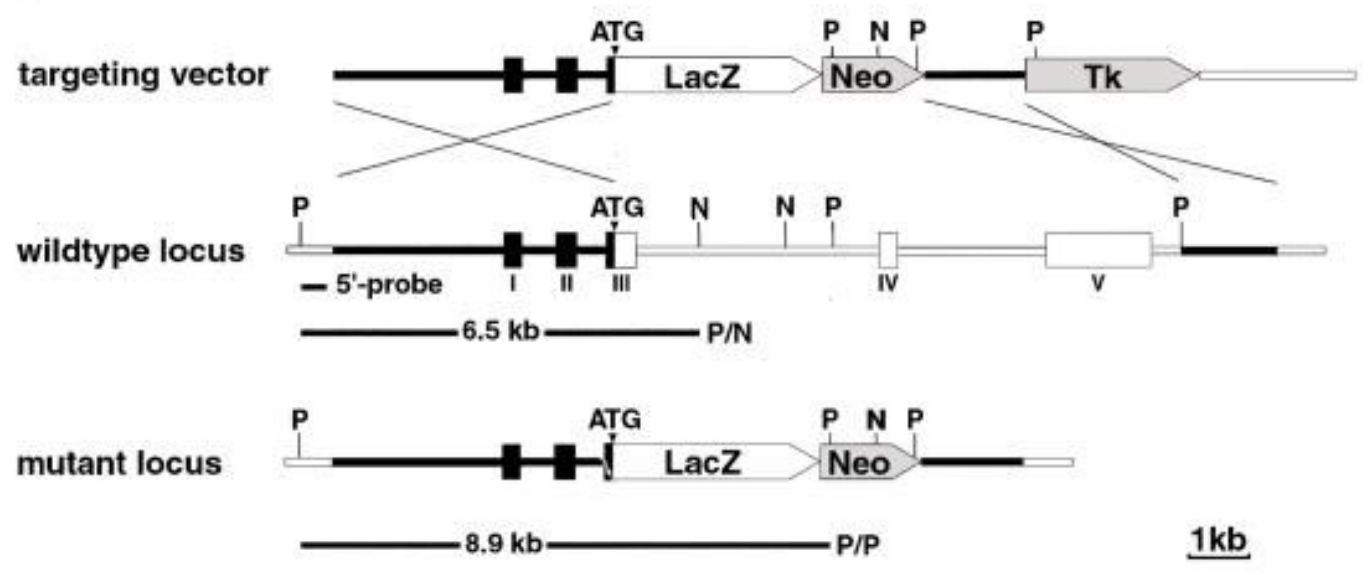

Figure 1.4 Sox10 mutant locus. Schematic representation of targeted deletion of Sox10 locus and insertion of the reporter gene LacZ. The targeting vector (top) via homologous recombination disrupted the Sox10 locus (middle) inserting the LacZ gene (bottom) in its place (Britsch et al., 2001). Noncoding exons are represented by black boxes while coding exons are represented by white boxes. $\mathrm{P}=$ restriction site Spel; $\mathrm{N}=$ restriction site $\mathrm{Ncol}$. 

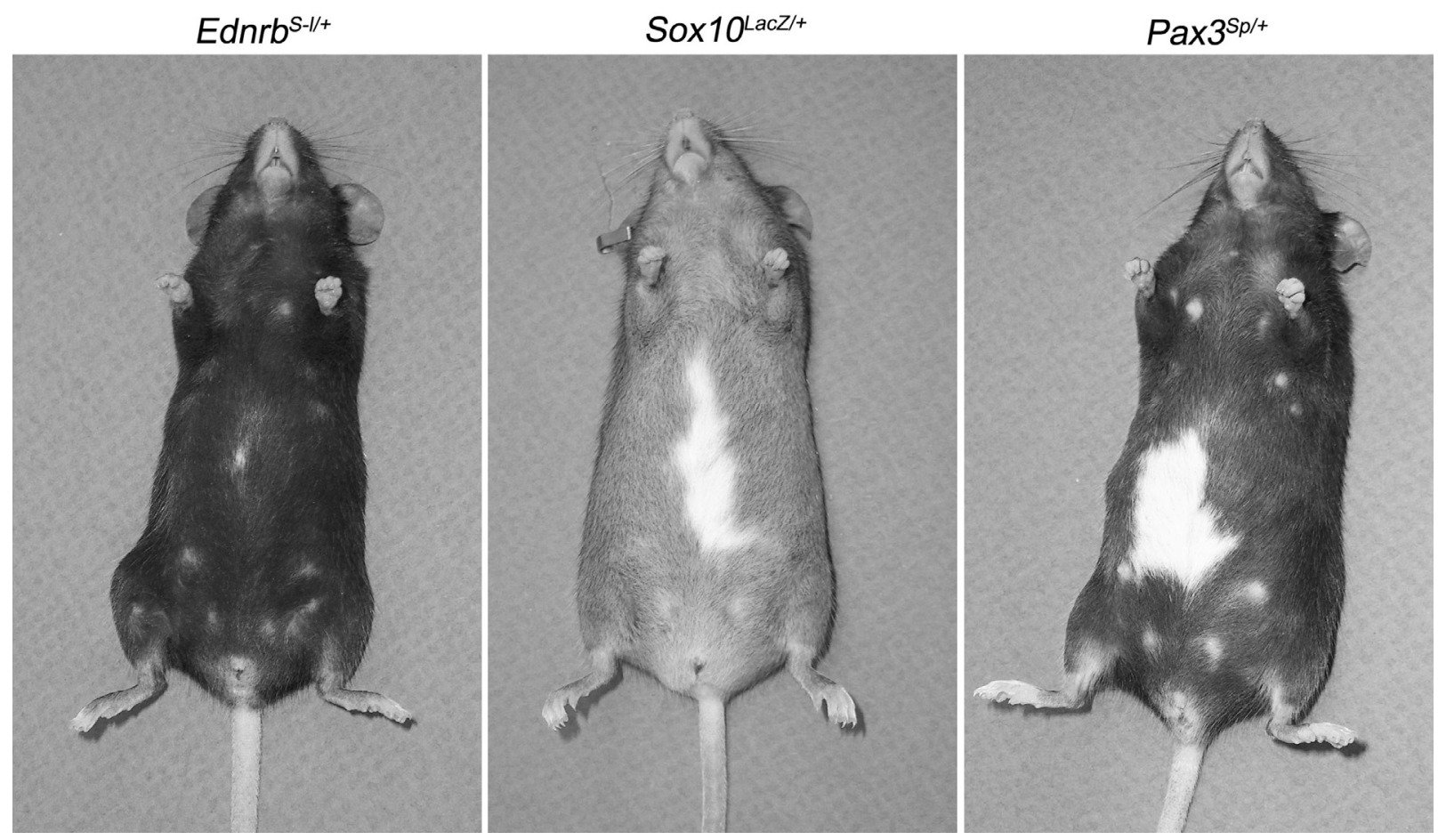

Figure 1.5 Pigmentation mutants. Typical hypopigmentation phenotypes of mutant mice used in studies. The Ednrb ${ }^{S-1 /+}$ hypopigmentation is quite small while the Sox $10^{\mathrm{LacZ} /+}$ hypopigmentation (when present) and Pax3 ${ }^{\mathrm{Sp} /+}$ hypopigmentation (always present) are larger. Pigmentation defects in all three genotypes are confined to the ventral aspect of the animals. 

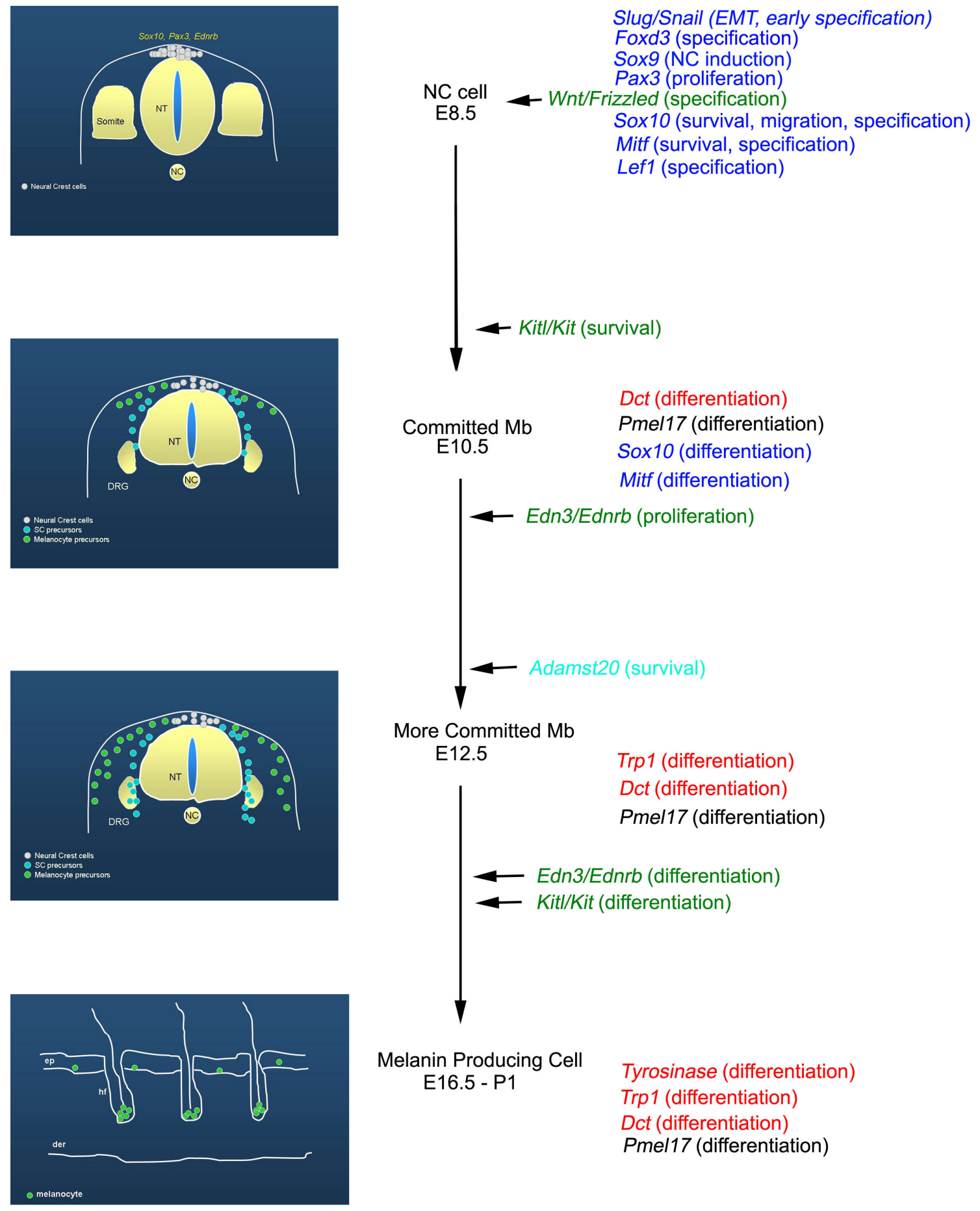

Melanin Producing Cell

E16.5 - P1
Tyrosinase (differentiation)

Trp1 (differentiation)

Dct (differentiation)

Pmel17 (differentiation)

Figure 1.6 Genes governing murine melanocyte development. A timeline of melanogenic genes are detailed from the emergence of premigratory melanoblasts (E8.5) through the differentiation of melanin producing cells (E16.5). Transcription factors present as the neural tube closes at E8.5 are essential for EMT, NC induction, specification of NC cells, survival and migration. In addition, the Wnt/Frizzed signaling pathway is critically important for proper cellular specification at this time. As NC cells emerge, Kit//Kit 
becomes important for the survival of melanoblasts and at E10.5, Dct, Pmel17, Sox10 and Mitf are all important differentiation factors. Between E10.5-12.5, the Edn3/Ednrb signaling pathway is necessary for proliferation and towards the end of this time period Adamst20 is important for survival. Other necessary differentiation factors that either turn on or remain activated in the next phase of development (E12.5-16.5) are Trp1, Dct and Pmel17, along with the signaling pathways Edn3/Ednrb and Kit//Kit. At E16.5, tyrosinase is activated and along with Trp1, Dct and Pmel17 the maturing melanocyte becomes a pigment producing cell. Color key: transcription factors are in blue, signaling pathways are green, enzymes in red, melanosomal protein in black, extracellular matrix component in turquoise. EMT = epithelial mesenchymal transition, ep = epidermis, $\mathrm{hf}=$ hair follicle, der $=$ dermis, $\mathrm{P} 1=$ postnatal day 1 , Kitl $=$ Kit ligand, Dct $=$ DOPAchrome tautomerase, Edn3 $=$ Endothelin 3, Ednrb $=$ Endothelin receptor $b, \operatorname{Trp} 1=$ Tyrosinase related protein $1, \mathrm{Mb}=$ Melanoblast. 


\section{References}

Alberts, B., Bray, D. Lewis, J. Raff, M., Roberts, K. and Watson, J. D. (2002). Molecular Biology of the Cell. Garland Science, New York.

Anderson, D. J. (1989). The neural crest cell lineage problem: neuropoiesis? Neuron 3, 1-12.

Astrof, S., Kirby, A., Lindblad-Toh, K., Daly, M. and Hynes, R. O. (2007). Heart development in fibronectin-null mice is governed by a genetic modifier on chromosome four. Mech Dev 124, 551-8.

Aybar, M. J., Nieto, M. A. and Mayor, R. (2003). Snail precedes slug in the genetic cascade required for the specification and migration of the Xenopus neural crest. Development 130, 483-94.

Baxter, L. L. and Pavan, W. J. (2003). Pmel17 expression is Mitf-dependent and reveals cranial melanoblast migration during murine development. Gene Expr Patterns 3, 703-7.

Baynash, A. G., Hosoda, K., Giaid, A., Richardson, J. A., Emoto, N., Hammer, R. E. and Yanagisawa, M. (1994). Interaction of endothelin-3 with endothelin-B receptor is essential for development of epidermal melanocytes and enteric neurons. Cell 79, 1277-85.

Bondurand, N., Dastot-Le Moal, F., Stanchina, L., Collot, N., Baral, V., Marlin, S., Attie-Bitach, T., Giurgea, I., Skopinski, L., Reardon, W. et al. (2007). Deletions at the SOX10 gene locus cause Waardenburg syndrome types 2 and 4. Am J Hum Genet 81, 1169-85.

Bondurand, N., Pingault, V., Goerich, D. E., Lemort, N., Sock, E., Caignec, C. L., Wegner, M. and Goossens, M. (2000). Interaction among SOX10, PAX3 and MITF, three genes altered in Waardenburg syndrome. Hum Mol Genet 9, 1907-17.

Brito, F. C. and Kos, L. (2008). Timeline and distribution of melanocyte precursors in the mouse heart. Pigment Cell Melanoma Res 21, 464-70.

Britsch, S., Goerich, D. E., Riethmacher, D., Peirano, R. I., Rossner, M., Nave, K. A., Birchmeier, C. and Wegner, M. (2001). The transcription factor Sox10 is a key regulator of peripheral glial development. Genes Dev 15, 6678.

Bronner-Fraser, M. (2004). Development. Making sense of the sensory lineage. Science 303, 966-8. 
Cano, A., Perez-Moreno, M. A., Rodrigo, I., Locascio, A., Blanco, M. J., del Barrio, M. G., Portillo, F. and Nieto, M. A. (2000). The transcription factor snail controls epithelial-mesenchymal transitions by repressing E-cadherin expression. Nat Cell Biol 2, 76-83.

Cantrell, V. A., Owens, S. E., Chandler, R. L., Airey, D. C., Bradley, K. M., Smith, J. R. and Southard-Smith, E. M. (2004). Interactions between Sox10 and EdnrB modulate penetrance and severity of aganglionosis in the Sox10Dom mouse model of Hirschsprung disease. Hum Mol Genet 13, 2289-301.

Carney, T. J., Dutton, K. A., Greenhill, E., Delfino-Machin, M., Dufourcq, P., Blader, P. and Kelsh, R. N. (2006). A direct role for Sox10 in specification of neural crest-derived sensory neurons. Development 133, 4619-30.

Ceccherini, I., Zhang, A. L., Matera, I., Yang, G., Devoto, M., Romeo, G. and Cass, D. T. (1995). Interstitial deletion of the endothelin-B receptor gene in the spotting lethal (sl) rat. Hum Mol Genet 4, 2089-96.

Chakravarti, A. (1996). Endothelin receptor-mediated signaling in hirschsprung disease. Hum Mol Genet 5, 303-7.

Corry, G. N. and Underhill, D. A. (2005). Pax3 target gene recognition occurs through distinct modes that are differentially affected by disease-associated mutations. Pigment Cell Res 18, 427-38.

Duband, J. L., Monier, F., Delannet, M. and Newgreen, D. (1995).

Epithelium-mesenchyme transition during neural crest development. Acta Anat (Basel) 154, 63-78.

Dunn, K. J., Williams, B. O., Li, Y. and Pavan, W. J. (2000). Neural crestdirected gene transfer demonstrates Wnt1 role in melanocyte expansion and differentiation during mouse development. Proc Natl Acad Sci U S A 97, 10050-5.

Dupin, E., Glavieux, C., Vaigot, P. and Le Douarin, N. M. (2000). Endothelin 3 induces the reversion of melanocytes to glia through a neural crestderived glial-melanocytic progenitor. Proc Natl Acad Sci U S A 97, 7882-7.

Dupin, E., Real, C. and Le Douarin, N. (2001). The neural crest stem cells: control of neural crest cell fate and plasticity by endothelin-3. An Acad Bras Cienc 73, 533-45.

Futuyma, D. (1998). Evolutionary Biology: Sinauer, MA. 
Gammill, L. S. and Bronner-Fraser, M. (2003). Neural crest specification: migrating into genomics. Nat Rev Neurosci 4, 795-805.

Gans, C. and Northcutt, R. (1983). Neural crest and the origin of vertebrates, a new head. Science 220, 268-274.

Gariepy, C. E., Cass, D. T. and Yanagisawa, M. (1996). Null mutation of Endothelin receptor type $B$ gene in spotting lethal rats causes aganglionic megacolon and white coat color. Proc Natl Acad Sci U S A 93, 867-72.

Gariepy, C. E., Williams, S. C., Richardson, J. A., Hammer, R. E. and Yanagisawa, M. (1998). Transgenic expression of the endothelin-B receptor prevents congenital intestinal aganglionosis in a rat model of Hirschsprung disease. J Clin Invest 102, 1092-101.

Genin, E., Feingold, J. and Clerget-Darpoux, F. (2008). Identifying modifier genes of monogenic disease: strategies and difficulties. Hum Genet 124, 357-68.

Gilbert, S., 2003. Developmental Biology. Sinauer Associates Inc., Sunderland, MA.

Goldfarb, L. G., Petersen, R. B., Tabaton, M., Brown, P., LeBlanc, A. C., Montagna, P., Cortelli, P., Julien, J., Vital, C., Pendelbury, W. W. et al. (1992). Fatal familial insomnia and familial Creutzfeldt-Jakob disease: disease phenotype determined by a DNA polymorphism. Science 258, 8068.

Goulding, M. D., Chalepakis, G., Deutsch, U., Erselius, J. R. and Gruss, P. (1991). Pax-3, a novel murine DNA binding protein expressed during early neurogenesis. Embo J 10, 1135-47.

Gouya, L., Martin-Schmitt, C., Robreau, A. M., Austerlitz, F., Da Silva, V., Brun, P., Simonin, S., Lyoumi, S., Grandchamp, B., Beaumont, C. et al. (2006). Contribution of a common single-nucleotide polymorphism to the genetic predisposition for erythropoietic protoporphyria. Am J Hum Genet 78, 2-14.

Haldane, J. (1941). The relative importance of principal and modifying genes in determining some human diseases. J Genet 41, 149-157.

Hari, L., Brault, V., Kleber, M., Lee, H. Y., Ille, F., Leimeroth, R., Paratore, C., Suter, U., Kemler, R. and Sommer, L. (2002). Lineage-specific requirements of beta-catenin in neural crest development. J Cell Biol 159, 867-80. 
Henion, P. D. and Weston, J. A. (1997). Timing and pattern of cell fate restrictions in the neural crest lineage. Development 124, 4351-9.

Herbarth, B., Pingault, V., Bondurand, N., Kuhlbrodt, K., HermansBorgmeyer, I., Puliti, A., Lemort, N., Goossens, M. and Wegner, M. (1998). Mutation of the Sry-related Sox10 gene in Dominant megacolon, a mouse model for human Hirschsprung disease. Proc Natl Acad Sci U S A 95, 5161-5.

Hornyak, T. J., Hayes, D. J., Chiu, L. Y. and Ziff, E. B. (2001). Transcription factors in melanocyte development: distinct roles for Pax-3 and Mitf. Mech Dev 101, 47-59.

Hosoda, K., Hammer, R. E., Richardson, J. A., Baynash, A. G., Cheung, J. C., Giaid, A. and Yanagisawa, M. (1994). Targeted and natural (piebaldlethal) mutations of endothelin-B receptor gene produce megacolon associated with spotted coat color in mice. Cell 79, 1267-76.

Hou, L., Arnheiter, H. and Pavan, W. J. (2006). Interspecies difference in the regulation of melanocyte development by SOX10 and MITF. Proc Natl Acad Sci U S A 103, 9081-5.

Hou, L., Pavan, W. J., Shin, M. K. and Arnheiter, H. (2004). Cell-autonomous and cell non-autonomous signaling through endothelin receptor $B$ during melanocyte development. Development 131, 3239-47.

Jackson Laboratory. (2009). Why mouse genetics?

Jiao, Z., Mollaaghababa, R., Pavan, W. J., Antonellis, A., Green, E. D. and Hornyak, T. J. (2004). Direct interaction of Sox10 with the promoter of murine Dopachrome Tautomerase (Dct) and synergistic activation of Dct expression with Mitf. Pigment Cell Res 17, 352-62.

Kapur, R. P. (1999). Early death of neural crest cells is responsible for total enteric aganglionosis in Sox10(Dom)/Sox10(Dom) mouse embryos. Pediatr Dev Pathol 2, 559-69.

Kapur, R. P., Hoyle, G. W., Mercer, E. H., Brinster, R. L. and Palmiter, R. D. (1991). Some neuronal cell populations express human dopamine betahydroxylase-lacZ transgenes transiently during embryonic development. Neuron 7, 717-27.

Kim, J., Lo, L., Dormand, E. and Anderson, D. J. (2003). SOX10 maintains multipotency and inhibits neuronal differentiation of neural crest stem cells. Neuron 38, 17-31. 
Kos, R., Reedy, M. V., Johnson, R. L. and Erickson, C. A. (2001). The winged-helix transcription factor FoxD3 is important for establishing the neural crest lineage and repressing melanogenesis in avian embryos. Development 128, 1467-79.

Kuhlbrodt, K., Herbarth, B., Sock, E., Hermans-Borgmeyer, I. and Wegner, M. (1998). Sox10, a novel transcriptional modulator in glial cells. J Neurosci 18, 237-50.

LaBonne, C. and Bronner-Fraser, M. (2000). Snail-related transcriptional repressors are required in Xenopus for both the induction of the neural crest and its subsequent migration. Dev Biol 221, 195-205.

Lahav, R., Ziller, C., Dupin, E. and Le Douarin, N. M. (1996). Endothelin 3 promotes neural crest cell proliferation and mediates a vast increase in melanocyte number in culture. Proc Natl Acad Sci U S A 93, 3892-7.

Lane, P. W. (1966). Association of megacolon with two recessive spotting genes in the mouse. $J$ Hered 57, 29-31.

Lang, D., Lu, M. M., Huang, L., Engleka, K. A., Zhang, M., Chu, E. Y., Lipner, S., Skoultchi, A., Millar, S. E. and Epstein, J. A. (2005). Pax3 functions at a nodal point in melanocyte stem cell differentiation. Nature 433, 884-7.

Le Douarin, N. (1982). The Neural Crest. New York: Cambridge University Press.

Le Douarin, N. M., Creuzet, S., Couly, G. and Dupin, E. (2004). Neural crest cell plasticity and its limits. Development 131, 4637-50.

Le Douarin, N. M. and Teillet, M. A. (1974). Experimental analysis of the migration and differentiation of neuroblasts of the autonomic nervous system and of neurectodermal mesenchymal derivatives, using a biological cell marking technique. Dev Biol 41, 162-84.

Le Douarin, N. M. and Kalcheim, C. (1999). The Neural Crest. New York: Cambridge University Press.

Le Lievre, C. S. and Le Douarin, N. M. (1975). Mesenchymal derivatives of the neural crest: Analysis of chimaeric quail and chick embryos. J Embryol Exp Morphol 34, 125-154.

Lecoin, L., Sakurai, T., Ngo, M. T., Abe, Y., Yanagisawa, M. and Le Douarin, N. M. (1998). Cloning and characterization of a novel endothelin receptor subtype in the avian class. Proc Natl Acad Sci U S A 95, 3024-9. 
Lee, H. O., Levorse, J. M. and Shin, M. K. (2003). The endothelin receptor-B is required for the migration of neural crest-derived melanocyte and enteric neuron precursors. Dev Biol 259, 162-75.

Lee, M., Goodall, J., Verastegui, C., Ballotti, R. and Goding, C. R. (2000). Direct regulation of the Microphthalmia promoter by Sox10 links Waardenburg-Shah syndrome (WS4)-associated hypopigmentation and deafness to WS2. J Biol Chem 275, 37978-83.

Locascio, A., Manzanares, M., Blanco, M. J. and Nieto, M. A. (2002). Modularity and reshuffling of Snail and Slug expression during vertebrate evolution. Proc Natl Acad Sci U S A 99, 16841-6.

Loftus, S. K., Baxter, L. L., Buac, K., Watkins-Chow, D. E., Larson, D. M. and Pavan, W. J. (2009). Comparison of melanoblast expression patterns identifies distinct classes of genes. Pigment Cell Melanoma Res. Epub ahead of print.

Ludwig, A., Rehberg, S. and Wegner, M. (2004). Melanocyte-specific expression of dopachrome tautomerase is dependent on synergistic gene activation by the Sox10 and Mitf transcription factors. FEBS Lett 556, 23644.

Matera, I., Watkins-Chow, D. E., Loftus, S. K., Hou, L., Incao, A., Silver, D. L., Rivas, C., Elliott, E. C., Baxter, L. L. and Pavan, W. J. (2008). A sensitized mutagenesis screen identifies Gli3 as a modifier of Sox10 neurocristopathy. Hum Mol Genet 17, 2118-31.

Mayer, T. C. (1973). The migratory pathway of neural crest cells into the skin of mouse embryos. Dev Biol 34, 39-46.

Mollaaghababa, R. and Pavan, W. J. (2003). The importance of having your SOX on: role of SOX10 in the development of neural crest-derived melanocytes and glia. Oncogene 22, 3024-34.

Mori-Akiyama, Y., Akiyama, H., Rowitch, D. H. and de Crombrugghe, B. (2003). Sox9 is required for determination of the chondrogenic cell lineage in the cranial neural crest. Proc Natl Acad Sci U S A 100, 9360-5.

Morrison, S. J., Shah, N. M. and Anderson, D. J. (1997). Regulatory mechanisms in stem cell biology. Cell 88, 287-98.

Nataf, V., Amemiya, A., Yanagisawa, M. and Le Douarin, N. M. (1998). The expression pattern of endothelin 3 in the avian embryo. Mech Dev 73, 21720. 
Nataf, V., Lecoin, L., Eichmann, A. and Le Douarin, N. M. (1996). Endothelin-B receptor is expressed by neural crest cells in the avian embryo. Proc Natl Acad Sci U S A 93, 9645-50.

National Human Genome Research Institute. (2002) Background History of the Mouse.

Nieto, M. A., Sargent, M. G., Wilkinson, D. G. and Cooke, J. (1994). Control of cell behavior during vertebrate development by Slug, a zinc finger gene. Science 264, 835-9.

Nishikawa, S., Kusakabe, M., Yoshinaga, K., Ogawa, M., Hayashi, S., Kunisada, T., Era, T., Sakakura, T. and Nishikawa, S. (1991). In utero manipulation of coat color formation by a monoclonal anti-c-kit antibody: two distinct waves of c-kit-dependency during melanocyte development. Embo J 10, 2111-8.

Ohlstein, B., Kai, T., Decotto, E. and Spradling, A. (2004). The stem cell niche: theme and variations. Curr Opin Cell Biol 16, 693-9.

Opdecamp, K., Nakayama, A., Nguyen, M. T., Hodgkinson, C. A., Pavan, W. J. and Arnheiter, H. (1997). Melanocyte development in vivo and in neural crest cell cultures: crucial dependence on the Mitf basic-helix-loophelix-zipper transcription factor. Development 124, 2377-86.

Paratore, C., Eichenberger, C., Suter, U. and Sommer, L. (2002a). Sox10 haploinsufficiency affects maintenance of progenitor cells in a mouse model of Hirschsprung disease. Hum Mol Genet 11, 3075-85.

Paratore, C., Hagedorn, L., Floris, J., Hari, L., Kleber, M., Suter, U. and Sommer, L. (2002b). Cell-intrinsic and cell-extrinsic cues regulating lineage decisions in multipotent neural crest-derived progenitor cells. Int J Dev Biol 46, 193-200.

Pavan, W. J. and Tilghman, S. M. (1994). Piebald lethal (sl) acts early to disrupt the development of neural crest-derived melanocytes. Proc Natl Acad Sci U S A 91, 7159-63.

Potterf, S. B., Furumura, M., Dunn, K. J., Arnheiter, H. and Pavan, W. J. (2000). Transcription factor hierarchy in Waardenburg syndrome: regulation of MITF expression by SOX10 and PAX3. Hum Genet 107, 1-6.

Puffenberger, E. G., Hosoda, K., Washington, S. S., Nakao, K., deWit, D., Yanagisawa, M. and Chakravart, A. (1994). A missense mutation of the endothelin-B receptor gene in multigenic Hirschsprung's disease. Cell 79, 1257-66. 
Pusch, C., Hustert, E., Pfeifer, D., Sudbeck, P., Kist, R., Roe, B., Wang, Z., Balling, R., Blin, N. and Scherer, G. (1998). The SOX10/Sox10 gene from human and mouse: sequence, expression, and transactivation by the encoded HMG domain transcription factor. Hum Genet 103, 115-23.

Reid, K., Turnley, A. M., Maxwell, G. D., Kurihara, Y., Kurihara, H., Bartlett, P. F. and Murphy, M. (1996). Multiple roles for endothelin in melanocyte development: regulation of progenitor number and stimulation of differentiation. Development 122, 3911-9.

Reiprich, S., Stolt, C. C., Schreiner, S., Parlato, R. and Wegner, M. (2008). SoxE proteins are differentially required in mouse adrenal gland development. Mol Biol Cell 19, 1575-86.

Rhim, H., Dunn, K. J., Aronzon, A., Mac, S., Cheng, M., Lamoreux, M. L., Tilghman, S. M. and Pavan, W. J. (2000). Spatially restricted hypopigmentation associated with an Ednrbs-modifying locus on mouse chromosome 10. Genome Res 10, 17-29.

Sanchez-Martin, M., Rodriguez-Garcia, A., Perez-Losada, J., Sagrera, A., Read, A. P. and Sanchez-Garcia, I. (2002). SLUG (SNAI2) deletions in patients with Waardenburg disease. Hum Mol Genet 11, 3231-6.

Santschi, E. M., Purdy, A. K., Valberg, S. J., Vrotsos, P. D., Kaese, H. and Mickelson, J. R. (1998). Endothelin receptor B polymorphism associated with lethal white foal syndrome in horses. Mamm Genome 9, 306-9.

Sasai, N., Mizuseki, K. and Sasai, Y. (2001). Requirement of FoxD3-class signaling for neural crest determination in Xenopus. Development 128, 2525-36.

Sato-Jin, K., Nishimura, E. K., Akasaka, E., Huber, W., Nakano, H., Miller, A., Du, J., Wu, M., Hanada, K., Sawamura, D. et al. (2008). Epistatic connections between microphthalmia-associated transcription factor and endothelin signaling in Waardenburg syndrome and other pigmentary disorders. Faseb J 22, 1155-68.

Schepers, G. E., Teasdale, R. D. and Koopman, P. (2002). Twenty pairs of sox: extent, homology, and nomenclature of the mouse and human sox transcription factor gene families. Dev Cell 3, 167-70.

Selleck, M. A. and Bronner-Fraser, M. (1995). Origins of the avian neural crest: the role of neural plate-epidermal interactions. Development 121, 52538. 
Serbedzija, G. N., Bronner-Fraser, M. and Fraser, S. E. (1994). Developmental potential of trunk neural crest cells in the mouse. Development 120, 1709-18.

Serbedzija, G. N., Fraser, S. E. and Bronner-Fraser, M. (1990). Pathways of trunk neural crest cell migration in the mouse embryo as revealed by vital dye labelling. Development 108, 605-12.

Shah, N. M. and Anderson, D. J. (1997). Integration of multiple instructive cues by neural crest stem cells reveals cell-intrinsic biases in relative growth factor responsiveness. Proc Natl Acad Sci U S A 94, 11369-74.

Shah, N. M., Marchionni, M. A., Isaacs, I., Stroobant, P. and Anderson, D. J. (1994). Glial growth factor restricts mammalian neural crest stem cells to a glial fate. Cell 77, 349-60.

Shin, M. K., Levorse, J. M., Ingram, R. S. and Tilghman, S. M. (1999). The temporal requirement for endothelin receptor-B signalling during neural crest development. Nature 402, 496-501.

Shin, M. K., Russell, L. B. and Tilghman, S. M. (1997). Molecular characterization of four induced alleles at the Ednrb locus. Proc Natl Acad Sci U S A 94, 13105-10.

Silver, D. L., Hou, L., Somerville, R., Young, M. E., Apte, S. S. and Pavan, W. J. (2008). The secreted metalloprotease ADAMTS20 is required for melanoblast survival. PLoS Genet 4, e1000003.

Sommer, L. (2001). Context-dependent regulation of fate decisions in multipotent progenitor cells of the peripheral nervous system. Cell Tissue Res 305, 211-6.

Southard-Smith, E. M., Kos, L. and Pavan, W. J. (1998). Sox10 mutation disrupts neural crest development in Dom Hirschsprung mouse model. Nat Genet 18, 60-4.

Stone, J. G., Spirling, L. I. and Richardson, M. K. (1997). The neural crest population responding to endothelin-3 in vitro includes multipotent cells. $J$ Cell Sci 110 (Pt 14), 1673-82.

Strunk, K. E., Amann, V. and Threadgill, D. W. (2004). Phenotypic variation resulting from a deficiency of epidermal growth factor receptor in mice is caused by extensive genetic heterogeneity that can be genetically and molecularly partitioned. Genetics 167, 1821-32. 
Suzuki, T., Kashiwagi, A., Mori, K., Urabe, I. and Yomo, T. (2004). History dependent effects on phenotypic expression of a newly emerged gene. Biosystems 77, 137-41.

Tachibana, M., Kobayashi, Y. and Matsushima, Y. (2003). Mouse models for four types of Waardenburg syndrome. Pigment Cell Res 16, 448-54.

Takeda, K., Yasumoto, K., Takada, R., Takada, S., Watanabe, K., Udono, T., Saito, H., Takahashi, K. and Shibahara, S. (2000). Induction of melanocyte-specific microphthalmia-associated transcription factor by Wnt3a. J Biol Chem 275, 14013-6.

Tassabehji, M., Newton, V. E. and Read, A. P. (1994). Waardenburg syndrome type 2 caused by mutations in the human microphthalmia (MITF) gene. Nat Genet 8, 251-5.

Tassabehji, M., Read, A. P., Newton, V. E., Harris, R., Balling, R., Gruss, P. and Strachan, T. (1992). Waardenburg's syndrome patients have mutations in the human homologue of the Pax-3 paired box gene. Nature $355,635-6$.

Tsukamoto, K., Jackson, I. J., Urabe, K., Montague, P. M. and Hearing, V. J. (1992). A second tyrosinase-related protein, TRP-2, is a melanogenic enzyme termed DOPAchrome tautomerase. Embo J 11, 519-26.

Wegner, M. (1999). From head to toes: the multiple facets of Sox proteins. Nucleic Acids Res 27, 1409-20.

Yokoyama, S., Takeda, K. and Shibahara, S. (2006). SOX10, in combination with $S p 1$, regulates the endothelin receptor type B gene in human melanocyte lineage cells. Febs $J$ 273, 1805-20.

Yoshida, H., Kunisada, T., Kusakabe, M., Nishikawa, S. and Nishikawa, S. I. (1996). Distinct stages of melanocyte differentiation revealed by anlaysis of nonuniform pigmentation patterns. Development 122, 1207-14.

Zhu, L., Lee, H. O., Jordan, C. S., Cantrell, V. A., Southard-Smith, E. M. and Shin, M. K. (2004). Spatiotemporal regulation of endothelin receptor-B by SOX10 in neural crest-derived enteric neuron precursors. Nat Genet 36, 732-7. 
Chapter II.

\section{INTERACTION BETWEEN THE TRANSCRIPTION FACTORS Sox10 AND Pax3 WITH Endothelin receptor $b$ IN THE MELANOCYTE LINEAGE}


II. INTERACTION BETWEEN THE TRANSCRIPTION FACTORS SOX10 AND PAX3 WITH ENDOTHELIN RECEPTOR B IN THE MELANOCYTE LINEAGE

\section{Abstract}

Genetic interactions, the cornerstone of cell fate and specification, are often difficult to elucidate due to the complex nature of cell development. Neural crest (NC) cells arise in the developing neural tube and migrate throughout the organism, all the while differentiating in accordance to environmental signals they encounter along the way. The diverse array of NC derivatives, which includes melanocytes, provides an intriguing system in which to explore the complex interactions necessary for cell differentiation. Sox10, Pax3 and Endothelin receptor $b$ are temporally and spatially co-expressed early in NC cells and mutations in these genes lead to similar hypopigmentation phenotypes due to a reduced number of melanocyte precursors. The goal of this study is to establish whether Sox10 and Ednrb and/or Pax3 and Ednrb interact to promote normal murine melanocyte development. Breeding experiments crossing heterozygous mutants of Sox10 and Ednrb or Pax3 and Ednrb were set to determine if animals with mutations in both genes exhibited an aggravated phenotype. Hypopigmentation was measured and analyzed using Canvas 9, Matlab and Box-Cox transformations. Double heterozygous mutants display a phenotype that is significantly more pronounced than phenotypes of single heterozygous animals implying that a synergistic interaction exists between Sox10 and Ednrb and Pax3 and Ednrb. 


\section{Introduction}

In the mouse, emigration of NC cells from the neural tube begins around embryonic day (E)8.5. Melanocyte precursors are few in number early in development, despite the later need for numerous cells to populate the entire skin (Mintz, 1967; Schaible, 1969). Mutations that decrease the number of melanocyte progenitors early in embryogenesis cause significant alterations of phenotype, resulting in areas of hypopigmentation. In fact, depending on the timing and severity of the insult, the effects on hypopigmentation will vary since melanocyte precursors proliferate along their migratory path. Melanocyte progenitors emerge according to their axial level and the embryo is populated from both the rostral and caudal ends with rostral melanoblasts emerging and migrating slightly ahead of caudal melanoblasts; after melanoblasts have populated the entire length of the embryo via the dorsolateral pathway they turn inward to travel towards ventral aspects of the embryo (LeDouarin and Kalcheim, 1999; Pavan and Tilghman, 1994). For this reason, many hypopigmentation phenotypes present with ventral white areas, and depending on the severity of the effect, dorsal spots and belts are seen. In the most extreme cases, the animal is completely white.

The spatial and temporal specification, migration, proliferation and differentiation of cells depend on the genetic networks controlling developmental processes and phenotypes. It is this highly coordinated process that generates cell diversity and proper morphology within each individual regardless of species, and it is also what motivates developmental biologists 
and geneticists to elucidate the transient stages between conception and senescence.

Sox10 and Pax3 and Ednrb are present as the neural tube closes and NC cells begin their emigration (Baynash et al., 1994; Goulding et al., 1991; Wegner, 1999) and all appear to help orchestrate the NC cell journey towards final determination. Sox10 is involved in the regulation of cell survival, proliferation and cell specification (Mollaaghababa and Pavan, 2003; Schepers et al., 2002) while Pax3 is crucial for the survival of melanocyte progenitors until they reach the migratory staging area (MSA) and then later for proper migration (Hornyak et al., 2001). Ednrb is not instructive in the initial specification of melanocyte progenitors but is essential for survival, migration, proliferation and later indirectly activating the downstream targets of melanin production (Hou et al., 2004b; Lee et al., 2003).

Investigations into whether Ednrb, Sox10 and/or Pax3 interact genetically sprung from their spatiotemporal patterns of expression in early embryogenesis and that mutations of these genes can cause variations of Waardenburg syndrome (Read and Newton, 1997; Tachibana, 1999). Waardenburg syndrome (WS) was originally clinically described as four different types, all displaying pigmentary defects and some extent of hearing loss; the presence of additional signs and symptoms determined further classification (Read and Newton, 1997). Waardenburg syndrome Type I (WS I [MIM 193500]) were the original cases described by the Dutch ophthalmologist and geneticist Petrus $\mathrm{J}$. Waardenburg back in 1947 in a meeting of the Dutch Ophthalmological Society 
(Waardenburg, 1951). The additional features included dystopia canithorum and broad nasal root. Type III WS (WS III [MIM 148820]) is a more extreme version of Type I and most patients with either type I or III are heterozygous for Pax3 (Read and Newton, 1997; Tassabehji et al., 1992). Type II WS (WS II [MIM 193510]) patients are profoundly deaf and have pigmentation defects; mutations in Mitf are seen in $15 \%$ of the cases and there have been a couple of cases with mutations in SNAI2 (Read and Newton, 1997; Tassabehji et al., 1994), leaving approximately $85 \%$ of the cases from unknown mutations. Type IV WS (WS IV [MIM 277580]) has the additional feature of Hirschprung's disease, the failure of the distal colon to be innervated by NC derived enteric neurons which results in loss of peristalsis and inability to defecate (Shah et al., 1981). Some Type IV patients have been diagnosed with mutations in Sox10, Ednrb and/or Edn3 (McCallion and Chakravarti, 2001; Paratore et al., 2002; Puffenberger et al., 1994).

Given the pattern of co-expression, similarity of phenotypes and the presence of mutations in Sox10, Pax3 and Ednrb in the various forms of WS, investigations into possible genetic interactions have begun. In fact, a synergistic interaction between Sox10 and Pax3 has been identified in the transcriptional regulation of Mitf (Bondurand et al., 2000) and Edn3 regulates Mitf in an Ednrb-dependent manner (Sato-Jin et al., 2008) in the melanocyte lineage. Typically, Sox10 mutations have been identified as nonsense or frameshift mutations (Bondurand et al., 1999; Pingault et al., 1998; Touraine et al., 2000) but recently long deletions at the Sox10 locus has been found to be 
the cause of deleterious effects, including the novel finding that Sox10 is mutated in some cases of Type II WS (Antonellis et al., 2006; Bondurand et al., 2007).

Taken together, I wanted to elucidate whether or not synergistic genetic interactions exist among Sox10, Pax3 and Ednrb in the development of the melanocyte lineage and generation of a normal coat color pattern. In order to do so, specified matings were set to evaluate whether or not the phenotype of double heterozygous animals (Sox10 ${ }^{\mathrm{LacZ} /+}:: E d n r b^{\mathrm{S}-/ /+}$ or $P a x 3^{\mathrm{Sp} /+}:: E d n r b^{S-/ /+}$ ) was significantly exacerbated when compared to the phenotype of the single heterozygous animals. Areas of hypopigmentation were quantified and statistical analyses performed.

\section{Materials and methods}

\subsection{Animals and Genotyping}

Heterozygous Ednrb ${ }^{s-1}$ on SSL/Le background and $P a x 3^{S p}$ on C57BL/6J background were originally obtained from Jackson Laboratory and maintained in the FIU Animal Care Facility. Heterozygous Ednrb ${ }^{s-l}$ mice display small to medium areas of ventral hypopigmentation while homozygous animals are almost completely white, with small areas of pigmentation around the pinna and base of the tail. Tail biopsies were used as sources of genomic DNA for PCR genotyping (Appendix I.A). To detect the $E d n r b^{s-l}$ allele, the tightly linked D14Mit7 microsatelite polimorphic marker (Metallinos et al., 1994) was used to distinguish between $E d n r b^{s-1}$ and C57B/6J mice using conditions previously described (Pavan and Tilghman, 1994; and Appendix I.B). Pax3 ${ }^{S P}$ animals 
carry a point mutation within intron 3 of the paired homeobox $3(P a x 3)$ gene on mouse Chromosome 1. The mutation interferes with normal splicing of intron 3 and leads to at least 4 aberrantly spliced mRNAs with exon 4 deleted. Pax $3^{S p}$ heterozygotes consistently display ventral hypopigmentation; mice homozygous for this mutation are embryonic lethal by E13.5. To genotype Pax ${ }^{S p}$ mice, the intron 3/exon 4 boundary of Pax3 was amplified with primers: P3in3F (5'GAGAGGGTTGAGTACGTTAGCTGG-3') and P3ex4 (5'CTCGCTCACTCAGGATGCC-3'). Products were visualized on a $15 \%$ polyacrylamide gel resulting in a single band around 230bp for a wildtype and a heteroduplex band at this same site for the heterozygote (Appendix I.B).The PCRs were performed for 30 cycles under the following conditions: $94^{\circ} \mathrm{C}$ for 30 $\mathrm{s}, 58^{\circ} \mathrm{C}$ for $30 \mathrm{~s}, 72^{\circ} \mathrm{C}$ for $30 \mathrm{~s}$.

The generation of Sox $10^{\text {tm/WegLacZ }}$ (from here on noted as Sox $10^{\text {LacZ }}$ ) mice was described by Britsch et. al. (2001). Briefly, Sox10 was mutated using a targeting vector that deleted the coding sequence and inserted LacZ into the allele. We have maintained these mice by backcrossing and keeping them on their original mixed $\mathrm{C} 3 \mathrm{H}$ background. While many Sox $10^{\mathrm{LacZ} /+}$ mice have ventral hypopigmentation, it is not a consistent phenotype thereby requiring genotyping. Tail biopsies were used as sources of genomic DNA for PCR genotyping using the following primers: 5' Sox10 (5'CAGGTGGGCGTTGGGCTC-3'); 3' Sox10 (5'-CAGAGCTTGCCTAGTGTCTT3'); and 3' LacZ (5'-TAAAAATGCGCTCAGGTCAA-3'). The PCRs were performed for 32 cycles under the following conditions: $94^{\circ} \mathrm{C}$ for $30 \mathrm{~s}, 55^{\circ} \mathrm{C}$ for 
$30 \mathrm{~s}$, and $72^{\circ} \mathrm{C}$ for $30 \mathrm{~s}$. Products were visualized on a $2 \%$ agarose gel resulting in a $500 \mathrm{bp}$ band for wildtype and a $600 \mathrm{bp}$ for the mutated allele (Appendix I.B). Animals homozygous for Sox10 are embryonic lethal, typically by E13.5.

All animals used in this study were housed in the Animal Care Facility at Florida International University (Miami, FL). Water and murine chow were fed ad libitum and light/dark was cycled every 12 hours. All animal work was performed according to institutional guidelines established by NIH (Guide for the Care and Use of Laboratory Animals, 2009; IACUC protocol \# 08-001).

\subsection{Crosses and Phenotype Analysis}

Sox $10^{\mathrm{LacZ} /+}$ mice were crossed with $E d n r b^{\text {s-l/+ }}$ mice to produce offspring that were either heterozygous for Sox10, Ednrb or double heterozygous for Sox10 and Ednrb. At 2 months of age hypopigmentation was measured and the area calculated using the Canvas 9 program; double heterozygous animals were euthanized at this time. First generation single heterozygous animals were crossed and hypopigmentation of $F_{2}$ offspring was evaluated at 2 months of age as described. As with $F_{1}, F_{2}$ double heterozygous animals were euthanized and single heterozygous animals were crossed to produce a third generation of animals. Again, at 2 months of age hypopigmentation was measured and all $F_{3}$ animals were euthanized.

$\mathrm{Pax}^{\mathrm{Sp} / \mathrm{+}}$ mice were crossed with $E d n r b^{s-/ /+}$ mice as described above, also for three generations, to produce progeny that were either $\mathrm{Pax}^{\mathrm{Sp} /+}, E d n r b^{\mathrm{s} / /+}$ or $\operatorname{Pax}^{S p /+}:: E d n r b^{S-1 /+}$. 


\subsection{Statistical Analysis}

In order to evaluate the data, hypopigmentation areas of the single heterozygous animals were added and then compared to the hypopigmentation of animals manifesting both mutations. These data were then analyzed using a one-tailed t-test, the Wilcoxon rank sum test and Box-Cox square root transformations. These statistical tests are non-parametric, rely on independent samples and do not assume normality of data. In addition, individual data points were plotted on a scatter plot using Matlab (The MathWorks, Inc.).

\section{Results}

\subsection{Genetic Interaction between Sox10 and Ednrb}

To elucidate whether or not genetic interactions exist between Sox10 and Ednrb in the melanocyte lineage, I analyzed the sum of hypopigmentation of mice carrying heterozygous alleles in Sox10 and Ednrb and compared it to the hypopigmentation of mice that were heterozygous for both genes (Figure 1). Representative pictures of the three generations of mice imply some interaction between Sox 10 and Ednrb in generations 2 and 3 . Ednrb $b^{s-/ /+}$ mice typically have proper pigmentation or a very small area of ventral hypopigmentation, whereas null mutant $\left(E d n r b^{\text {s-l/s-l }}\right)$ mice are completely white with the occasional dark spot near the pinna and/or at the base of the tail. Sox $10^{\text {LacZ/+ }}$ mice have ventral hypopigmentation approximately three-quarters of the time (Sox $10^{\operatorname{LacZ} / L a c Z}$ mice are embryonic lethal). A scatter plot of hypopigmentation areas of individual animals (Figure 2) indicates that a genetic interaction becomes apparent in generations 2 and 3 since the areas of ventral hypopigmentation look larger in 
the double heterozygous mice than the areas of hypopigmentation in single heterozygous animals.

Hypopigmentation was measured by photographing mice at two months of age and using the Canvas 9 program to outline and calculate the area. While areas of hypopigmentation varied, the individual values were used in nonparametric assays that did not assume normality of data. Three statistical tests were used to analyze the data: Box-Cox square root transformations, Wilcoxon rank sum test and the one-tailed t-test, each of which took into account unequal size of the groups and variability and standard error of the samples. All analyses produced similar results (Tables 1 and 2).

In generation one $(\mathrm{n}=71)$, surprisingly, hypopigmentation of Sox $10^{\mathrm{LacZ} /+}$ was larger than hypopigmentation seen in $E d n r b^{s-/ /+}$ or Sox $10^{L a c Z /+}:: E d n r b^{s / /+}$ mice. However, in generations $2(n=52)$ and $3(n=27)$ the hypopigmentation of Sox $10^{\mathrm{LacZ} /+-.: E d n r b^{\mathrm{s} / /+}}$ mice was significantly larger (means of 404 and 298; $\mathrm{p}$ values ranging from $.005-.012$, and $.005-.026$, respectively for $F_{2}$ and $F_{3}$ ) than the sum of the single heterozygous animals (means of 66.5 and 37.7 , respectively for $F_{2}$ and $F_{3}$; Table 3 ) implying that background exerts an influence on pigmentation (Cantrell et al., 2004) and that as the $\mathrm{C} 3 \mathrm{H}$ and C57BL/6J backgrounds blend the nature of the interaction between Sox10 $0^{\mathrm{LaCZ} /+}$ and Ednrb ${ }^{s-/ /+}$ becomes apparent. 


\subsection{Genetic Interaction between Pax3 and Ednrb}

As with the cross mentioned above, $P a \times 3^{S p}$ and $E d n r b^{s-l}$ heterozygous mice were crossed to reveal whether or not a genetic interaction exists between these melanocytic genes (Hornyak et al., 2001; Pavan and Tilghman, 1994). All animals were genotyped and progeny crossed as described above, and at 2 months of age, hypopigmentation was photographed and measured using the Canvas 9 program. Representative pictures (Figure 3) of the three generations of mice imply some interaction between Pax3 and Ednrb. As mentioned above, $E d n r b^{s-l /+}$ mice exhibit either proper pigmentation or a very small area of ventral hypopigmentation while the Ednrb ${ }^{s-/ s-l}$ mice are completely white with the occasional dark spot near the pinna and/or at the base of the tail. Pax3 $3^{S p /+}$ mice, on the hand, consistently have ventral hypopigmentation and $P a x 3^{S p / S p}$ mice are embryonic lethal by E13.5.

A scatter plot of the hypopigmentation areas of individual animals (Figure 4) indicates that a genetic interaction becomes apparent in generations 2 and 3 . The three statistical analyses (Tables 4 and 5), Box-Cox square root transformations, Wilcoxon rank sum test and the one-tailed t-test, all indicate that a significant difference exists between the area of hypopigmentation of the double heterozygous mutants in generations 2 and 3 (means of 477.8 and 340.0; $p$ values ranging from $.010-.079$ and $.0004-.021$, respectively for $F_{2}$ and $F_{3}$ ) when compared to the sum of the areas of hypopigmentation of the single heterozygous mutants (means of 12.5 and 84.0 , respectively for $F_{2}$ and $F_{3}$; 
Table 6) even when considering the unequal sample sizes of the groups and the natural variability between the animals.

\section{Discussion}

Manipulating pigmentation phenotypes has long been a model system in which to elucidate genetic crosstalk and influences in health and disease. In the case of Waardenburg Syndrome, four out of the five genes responsible for variants of this disease are also involved in the development of melanocytes: Sox10, Pax3, Ednrb and Mitf. Investigating genetic interactions in the context of biological systems has the tremendous potential to increase our understanding of cellular development and the etiology of disease. One way to do this is by creating compound heterozygotes in animal models to investigate in vivo genetic interactions. Recent examples that have employed this approach include studies investigating candidate genes for autism spectrum disorder and cardiac development.

PTEN (PI3K pathway) and SLC6A4 (serotonin pathway) are considered autism candidate genes (Bartlett et al., 2005; Herman et al., 2007). Page and colleagues (2009) examined the question of whether these two genes, both candidates for a complicated disease and whose pathways intersect ( $\mathrm{Ji}$ et al., 2006), interact by creating double heterozygous animals and evaluating their phenotype. In a completely different system, the effect of using compound heterozygous mice was employed to study genetic interactions between Gata4/6 and Tbx5 in cardiac development. Gata4 and Gata6 belong to a (zinc finger) transcription family, are expressed in a variety of cells and are important 
in cardiovascular development (Molkentin, 2000; Pu et al., 2004); Tbx5 is a transcription factor whose haploinsufficiency causes a variety of cardiac defects (Bruneau, 2008). Based on earlier experiments indicating a possible interaction between Gata4 and Tbx5, heterozygous Gata4 or Gata6 mice were crossed with $T b x 5$ heterozygous mice to generate compound heterozygous Gata4 ${ }^{+/}$ $:: \mathrm{Tb}^{+} 5^{+/}$or $\mathrm{Gata}^{+/-}:: \mathrm{Tb} \times 5^{+/}$embryos and pups in order to determine whether or not synergistic interactions occur between these genes (Maitra et al., 2009). Both of these studies helped elucidate interactions between genes of interest.

In this study, I have taken mice that were heterozygous for either of the transcription factors Sox10 or Pax3 and crossed them with mice harboring the heterozygous mutation of Ednrb. Progeny of the Sox $10^{\mathrm{LacZ} /+}$ and Ednrb $b^{\mathrm{s} / /+}$ cross, alongside progeny of the $P a x 3^{S p /+}$ and $E d n r b^{s-1 /+}$ cross, were evaluated over the course of three generations to see if there was a genetic interaction between either transcription factor and Ednrb.

The Sox $10^{\mathrm{LacZ} /+}$ and $E d n r b^{\mathrm{s} / /+}$ crossed over three generations produced second and third generation double heterozygous progeny in which the area of hypopigmentation was significantly larger than the sum of the area of hypopigmentation of single heterozygous animals from the same generation. A previous study using an Ednrb hypomorph $\left(E d n r b^{s}\right)$ crossed with a spontaneously occurring Sox10 mutation $\left(\operatorname{Sox} 10^{D o m /+}\right)$ or the knock-in Sox $10^{\mathrm{LacZ} /+}$ revealed that the pigmentation phenotype, in addition to the hearing and aganglionosis phenotypes, seen in Ednrb and Sox10 haploinsufficient mice were aggravated in the double heterozygous animals (Stanchina et al., 2006). 
In addition, pups born with a mutation in both Ednrb and Sox $10^{D o m /+}$ had increased mortality regardless of the Ednrb allele used in the cross (Cantrell et al., 2004; Stanchina et al., 2006). The Ednrb hypomorph $\left(E d n r b^{s}\right)$ used in these studies retains about $25 \%$ of functional receptor activity; even without losing all the functional capacity of the mutated allele, a genetic interaction was seen between Ednrb and Sox $10^{D o m / t}$. This study used the Ednrb $b^{s-1}$ allele which has essentially no receptor activity.

However, data from two other studies suggested no interaction between Sox10 and Ednrb in the melanocyte lineage (Cantrell et al., 2004; Hakami et al., 2006). The differences in the results found in these studies could be attributed to the allelic variants of the mouse mutants that were used. Cantrell et al (2004) and Hakami et al (2006) used the Sox10 variant Dom. Sox10 Dom mice lack the transactivation domain (Herbarth et al., 1998; Southard-Smith et al., 1998) of the gene; Sox $10^{L a c Z}$ mice (used by Stanchina et al and in this study) have LacZ knocked into the gene at the initiation codon (Britsch et al., 2001). Cantrell et al. (2004) used Ednrb ${ }^{\text {tm/Ywa }}$ in which $4.2 \mathrm{~kb}$ is replaced by a neomycin cassette in exon 3 rendering the gene null (Hosoda et al., 1994) while Hakami et al. (2006) and Stanchina et al. (2006) used a Ednrb hypomorph where a $5.5 \mathrm{~kb}$ retrotransposon was placed in intron 1 rendering the gene 25\% functional (Roix et al., 2001). Cantrell et al. (2004) and Hakami et al. (2006) also used $E d n r b^{s-1}$ in which all coding exons are deleted and there is no functional transcript available (Hosoda et al., 1994). This study consistently used Sox $10^{\mathrm{LacZ}}$ and $E d n r b^{\mathrm{s}-1}$ mice to assess whether an interaction between 
these genes exists; neither heterozygous animal had residual functional effects from the mutated allele.

Another difference between these studies that may have influenced the varying outcomes is the background of the mouse strains used. Although the mice originally came from the same sources (e.g. Jackson Labs; Dr. Wegner, Universitat Erlangen), they had typically resided in the animal facilities of the respective labs for some time. Some mice were outcrossed to switch the background (Cantrell et al., 2004; Hakami et al., 2006) while other mice were maintained in their mixed background for a number of years (Stanchina et al., 2006). The $E d n r b^{s-l}$ mice used in this study were originally switched over from an LLE background to a C57BL/6J background where they have been maintained for years. The Sox $10^{L a c Z}$ mice were originally on a $\mathrm{C} 3 \mathrm{H}$ mixed background and have been backcrossed since their arrival. Colony size and number of years being inbred or outcrossed could increase, or decrease, the expression of background modifiers and genetic heterogeneity which in turn might affect gene expression and penetrance (Cantrell et al., 2004; Genin et al., 2008; Strunk et al., 2004). Biological complexities of studying genetic interactions in vivo imply that a myriad of genes, allelic variants of those genes, modifiers and/or environmental influences can impact gene expression underscoring the need to perform experiments over generations and in varying backgrounds to truly elucidate genetic interactions. The C57BL/6J background is known to diminish pigmentation phenotypes (Cantrell et al., 2004), which is possibly why the hypopigmentation of generation 1 double heterozygous 
animals was not significantly different than the hypopigmentation of the single heterozygous animals. As the single heterozygous animals from each subsequent generation were crossed, the backgrounds continued to mix to create a more homogeneous (mixture of $\mathrm{C} 57 \mathrm{BL} / 6 \mathrm{~J}+\mathrm{C} 3 \mathrm{H}$ ) background allowing the phenotype from the genetic interaction to become apparent.

Given that Ednrb and Sox10 are spatially and temporally co-expressed as neural crest cells emigrate from the dorsal aspect of the neural tube and melanocyte and enteric neuron precursors migrate via the dorso-lateral and ventro-medial pathways, respectively (Le Douarin and Dupin, 2003), one might suspect that the expression of one might be dependent on the expression of the other. In fact, interactions between Sox10 and Ednrb have been shown to modulate the development of enteric neurons (Cantrell et al., 2004; Zhu et al., 2004), and an Ednrb enhancer that is activated specifically in enteric neuron precursors has been identified that contains multiple binding sites for Sox10 (Zhu et al., 2004). Recently, in human melanocytes, Sox10 has been shown to directly regulate Ednrb at the transcriptional level through two different promoters (Yokoyama et al., 2006).

In situ hybridization has shown that Sox $10^{\text {Dom/Dom }}$ embryos still express Ednrb and that, at least for neural crest cells explants, the converse is true as well, that Ednrb null mutant cells express Sox10 (Hakami et al., 2006). However, the expression of either gene in the mutant of the other occurs in a significantly reduced manner. Of interest is that in these mutants certain structures (e.g., the PNS in Sox10 homozygous mice) or cells (e.g., 
melanoblasts in Ednrb homozygous mice) begin to deteriorate or are missing. Structures that are deteriorating or missing prevent the distinction between the lack of expression of the gene of interest due to regulation of the mutated gene or simply because the tissues and structures where the gene is expressed are not there Ednrb and Sox10 may interact in a functional hierarchical manner at a specified time during development to promote melanoblast differentiation. For example, while Ednrb is not required for initial melanoblast specification, it is required during E10.5-E12.5 for proper melanocyte development (Lee et al., 2003; Shin et al., 1999). This is the same critical window in which Sox10 expression is needed for melanoblasts to proceed normally in development (Britsch et al., 2001).

Sox proteins are abundant in tissues, each of them present in a variety of tissues and transcriptionally active at different times throughout the vertebrate lifecycle (Wegner, 1999). Besides being important architectural modifiers, Sox proteins cooperatively bind with other proteins to ensure specificity of their action (Kuhlbrodt et al., 1998; Schlierf et al., 2002). Sox10 undoubtedly needs a partner to activate (Kamachi et al., 2000) and become fully functional in melanoblast development and, since Sox10 and Pax3 work coordinately to transcriptionally activate the melanocytic downstream target Mitf, could they possibly each work to activate Ednrb as well?

$\mathrm{Pax}^{\mathrm{Sp} / \mathrm{+}}$ mice have a phenotype similar to $\mathrm{Ednr} \mathrm{b}^{\mathrm{S} / /+}$ and Sox $10^{\mathrm{LacZ} /+}$ (ventral hypopigmentation), but unlike the other mutants $\mathrm{Pax}^{\mathrm{S} / \mathrm{t}}$ is a fully penetrant phenotype, apparent in all heterozygous mice. Pax3 is present in the dorsal 
aspect of the neural tube as NC cells begin their emigration and while the prospective melanocytes are in the MSA prior to their emigration. Acting as a nodal point in melanocyte stem cell differentiation, Pax3 in conjunction with Sox10 coordinately regulates Mitf (Bondurand et al., 2000; Potterf et al., 2000) and subsequently acts to repress this activation as well (Lang et al., 2005). In NC derived enteric neurons, Sox10 and Pax3 synergistically interact to regulate c-RET (Lang et al., 2000) Intriguingly, a Sox10 transgene put under the control of the Pax3 promoter rescues Sox10 deficient melanocytes (Hou et al., 2004a). Given the seemingly related roles that Sox10 and Pax3 play in melanogenesis, the question of whether Pax3 and Ednrb interact needed to be addressed.

Heterozygous mutants of Pax3 and Ednrb were crossed to evaluate the hypopigmentation of single and double heterozygous animals for 3 generations. The results of these crosses indicate that there is indeed a genetic interaction between Pax3 and Ednrb in the melanocyte lineage. As with the Sox10 experiment the progeny of $\mathrm{Pax}^{\mathrm{Sp} /+}$ crossed with $E d n r b^{s-/ /+}$ showed that the hypopigmentation of the double mutants in generations 2 and 3 was significantly larger than the sum of the hypopigmentation of the single mutants.

Haploinsufficiency of Sox10 or Pax3 in combination with haploinsufficiency of Ednrb caused an aggravated hypopigmentation phenotype in second and third generation progeny. First generation results may have been obscured by initial mixing of varying genetic backgrounds $(\mathrm{C} 3 \mathrm{H}, \mathrm{C} 57 \mathrm{BL} / 6 \mathrm{~J}$ and $\mathrm{LLE})$ which may have altered the expressivity and penetrance of the pigmentation 
phenotype. Taken together, these results suggest a genetic interaction between Sox10 and Ednrb as well as Pax3 and Ednrb.

The question that naturally follows is whether the hypopigmentation phenotype of these mutants could be rescued by the targeted addition of the complimentary gene. For instance, could the Sox $10 / P a x 3$ phenotype be rescued by additional Ednrb or could the Ednrb phenotype be rescued by additional Sox10/Pax3? In light of previous research showing that Ednrb contains multiple binding sites for Sox10 in enteric neurons (Zhu et al., 2004) and in human melanocytes (Yokoyama et al., 2006), I will attempt to answer this question by delivering additional Ednrb to Sox $10^{s-/ /+}$ and $P a x 3^{S p /+}$ mice. 


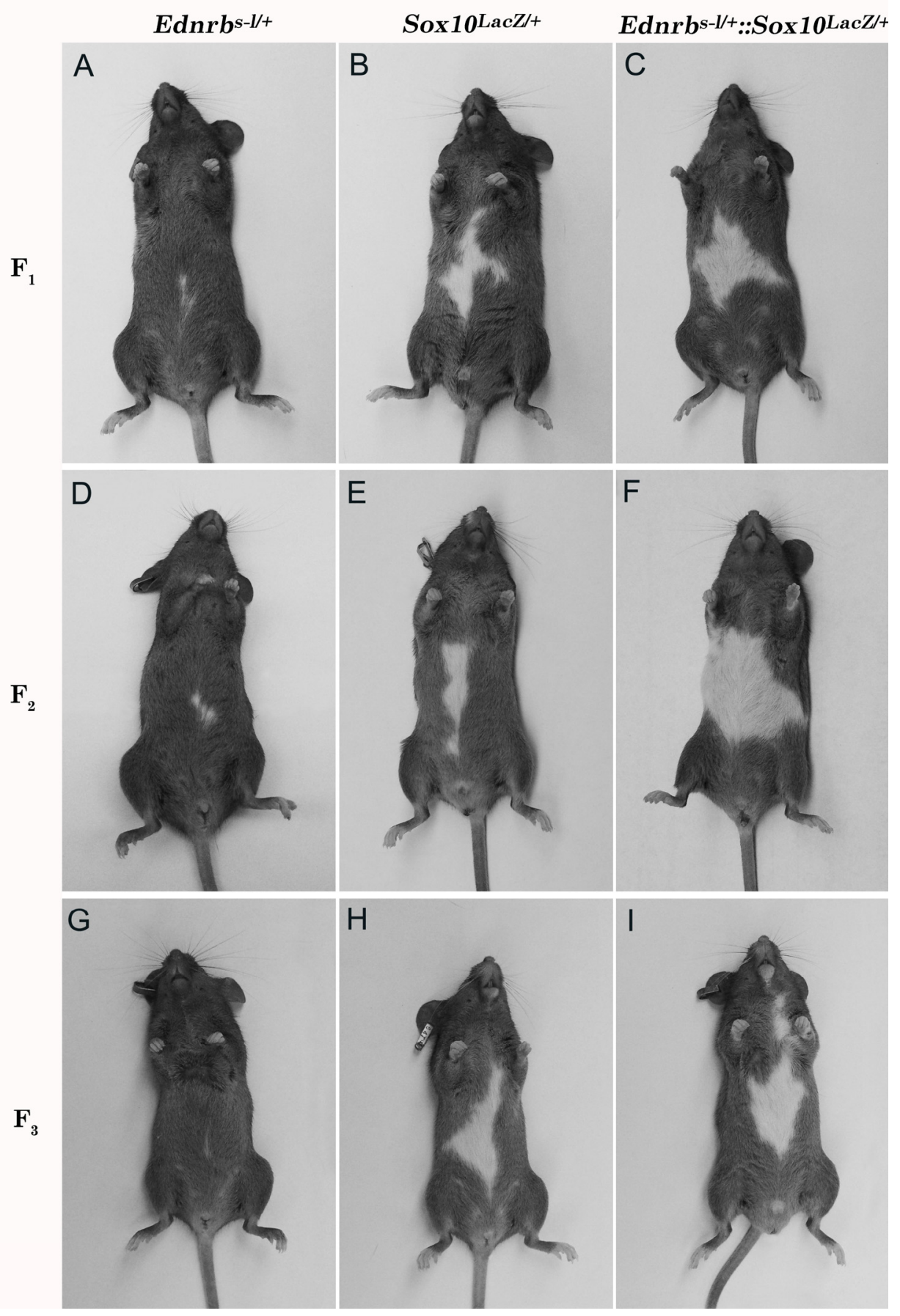

Figure 2.1 Sox10 and Ednrb double heterozygosity results in an aggravated hypopigmentation phenotype. Representative pictures of hypopigmentation for each genotype show ventral hypopigmentation of double heterozygous mutants for generation 1 was not different than the hypopigmentation of single mutants. In generations 2 and 3 , double heterozygous mice had larger areas of hypopigmentation than did the Sox10 heterozygous and the Ednrb heterozygous animals $\left(F_{1}=1^{\text {st }}\right.$ generation, $F_{2}=2^{\text {nd }}$ generation, $F_{3}=3^{\text {rd }}$ generation). 

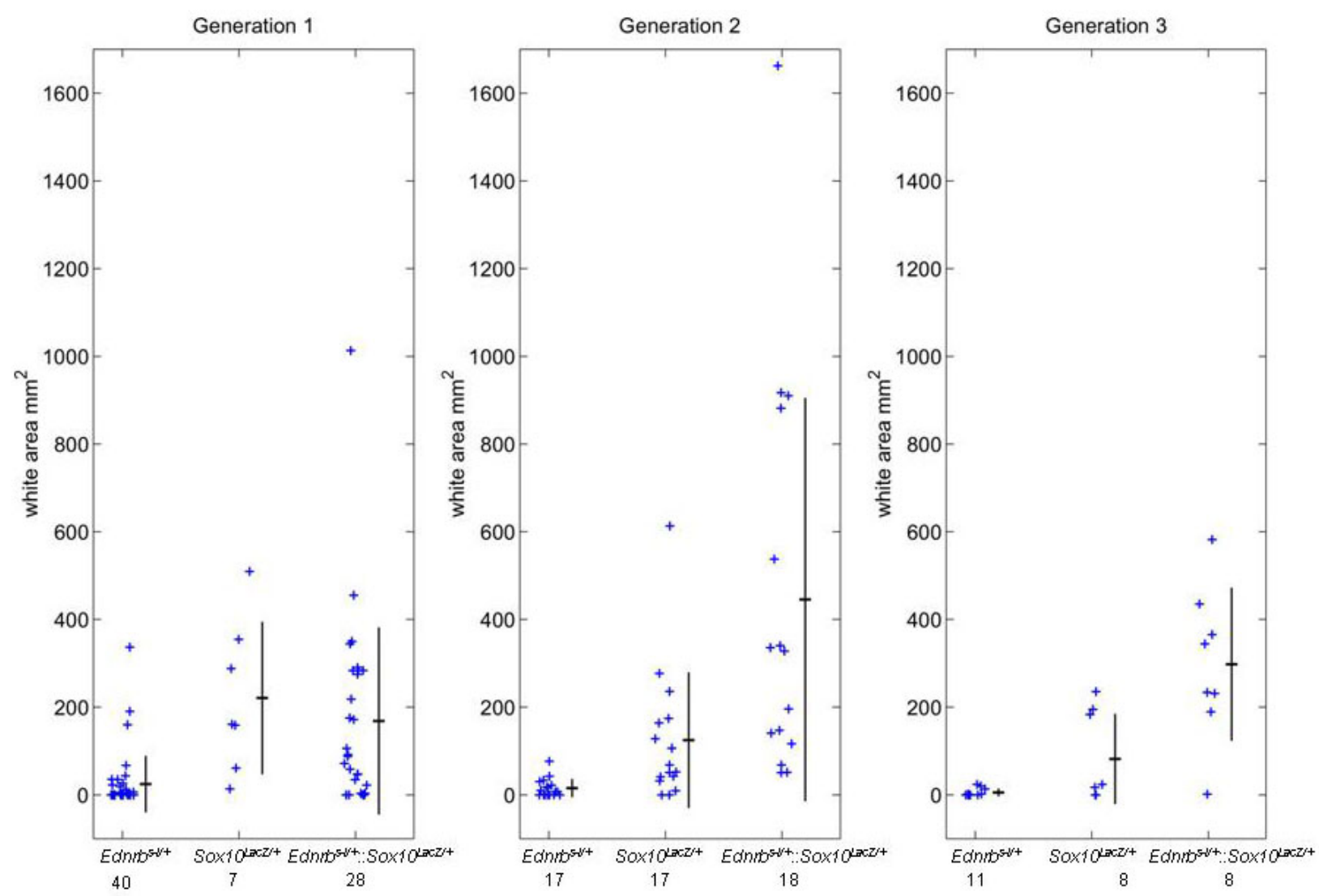

Figure 2.2 Double heterozygous progeny of generations 2 and 3 exhibit larger areas of hypopigmentation than single heterozygous animals. Numerical scatter plots of individual progeny of Sox $10^{\mathrm{LacZ} /+}$ crossed with $E d n r b^{s-/ /+}$ over three generations, including means and standard deviations. The numbers below the genotype represent the number of animals in that group; white area in $\mathrm{mm}^{2}$ denotes area of hypopigmentation. 


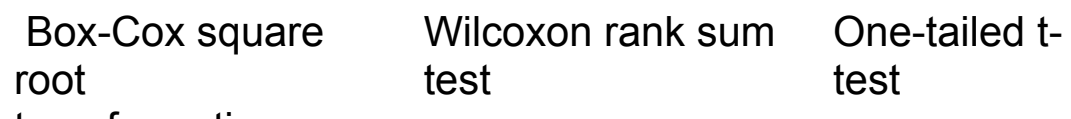

$\begin{array}{llcc}\text { F1 } & \text { NS } & \text { NS } & \text { NS } \\ \text { F2 } & p=.012 & p=.005 & p=.010 \\ \text { F3 } & p=.026 & p=.014 & p=.005\end{array}$

Table 2.1 Sox10 and Ednrb double heterozygosity results in an aggravated phenotype. Various analyses were employed given that samples were uneven in size. Statistical analyses robustly indicate that in generations 2 and 3 a statistically significant difference exists between the sum of hypopigmentation of single heterozygous animals (Sox $10^{\text {lacz/+ }}$ and Ednrb $b^{s-/ /+}$ ) and the hypopigmentation of double heterozygous animals $\left(\right.$ Sox $10^{\mathrm{lacZ} /+}:: E d n r b^{\mathrm{s}-/ /+} ; \mathrm{F}_{1}=1^{\text {st }}$ generation, $F_{2}=2^{\text {nd }}$ generation, $F_{3}=3^{\text {rd }}$ generation). 


\begin{tabular}{|c|c|c|c|c|}
\hline Generation & Genotype & $\begin{array}{l}\text { Number } \\
\text { of }\end{array}$ & $\begin{array}{c}\text { Mean area of } \\
\text { hypopigmentation }\end{array}$ & Significance \\
\hline \multirow{3}{*}{ F1 } & $E d n r b^{s-1 /+}$ & 40 & 25 & \multirow{3}{*}{ NS } \\
\hline & Sox $10^{\mathrm{LacZ} /+}$ & 7 & 221 & \\
\hline & $\begin{array}{l}E d n r b^{s-/ /+}:: \\
\quad \text { Sox } 10^{L a c z /+}\end{array}$ & 28 & 168 & \\
\hline \multirow{3}{*}{$\mathrm{F} 2$} & $E d n r b^{s-1 /+}$ & 17 & 15 & \multirow{3}{*}{$p=.005$} \\
\hline & Sox $10^{\mathrm{LacZ} /+}$ & 17 & 118 & \\
\hline & $\begin{array}{l}E d n r b^{s-/ /+}:: \\
\quad \text { Sox } 10^{L a c Z /+}\end{array}$ & 18 & 404 & \\
\hline \multirow{3}{*}{ F3 } & $E d n r b^{s-l /+}$ & 11 & 6 & \multirow{3}{*}{$p=.014$} \\
\hline & Sox $10^{\mathrm{LacZ} /+}$ & 8 & 82 & \\
\hline & $\begin{array}{l}\text { Ednrb } b^{s-/ /+}: . \\
\quad \text { Sox } 10^{L a c z /+}\end{array}$ & 8 & 298 & \\
\hline
\end{tabular}

Table 2.2 Wilcoxon rank sum test of hypopigmentation in Sox10 and Ednrb single heterozygotes versus double heterozygosity. In F2 and F3 progeny, hypopig-mentation is significantly larger in Ednrb ${ }^{\text {S///+}}::$ Sox $10^{\mathrm{LacZ} /+}$ mice than in mice with either gene mutated alone $\left(N S=\right.$ not significant, $F_{1}=1^{\text {st }}$ generation, $F_{2}=2^{\text {nd }}$ generation, $F_{3}=3^{\text {rd }}$ generation).

Sox $10^{L a c Z /+} \times E d n r b^{S-1 /+}$

$F_{1}$

$F_{2}$

$F_{3}$
Average of Hypopigmentation of Single Heterozygous

53.6

66.5

37.7
Average of Hypopigmentation of Double Heterozygous
168.5

404.0

298.0

Table 2.3 Sums of averages. The sum of hypopigmentation averages for single heterozygous animals $\left(\right.$ Sox $\left.10^{\mathrm{LacZ} /+} \times E d n r b^{\mathrm{S}-/ /+}\right)$ compared to the hypopig-

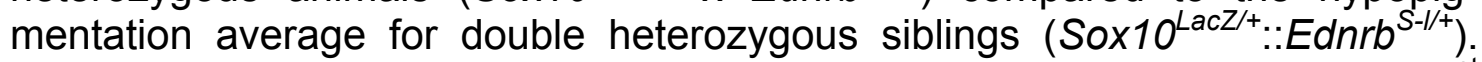
Levels of significance are listed by statistical measure used in Table 1. $\left(F_{1}=1^{\text {st }}\right.$ generation, $F_{2}=2^{\text {nd }}$ generation, $F_{3}=3^{\text {rd }}$ generation). 


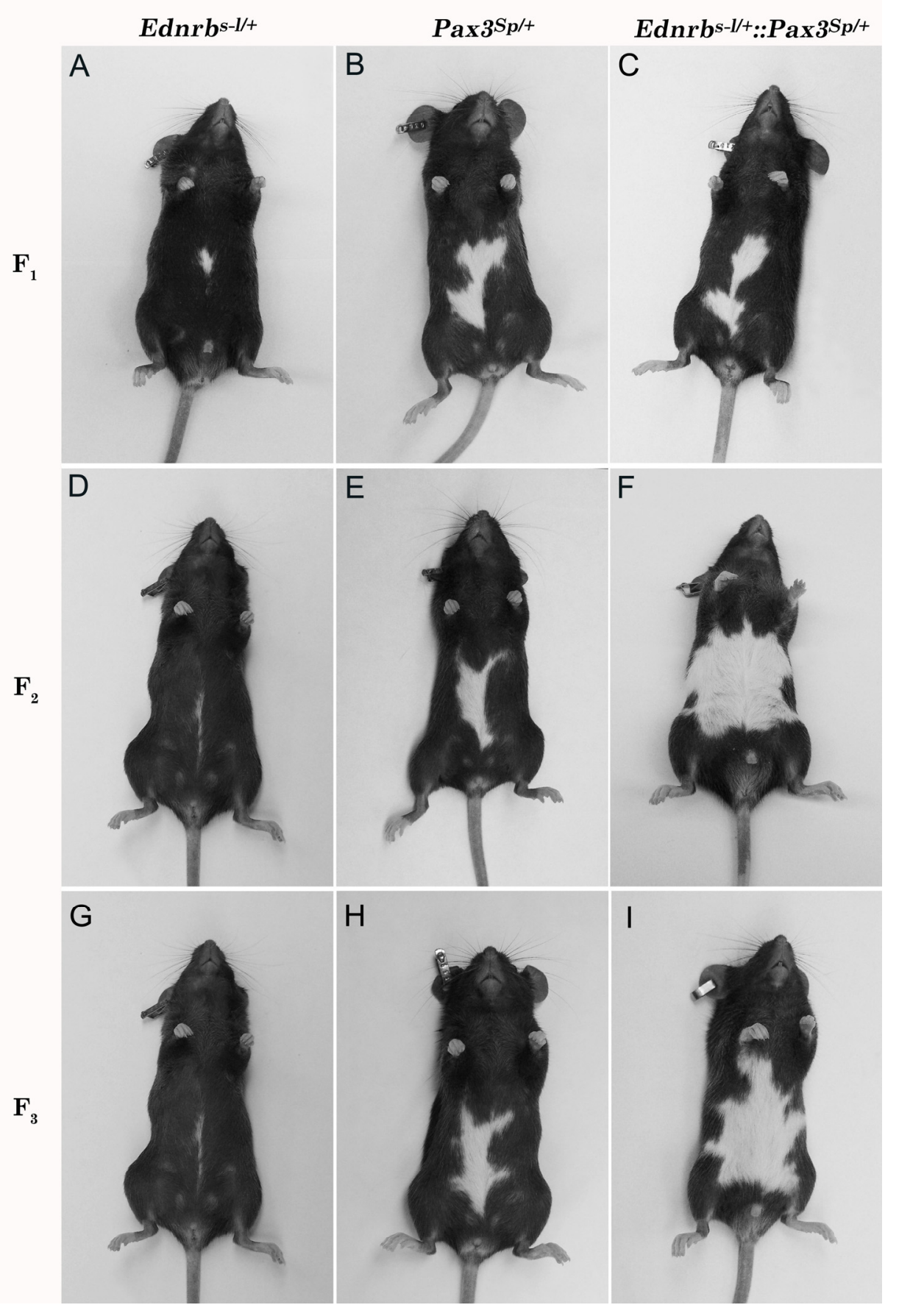

Figure 2.3 Pax3 and Ednrb double heterozygosity results in an aggravated hypopigmentation phenotype. Representative pictures of hypopigmentation for each genotype show ventral hypopigmentation of double heterozygous mutants for generation 1 was not different than the hypopigmentation of single mutants. In generations 2 and 3 , double heterozygous mice had much larger areas of hypopigmentation than did the Pax3 heterozygous and the Ednrb heterozygous animals $\left(F_{1}=1^{\text {st }}\right.$ generation, $F_{2}=2^{\text {nd }}$ generation, $F_{3}=3^{\text {rd }}$ generation). 

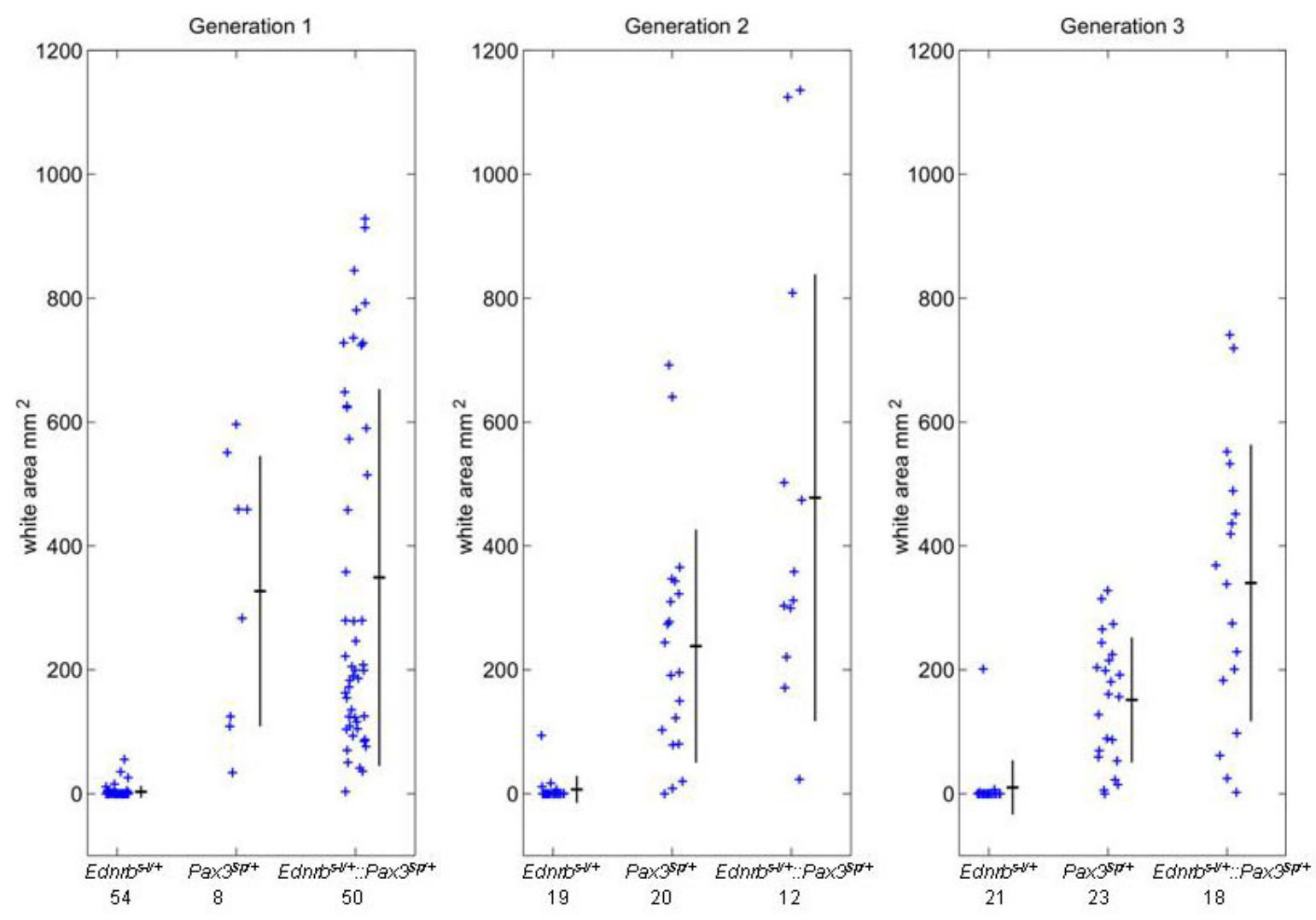

Figure 2.4 Double heterozygous progeny of generations 2 and 3 exhibit larger areas of hypopigmentation than single heterozygous animals. Numerical scatter plots of individual progeny of $\mathrm{Pax}^{\mathrm{Sp} / \mathrm{t}}$ crossed with Ednrb ${ }^{\mathrm{s-}}$ ${ }^{1 /+}$ over three generations, including means and standard deviations. The numbers below the genotype represent the number of animals in that group.

\begin{tabular}{|c|c|}
\hline Box-Cox square root & Wilcoxon rank sum \\
\hline
\end{tabular}

$\begin{array}{llll}\text { F1 NS } & \text { NS } & \text { NS }\end{array}$

F2 $p=.079 \quad p=.037 \quad p=.010$

F3

$p=.021$

$p=.004$

$p=.0004$

Table 2.4 Pax3 and Ednrb double heterozygosity results in an aggravated phenotype. Various analyses were employed given that samples were uneven in size. Statistical analyses robustly indicate that in generations 2 and 3 a statistically significant difference exists between the sum of hypopigmentation of single heterozygous animals $\left(\mathrm{Pax}^{\mathrm{Sp} /+}\right.$ and $\left.E d n r b^{\mathrm{s} / /++}\right)$ and the hypopig-mentation of double heterozygous animals $\left(P a \times 3^{S p /+}:: E d n r b^{S-}\right.$ ${ }^{I /+} ; F_{1}=1^{\text {st }}$ generation, $F_{2}=2^{\text {nd }}$ generation, $F_{3}=3^{\text {rd }}$ generation) . 


\begin{tabular}{|c|c|c|c|c|}
\hline Generation & Genotype & $\begin{array}{l}\text { Number } \\
\text { of }\end{array}$ & $\begin{array}{c}\text { Mean area of } \\
\text { hypopigmentation }\end{array}$ & Significance \\
\hline F1 & $\begin{array}{l}\text { Ednrb }^{+/-} \\
\text {Pax3 }^{+/-} \\
\text {Pax3 }^{+/-}: \text {: } \\
\text { Ednrb }^{+/-}\end{array}$ & $\begin{array}{c}\text { animals } \\
54 \\
8 \\
50\end{array}$ & $\begin{array}{r}3 \\
327 \\
349\end{array}$ & NS \\
\hline F2 & $\begin{array}{l}\mathrm{Ednrb}^{+/-} \\
\mathrm{Pax3}^{+/-} \\
\mathrm{Pax3}^{+/-} \\
: \because \mathrm{Ednrb}^{+/-}\end{array}$ & $\begin{array}{l}19 \\
20 \\
12\end{array}$ & $\begin{array}{r}7 \\
238 \\
478\end{array}$ & $p=.037$ \\
\hline F3 & $\begin{array}{l}\mathrm{Ednrb}^{+/-} \\
\mathrm{Pax3}^{+/-} \\
\mathrm{Pax3}^{+/-} \\
:: \mathrm{Ednrb}^{+/-}\end{array}$ & $\begin{array}{l}21 \\
23 \\
18\end{array}$ & $\begin{array}{r}10 \\
152 \\
340\end{array}$ & $p=.004$ \\
\hline
\end{tabular}

Table 2.5 Wilcoxon rank sum test of hypopigmentation in Pax3 and Ednrb single heterozygous versus double heterozygosity. In F2 and F3 progeny, hypopig-mentation is significantly larger in $E d n r b^{S-/ /+}:: P a x 3^{S p /+}$ mice than in mice with either gene mutated alone $\left(N S=\right.$ not significant, $F_{1}=1^{\text {st }}$ generation, $F_{2}=2^{\text {nd }}$ generation, $F_{3}=3^{\text {rd }}$ generation $)$.

$\begin{array}{ccc}\operatorname{Pax3}^{\mathrm{LacZ} /+} \times E d n r b^{\mathrm{S} / /+} & \begin{array}{c}\text { Average of } \\ \text { Hypopigmentation of } \\ \text { Single Heterozygous }\end{array} & \begin{array}{c}\text { Average of } \\ \text { Hypopigmentation of } \\ \text { Double Heterozygous }\end{array} \\ \mathrm{F}_{1} & 45.0 & 349.1 \\ \mathrm{~F}_{2} & 125.5 & 477.8 \\ \mathrm{~F}_{3} & 84.0 & 340.0\end{array}$

Table 2.6 Sums of Averages. The sum of hypopigmentation averages for single heterozygous animals $\left(\mathrm{Pax}^{\mathrm{LacZ} /+^{+}} \times \mathrm{Ednrb}^{\mathrm{S}-/ /+}\right)$ compared to the hypopig-mentation average for double heterozygous siblings $\left(\right.$ Pax $\left.^{\mathrm{LacZ} /+}:: E d n r b^{\mathrm{S}-/ /+}\right)$. Levels of significance are listed by statistical measure used in Table 1. $\left(F_{1}=1^{\text {st }}\right.$ generation, $F_{2}=2^{\text {nd }}$ generation, $F_{3}=3^{\text {rd }}$ generation $)$. 


\section{References:}

Antonellis, A., Bennett, W. R., Menheniott, T. R., Prasad, A. B., Lee-Lin, S. Q., Green, E. D., Paisley, D., Kelsh, R. N., Pavan, W. J. and Ward, A. (2006). Deletion of long-range sequences at Sox10 compromises developmental expression in a mouse model of Waardenburg-Shah (WS4) syndrome. Hum Mol Genet 15, 259-71.

Bartlett, C. W., Gharani, N., Millonig, J. H. and Brzustowicz, L. M. (2005). Three autism candidate genes: a synthesis of human genetic analysis with other disciplines. Int J Dev Neurosci 23, 221-34.

Baynash, A. G., Hosoda, K., Giaid, A., Richardson, J. A., Emoto, N., Hammer, R. E. and Yanagisawa, M. (1994). Interaction of endothelin-3 with endothelin-B receptor is essential for development of epidermal melanocytes and enteric neurons. Cell 79, 1277-85.

Bondurand, N., Dastot-Le Moal, F., Stanchina, L., Collot, N., Baral, V., Marlin, S., Attie-Bitach, T., Giurgea, I., Skopinski, L., Reardon, W. et al. (2007). Deletions at the SOX10 gene locus cause Waardenburg syndrome types 2 and 4. Am J Hum Genet 81, 1169-85.

Bondurand, N., Kuhlbrodt, K., Pingault, V., Enderich, J., Sajus, M., Tommerup, N., Warburg, M., Hennekam, R. C., Read, A. P., Wegner, M. et al. (1999). A molecular analysis of the yemenite deaf-blind hypopigmentation syndrome: SOX10 dysfunction causes different neurocristopathies. Hum Mol Genet 8, 1785-9.

Bondurand, N., Pingault, V., Goerich, D. E., Lemort, N., Sock, E., Caignec, C. L., Wegner, M. and Goossens, M. (2000). Interaction among SOX10, PAX3 and MITF, three genes altered in Waardenburg syndrome. Hum Mol Genet 9, 1907-17.

Britsch, S., Goerich, D. E., Riethmacher, D., Peirano, R. I., Rossner, M., Nave, K. A., Birchmeier, C. and Wegner, M. (2001). The transcription factor Sox10 is a key regulator of peripheral glial development. Genes Dev 15, 66-78.

Bruneau, B. G. (2008). The developmental genetics of congenital heart disease. Nature 451, 943-8.

Cantrell, V. A., Owens, S. E., Chandler, R. L., Airey, D. C., Bradley, K. M., Smith, J. R. and Southard-Smith, E. M. (2004). Interactions between Sox10 and EdnrB modulate penetrance and severity of aganglionosis in the Sox10Dom mouse model of Hirschsprung disease. Hum Mol Genet 13, 2289-301. 
Genin, E., Feingold, J. and Clerget-Darpoux, F. (2008). Identifying modifier genes of monogenic disease: strategies and difficulties. Hum Genet 124, $357-68$.

Goulding, M. D., Chalepakis, G., Deutsch, U., Erselius, J. R. and Gruss, P. (1991). Pax-3, a novel murine DNA binding protein expressed during early neurogenesis. Embo J 10, 1135-47.

Hakami, R. M., Hou, L., Baxter, L. L., Loftus, S. K., Southard-Smith, E. M., Incao, A., Cheng, J. and Pavan, W. J. (2006). Genetic evidence does not support direct regulation of EDNRB by SOX10 in migratory neural crest and the melanocyte lineage. Mech Dev 123, 124-34.

Herbarth, B., Pingault, V., Bondurand, N., Kuhlbrodt, K., HermansBorgmeyer, I., Puliti, A., Lemort, N., Goossens, M. and Wegner, M. (1998). Mutation of the Sry-related Sox10 gene in Dominant megacolon, a mouse model for human Hirschsprung disease. Proc Natl Acad Sci U S A 95, 5161-5.

Herman, G. E., Butter, E., Enrile, B., Pastore, M., Prior, T. W. and Sommer, A. (2007). Increasing knowledge of PTEN germline mutations: Two additional patients with autism and macrocephaly. Am J Med Genet A 143, 589-93.

Hornyak, T. J., Hayes, D. J., Chiu, L. Y. and Ziff, E. B. (2001). Transcription factors in melanocyte development: distinct roles for Pax-3 and Mitf. Mech Dev 101, 47-59.

Hosoda, K., Hammer, R. E., Richardson, J. A., Baynash, A. G., Cheung, J. C., Giaid, A. and Yanagisawa, M. (1994). Targeted and natural (piebaldlethal) mutations of endothelin-B receptor gene produce megacolon associated with spotted coat color in mice. Cell 79, 1267-76.

Hou, L., Loftus, S. K., Incao, A., Chen, A. and Pavan, W. J. (2004a). Complementation of melanocyte development in SOX10 mutant neural crest using lineage-directed gene transfer. Dev Dyn 229, 54-62.

Hou, L., Pavan, W. J., Shin, M. K. and Arnheiter, H. (2004b). Cellautonomous and cell non-autonomous signaling through endothelin receptor B during melanocyte development. Development 131, 3239-47.

Ji, S. P., Zhang, Y., Van Cleemput, J., Jiang, W., Liao, M., Li, L., Wan, Q., Backstrom, J. R. and Zhang, X. (2006). Disruption of PTEN coupling with 5 -HT2C receptors suppresses behavioral responses induced by drugs of abuse. Nat Med 12, 324-9. 
Kamachi, Y., Uchikawa, M. and Kondoh, H. (2000). Pairing SOX off: with partners in the regulation of embryonic development. Trends Genet 16, 1827.

Kuhlbrodt, K., Herbarth, B., Sock, E., Hermans-Borgmeyer, I. and Wegner, M. (1998). Sox10, a novel transcriptional modulator in glial cells. J Neurosci 18, 237-50.

Lang, D., Chen, F., Milewski, R., Li, J., Lu, M. M. and Epstein, J. A. (2000). Pax3 is required for enteric ganglia formation and functions with Sox10 to modulate expression of c-ret. J Clin Invest 106, 963-71.

Lang, D., Lu, M. M., Huang, L., Engleka, K. A., Zhang, M., Chu, E. Y., Lipner, S., Skoultchi, A., Millar, S. E. and Epstein, J. A. (2005). Pax3 functions at a nodal point in melanocyte stem cell differentiation. Nature 433, 884-7.

Le Douarin, N. M. and Dupin, E. (2003). Multipotentiality of the neural crest. Curr Opin Genet Dev 13, 529-36.

LeDouarin, N. M. and Kalcheim, C. (1999). The Neural Crest. New York: Cambridge University Press.

Lee, H. O., Levorse, J. M. and Shin, M. K. (2003). The endothelin receptor-B is required for the migration of neural crest-derived melanocyte and enteric neuron precursors. Dev Biol 259, 162-75.

Maitra, M., Schluterman, M. K., Nichols, H. A., Richardson, J. A., Lo, C. W., Srivastava, D. and Garg, V. (2009). Interaction of Gata4 and Gata6 with Tbx5 is critical for normal cardiac development. Dev Biol 326, 368-77.

McCallion, A. S. and Chakravarti, A. (2001). EDNRB/EDN3 and Hirschsprung disease type II. Pigment Cell Res 14, 161-9.

Mintz, B. (1967). Gene control of mammalian pigmentary differentiation. I. Clonal origin of melanocytes. Proc Natl Acad Sci U S A 58, 344-51.

Molkentin, J. D. (2000). The zinc finger-containing transcription factors GATA$4,-5$, and -6 . Ubiquitously expressed regulators of tissue-specific gene expression. J Biol Chem 275, 38949-52.

Mollaaghababa, R. and Pavan, W. J. (2003). The importance of having your SOX on: role of SOX10 in the development of neural crest-derived melanocytes and glia. Oncogene 22, 3024-34. 
Page, D. T., Kuti, O. J., Prestia, C. and Sur, M. (2009). Haploinsufficiency for Pten and serotonin transporter cooperatively influences brain size and social behavior. Proc Natl Acad Sci U S A 106, 1989-94.

Paratore, C., Eichenberger, C., Suter, U. and Sommer, L. (2002). Sox10 haploinsufficiency affects maintenance of progenitor cells in a mouse model of Hirschsprung disease. Hum Mol Genet 11, 3075-85.

Pavan, W. J. and Tilghman, S. M. (1994). Piebald lethal (sl) acts early to disrupt the development of neural crest-derived melanocytes. Proc Natl Acad Sci U S A 91, 7159-63.

Pingault, V., Bondurand, N., Kuhlbrodt, K., Goerich, D. E., Prehu, M. O., Puliti, A., Herbarth, B., Hermans-Borgmeyer, I., Legius, E., Matthijs, G. et al. (1998). SOX10 mutations in patients with Waardenburg-Hirschsprung disease. Nat Genet 18, 171-3.

Potterf, S. B., Furumura, M., Dunn, K. J., Arnheiter, H. and Pavan, W. J. (2000). Transcription factor hierarchy in Waardenburg syndrome: regulation of MITF expression by SOX10 and PAX3. Hum Genet 107, 1-6.

Pu, W. T., Ishiwata, T., Juraszek, A. L., Ma, Q. and Izumo, S. (2004). GATA4 is a dosage-sensitive regulator of cardiac morphogenesis. Dev Biol 275, 235-44.

Puffenberger, E. G., Hosoda, K., Washington, S. S., Nakao, K., deWit, D., Yanagisawa, M. and Chakravart, A. (1994). A missense mutation of the endothelin-B receptor gene in multigenic Hirschsprung's disease. Cell 79, 1257-66.

Read, A. P. and Newton, V. E. (1997). Waardenburg syndrome. J Med Genet 34, 656-65.

Roix, J. J., Hagge-Greenberg, A., Bissonnette, D. M., Rodick, S., Russell, L. B. and O'Brien, T. P. (2001). Molecular and functional mapping of the piebald deletion complex on mouse chromosome 14. Genetics 157, 803-15.

Sato-Jin, K., Nishimura, E. K., Akasaka, E., Huber, W., Nakano, H., Miller, A., Du, J., Wu, M., Hanada, K., Sawamura, D. et al. (2008). Epistatic connections between microphthalmia-associated transcription factor and endothelin signaling in Waardenburg syndrome and other pigmentary disorders. Faseb J 22, 1155-68.

Schaible, R. H. (1969). Clonal distribution of melanocytes in piebald-spotted and variegated mice. J Exp Zool 172, 181-99. 
Schepers, G. E., Teasdale, R. D. and Koopman, P. (2002). Twenty pairs of sox: extent, homology, and nomenclature of the mouse and human sox transcription factor gene families. Dev Cell 3, 167-70.

Schlierf, B., Ludwig, A., Klenovsek, K. and Wegner, M. (2002). Cooperative binding of Sox 10 to DNA: requirements and consequences. Nucleic Acids Res 30, 5509-16.

Shah, K. N., Dalal, S. J., Desai, M. P., Sheth, P. N., Joshi, N. C. and Ambani, L. M. (1981). White forelock, pigmentary disorder of irides, and long segment Hirschsprung disease: possible variant of Waardenburg syndrome. J Pediatr 99, 432-5.

Shin, M. K., Levorse, J. M., Ingram, R. S. and Tilghman, S. M. (1999). The temporal requirement for endothelin receptor-B signalling during neural crest development. Nature 402, 496-501.

Southard-Smith, E. M., Kos, L. and Pavan, W. J. (1998). Sox10 mutation disrupts neural crest development in Dom Hirschsprung mouse model. Nat Genet 18, 60-4.

Stanchina, L., Baral, V., Robert, F., Pingault, V., Lemort, N., Pachnis, V., Goossens, M. and Bondurand, N. (2006). Interactions between Sox10, Edn3 and Ednrb during enteric nervous system and melanocyte development. Dev Biol 295, 232-49.

Strunk, K. E., Amann, V. and Threadgill, D. W. (2004). Phenotypic variation resulting from a deficiency of epidermal growth factor receptor in mice is caused by extensive genetic heterogeneity that can be genetically and molecularly partitioned. Genetics 167, 1821-32.

Tachibana, M. (1999). Sound needs sound melanocytes to be heard. Pigment Cell Res 12, 344-54.

Tassabehji, M., Newton, V. E. and Read, A. P. (1994). Waardenburg syndrome type 2 caused by mutations in the human microphthalmia (MITF) gene. Nat Genet 8, 251-5.

Tassabehji, M., Read, A. P., Newton, V. E., Harris, R., Balling, R., Gruss, P. and Strachan, T. (1992). Waardenburg's syndrome patients have mutations in the human homologue of the Pax-3 paired box gene. Nature $355,635-6$.

Touraine, R. L., Attie-Bitach, T., Manceau, E., Korsch, E., Sarda, P., Pingault, V., Encha-Razavi, F., Pelet, A., Auge, J., Nivelon-Chevallier, A. et al. (2000). Neurological phenotype in Waardenburg syndrome type 4 
correlates with novel SOX10 truncating mutations and expression in developing brain. Am J Hum Genet 66, 1496-503.

Waardenburg, P. J. (1951). A new syndrome combining developmental anomalies of the eyelids, eyebrows and nose root with pigmentary defects of the iris and head hair and with congenital deafness. Am J Hum Genet 3, 195-253.

Wegner, M. (1999). From head to toes: the multiple facets of Sox proteins. Nucleic Acids Res 27, 1409-20.

Yokoyama, S., Takeda, K. and Shibahara, S. (2006). SOX10, in combination with $S p 1$, regulates the endothelin receptor type B gene in human melanocyte lineage cells. Febs $J$ 273, 1805-20.

Zhu, L., Lee, H. O., Jordan, C. S., Cantrell, V. A., Southard-Smith, E. M. and Shin, M. K. (2004). Spatiotemporal regulation of endothelin receptor-B by SOX10 in neural crest-derived enteric neuron precursors. Nat Genet 36, 732-7. 
Chapter III.

TRANSGENIC EXPRESSION OF Endothelin receptor $b$ RESUCES THE HYPOPIGMENTATION PHENOTYPE OF Sox10 AND Pax3 HETEROZYGOUS MICE 
III. TRANSGENIC EXPRESSION OF ENDOTHELIN RECEPTOR B RESCUES THE HYPOPIGMENTATION PHENOTYPE OF SOX10 AND PAX3 HETEROZYGOUS MICE

\section{Abstract}

Given the synergistic effect of Sox10 and Ednrb as well as Pax3 and Ednrb on the hypopigmentation phenotype of mice carrying mutations in these genes, I investigated the effects of a transgenic addition of Ednrb to melanocyte precursors. Using a transgene that uses the Dopachrome tautomerase (Dct) promoter to selectively deliver Ednrb to melanoblasts, I first elucidated the effect of delivering additional Ednrb to the melanocyte precursors in Sox $10^{\text {LacZ }}$ and $P a x 3^{S p}$ mutant mice. Coat color was completely restored in the Sox $10^{\mathrm{LacZ} /+}:$ :Dct-Ednrb mice and partially restored in the $P a \times 3^{S p /+}::$ Dct-Ednrb mice. Then, I compared melanoblast development in Sox10 mutant mice with and without this Dct-Ednrb transgene by harvesting embryos at E11.5 and E12.5, a critical time in melanoblast expansion, and comparing the amount of melanoblasts between transgenic and non-transgenic embryos. The transgenic addition of Ednrb rescued melanocyte precursors in Sox10 heterozygous animals but not in Sox10 homozygous animals. Cell survival assays indicate that the rescue is not due to an effect of the transgene on melanoblast survival. In conclusion, my data demonstrates that both Sox10 and Pax3 interact with Ednrb in the development of the melanocyte lineage. Transgenic expression of additional Ednrb may compensate for the detrimental effects of Sox10 haploinsufficiency in this lineage, and the reduced number of melanocyte precursors in Sox10 mutants is not due to increased apoptosis. 


\section{Introduction}

The results described in Chapter 2 established a synergistic genetic interaction between the transcription factors Sox10 and Pax3 and the Gcoupled receptor Ednrb. By crossing Sox10 or Pax3 heterozygotes with Ednrb heterozygotes, a clear aggravation of the pigmentation phenotype was observed. To further explore these genetic interactions, I will use a transgenic mouse that puts the delivery of Ednrb under the control of the Dct promoter to attempt the rescue of the hypopigmentation phenotype of the Sox 10 and Pax3 mutants.

The first transgenic mouse was created in mid-1980's (Palmiter and Brinster, 1985) and opened the way to examine genes and their mutations at the organismal level. Transgenically, genes can be manipulated to cause loss of function, gain of function, the addition of a new gene or exploration of activation and/or deactivation of genes during critical times of gene expression. This ability to modulate gene expression in vivo enables elucidation of the cascade of genetic interactions and eventually helps us determine whether these interactions are direct, indirect or working along parallel pathways. Untangling of genetic interactions is often difficult due to the complex, nonlinear influences that genes and other modulating factors have on each other's expression. For example, the C57BL/6J background diminishes the penetrance of the $E d n r b^{S-1 /+}$ hypopigmentation phenotype while augmenting the aganglionosis of Sox $10^{\mathrm{Dom} /+}$ mice when compared to other background strains (Cantrell et al., 2004). 
Gene expression in higher eukaryotes is predominantly regulated by transcriptional control; and it is this highly coordinated, tightly controlled activation and deactivation of genes that dictates cellular differentiation. A direct genetic interaction implies that one gene binds directly with another gene, as in the case of Sox10 and Mitf where Sox10 binds to the proximal region of the Mitf promoter activating it in melanoblasts (Bondurand et al., 2000; Hornyak et al., 2001; Potterf et al., 2000). An example of an indirect genetic interaction is that of Sox5 and Sox10: Sox5 binds and recruits CtBP2 and HDAC1 as transcriptional co-repressors that bind to the Sox10 regulatory region thereby decreasing Sox10 activity (Stolt et al., 2008). In some cases, mutations in multiple genes can cause a disease without ever interacting with each other as in the case of Hirschsprung's disease whereby mutations in Ret (Edery et al., 1994) or mutations in Ednrb (Puffenberger et al., 1994) result in similar disease phenotypes. In addition to these possibilities, enhancer regions can have binding sites for multiple transcription factors. This complexity adds to the difficulty of deciphering specific gene functions, sometimes necessitating more than one approach in order to elucidate whether or not an interaction exists.

In one study Sox10 was shown to bind directly to an Ednrb enhancer in migrating murine enteric neuroblasts (Zhu et al., 2004). In fact, Sox10 had 3 binding sites on the Ednrb enhancer and depending on the binding site(s) that were affected and the extent of the mutation, the penetrance and variability of the phenotype appeared to be affected. The pigmentation phenotype was not rescued suggesting that Sox10 regulation of Ednrb through this particular 
enhancer might function in enteric neurons and not in melanoblasts. However in another study, the expression of EDNRB in human melanocytes appeared directly dependent on Sox10 (Yokoyama et al., 2006). In fact in the presence of Sox10 siRNA, EDNRB protein was reduced by $46 \%$ and the presence or absence of Sox10 affected EDNRB promoter activity. Three putative SOX10 binding sites on the EDNRB promoter were evaluated and all three dramatically influenced EDNRB expression. Another transcription factor, $S p 1$, was found to work in conjunction with Sox10 to upregulate EDNRB even more than SOX10 alone and may contribute to specificity of SOX10 activation in the melanocyte lineage.

Using a transgene is another way in which to evaluate whether or not genetic interactions exist: typically a transgene adds to the genome but can also replace a gene, either entirely or partially, essentially creating a knock-out or knock-in mutant depending on the resulting gene expression. The Dct-Ednrb transgene used here delivers additional Ednrb to the Dct expressing melanoblasts of the murine embryo with expression at E11.5 confirmed (Ittah, 2005). Dct has been previously shown to start being expressed during E11.5 E12.5 (Mackenzie et al., 1997; Potterf et al., 2001; Steel et al., 1992) and is a well know melanoblast marker (Hornyak et al., 2001; Zhao and Overbeek, 1999). In fact, the Dct promoter has been used before to successfully deliver specific genes to melanoblasts (Hakami et al., 2006; Zhao and Overbeek, 1999) and also to track migrating melanoblasts (Silver et al., 2008). 
Recently, a Sox10 transgene was put under the control of the Dct promoter to see if additional Sox10 in an Ednrb mutant mouse could rescue the hypopigmentation phenotype (Hakami et al., 2006). While, the Dct-Sox10 transgene was able to adequately rescue Sox10 heterozygosity (implying that the transgene correctly targeted Sox10 positive cells), the Dct-Sox10 transgene was unable to rescue the pigmentation phenotype of $E d n r b^{S-/ /+}$ mice. In this study I will attempt to rescue the Sox $10^{\mathrm{LacZ} /+}$ hypopigmentation phenotype via the Dct-Ednrb transgene. If the transgenic addition of Ednrb can rescue the hypopigmentation of Sox10 heterozygosity, these results taken together with those results from Hakami et al. (2006), will imply that Sox10 directly regulates Ednrb expression during the critical window of melanoblast expansion.

\section{Materials and Methods}

\subsection{Animals and Genotyping}

Sox $10^{L a c Z}, P a x 3^{S p}$ and $E d n r b^{s-l}$ animals were maintained and genotyped as

described in Chapter 2. Sox $10^{\operatorname{LacZ} / L a c Z}$ are embryonic lethal at approximately E13.5; since embryos were harvested at E11.5 and E12.5 developmental changes in the Sox10 homozygous condition were observed (Appendix II.C). Staged embryos were dated $0.5 \mathrm{~d}$ at noon the day of vaginal plug. Embryos were harvested by euthanizing the pregnant dam via cervical dislocation and dissecting embryos through a transverse abdominal incision. Embryos were immediately placed in PBS (the $\mathrm{pH}$ of which was determined by the subsequent procedure, see Appendices II.D and II.H) and yolk sacs were saved for DNA extraction (Appendix II.B). Those destined for double staining with LysoTracker 
Red and LacZ, were immediately started on that protocol (Appendix II.H). Embryos for in situ hybridization were dehydrated through a methanol $(\mathrm{MeOH}$;

Fisher Scientific) series (25\%:75\% MeOH:PBS; 50\%:50\%; 75\%:25\% $\mathrm{MeOH}: \mathrm{PBS}$ for 5 min each) and stored in $100 \% \mathrm{MeOH}$ at $-20^{\circ} \mathrm{C}$.

Dct-Ednrb transgenic animals were generated in our laboratory (Avner Ittah, FIU dissertation 2005). The full length Ednrb cDNA (1958bp, genbank accession \# U32329) obtained from pmET-B (Hosoda et al., 1994) was inserted into the vector pmDct that contains $3431 \mathrm{bp}$ of the mouse Dct promoter and the BGH poly adenylation signal (Hornyak et al., 2000). Dct-Ednrb transgenic mice were generated by microinjection of the transgene into FVB $F_{1}$ zygotes. The studies presented here were carried out with a line that initially had 150 copies of the transgene. This line was crossed for over 10 generations with C57BL/6J mice from our colony. Mice were genotyped using $1 \mu \mathrm{M}$ of each primer DctEdnrbf (5'-ACAAGGAAGACTGGCGAGAA-3'); and, Dct-Ednrbr TCCTCCCCCTTGCTGTCCTGC-3'; Invitrogen), $1 \mathrm{X}$ buffer, $2 \mathrm{mM} \mathrm{MgCl,} 1$ unit Taq (Bioline), 5\% DMSO (Fisher Scientific), $2.5 \mathrm{mM}$ of each dNTP (Invitrogen) and $1 \mu \mathrm{L}$ DNA. The amplified DNA was visualized on a $1 \%$ agarose gel resulting in a 2217bp band (Appendix I).The PCRs were performed for 35 cycles under the following conditions: $94^{\circ} \mathrm{C}$ for $30 \mathrm{~s}, 57^{\circ} \mathrm{C}$ for $30 \mathrm{~s}$, and $72^{\circ} \mathrm{C}$ for 2 min.

All animals used in this study were housed in the Animal Care Facility at Florida International University (Miami, FL). Water and murine chow were fed ad libitum and light/dark was cycled every 12 hours. All animal work was 
performed according to institutional guidelines established by NIH (Guide for the Care and Use of Laboratory Animals, 2009; IACUC protocol \# 08-001).

\subsection{Crosses and Phenotype Analysis}

Sox $10^{L a c Z /+}$ mice were crossed with Dct-Ednrb mice to produce offspring that were Sox $10^{\mathrm{LacZ} /+}::$ Dct-Ednrb. These transgenic Sox $10^{\mathrm{LacZ} /+}$ mice were examined for the presence of pigmentation defects over the course of 4 generations. $P a x 3^{S p /+}$ mice were also crossed with Dct-Ednrb mice to produce offspring that were $P a x 3^{S p /+}::$ Dct-Ednrb in order to evaluate potential changes in pigmentation defects for 1 generation.

Sox $10^{\text {LacZ/+ }:: D c t-E d n r b}$ mice were crossed to each other to produce E11.5

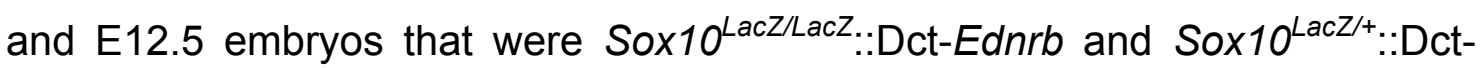

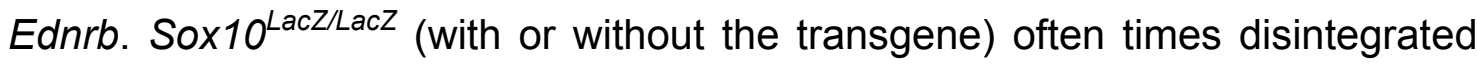
during dissection or during the procedures of in situ hybridization or Lysotracker Red/LacZ but all embryos, regardless of presentation or staining, were genotyped.

\subsection{In Situ Hybridization}

In situ hybridization (ISH) was performed on E11.5 embryos using the Pmel17 riboprobe. Pmel17 is a highly sensitive and early melanoblast marker with expression starting at E9.5 (Baxter and Pavan, 2003). The full length cDNA (1935bp, genbank accession number M77348) was inserted into DH5a Escherichia coli and this plasmid was purified and linearized prior to Pmel17 riboprobe synthesis (Appendix II.E). Pmel17 structure and homology to other melanocytic markers has been previously described by Kwon et al. (1991). 
On day 1 of $\mathrm{ISH}$, embryos were rehydrated via a $\mathrm{MeOH}$ series using $\mathrm{PBT}^{*}$ (PBS ${ }^{* *}$ plus $0.1 \%$ Tween-20; Fisher Scientific) $5 \mathrm{~min}$ for each of the following steps: $75 \%: 25 \% \mathrm{MeOH}: \mathrm{PBT} ; 50 \% 50 \% ; 25 \%: 75 \% \mathrm{MeOH}: \mathrm{PBT}$ and two washes in $100 \%$ PBT. Embryos were then bleached in $6 \% \mathrm{H}_{2} \mathrm{O}_{2}$ (Fisher Scientific) in PBT for $1 \mathrm{hr}$ at RT and then permeabilized using $10 \mu \mathrm{g} / \mathrm{ml}$ proteinase $\mathrm{K}$ (Promega) in PBT (15min for E11.5 and 18min for E12.5). To neutralize this reaction, $2 \mathrm{mg} / \mathrm{ml}$ glycine (Fisher Scientific) in PBT was added for $10 \mathrm{~min}$ at RT and then washed twice with PBT. Embryos were postfixed with $4 \%$ paraformaldehyde (Fisher Scientific), 0.2\% gluteraldehyde (Sigma) in PBT for 20min. Pre-hybridization was accomplished by adding $1 \mathrm{ml}$ hybridization solution ( $50 \%$ formamide, $5 x$ SSC pH4.5 1\% SDS, Fisher Scientific; $50 \mu \mathrm{g} / \mathrm{ml}$ yeast tRNA, Sigma; $50 \mu \mathrm{g} / \mathrm{ml}$ heparin, Sigma) and incubated in a $70^{\circ} \mathrm{C}$ water bath for $1 \mathrm{hr}$. The pre-hybridization solution was removed and fresh hybridization solution containing $2 \mu \mathrm{l} P$ mel17 riboprobe per $\mathrm{ml}$ of hybridization solution added and left overnight in the $70^{\circ} \mathrm{C}$ water bath.

Day 2 consisted of embryos being briefly rinsed in solution 1 (50\% formamide, 5xSSC and 1\%SDS; Fisher Scientific) and then washed 3 times more with solution 1 ( $30 \mathrm{~min}$ each time in a $70^{\circ} \mathrm{C}$ water bath). Washing was continued, 3 more times, using solution 2 (50\% formamide and 2xSSC; Fisher Scientific) and placed in a $65^{\circ} \mathrm{C}$ water bath for $30 \mathrm{~min}$ each time, followed by washing with TBS plus $0.1 \%$ Tween-20 (TBST) 3 times for 5 min each time. Blocking of embryos in $10 \%$ goat serum (Fisher Scientific) in TBST for $2 \mathrm{hrs}$, rocking at $\mathrm{RT}$, during which time the preabsorb anti-digoxigenin antibody was 
prepared by adding a pinch of embryo powder to microcentrifuge tubes containing $0.5 \mathrm{ml}$ TBST (1 microcentrifuge tube/embryo) and placed in $70^{\circ} \mathrm{C}$ water bath for $30 \mathrm{~min}$. Microcentrifuge tubes were removed from water bath, vortexed and cooled prior to the addition of $5 \mu \mathrm{l}$ of $100 \%$ goat serum and $1 \mu \mathrm{l}$ anti-digoxigenin antibody (Roche) and rocked at $4^{\circ} \mathrm{C}$ for $1 \mathrm{hr}$. After centrifuging for $5 \mathrm{~min}$, the supernatant was collected and $1.5 \mathrm{ml}$ of $1 \%$ goat serum in TBST per microcentrifuge tube was added. When embryos were ready, the blocking solution was removed, the antibody solution added and embryos were left rocking overnight at $4^{\circ} \mathrm{C}$.

To remove the antibody, on day 3 embryos were briefly rinsed in TBST and then washed 4 times in TBST for $1 \mathrm{hr}$ each time at RT. Levamisole $(2 \mathrm{mM}$; Sigma) was added to a $5^{\text {th }}$ TBST wash and left overnight, rocking at $4^{\circ} \mathrm{C}$. Finally, day 4 was the detection of the antibody in which the embryos were washed in NTMT $(100 \mathrm{mM} \mathrm{NaCl}, 100 \mathrm{mM}$ Tris pH9.5, $50 \mathrm{mM} \mathrm{MgCl} 2,0.1 \%$ Tween-20; Fisher Scientific; 2mM levamisole; Sigma) 3 times for 10min each time. While protecting from light, $45 \mu \mathrm{l} 4-$ Nitro blue tetrazolium chloride (NBT;

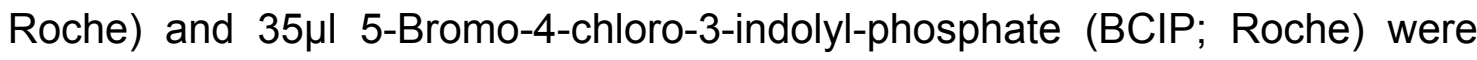
added to $10 \mathrm{ml}$ NTMT and added to each embryo. Still protected from light, embryos were monitored every $30 \mathrm{~min}$ to control the level of antibody development (Wilkinson 1998).

Cells labeled with the Pmel17 probe that were located in the torso were counted from a picture taken of the area at $3.2 x$ magnification. The angle of lines drawn to define the area intersected the posterior aspect of the forelimb 
and the anterior aspect of the hindlimb. Lines drawn to define the area, lighting and magnification were kept constant for all pictures taken.

\subsection{LysoTracker Red and LacZ Staining}

Embryos were dissected and rinsed in cold 0.05M PBS (pH7.2) and placed in $5 \mu \mathrm{M}$ LysoTracker Red DND-99 (Invitrogen), protected from light, at $37^{\circ} \mathrm{C}$ for 30 min. Continuing to protect the embryos from light, they were washed twice in PBS, $2 \%$ paraformaldehyde (PF; Fisher Scientific) for $1 \mathrm{hr}$ at room temperature (RT), washed twice more with PBS and then left overnight at $30^{\circ} \mathrm{C}$ in $\mathrm{LacZ}$ solution $\left(5 \mu \mathrm{M}\right.$ ferricyannide, $5 \mu \mathrm{M}$ ferrocyannide, $2 \mathrm{mM} \mathrm{MgCl}_{2}, 0.01 \%$ sodium deoxycholate (Fisher Scientific), $0.02 \%$ nonidate $\mathrm{p}-40$ (Roche) and $1 \mathrm{mg} / \mathrm{ml}$ Xgal (Invitrogen). Rinsed twice in PBS to stop reaction and a $10 \%$ sucrose (Fisher Scientific) solution was added to embryos for overnight incubation at $4^{\circ} \mathrm{C}$, rocking gently. Finally, embryos were placed in $20 \%$ sucrose solution for 4-6hrs and embedded in Tissue-Tek Tissue Freezing Medium (Sakura). Embryos were stored at $-80^{\circ} \mathrm{C}$.

Transverse cryosections of $10 \mu \mathrm{m}$ were taken of embryos from the brachial nerve to the sciatic nerve. Every third section was kept from E11.5 embryos while every $4^{\text {th }}$ section was kept from E12.5 embryos. Of these sections, 30 equally spaced sections (e.g. every other section) were selected for counting. Cells that were blue $(\mathrm{LacZ}+)$, elongated and appeared to be traveling along the dorsolateral pathway were counted and checked for double labeling with Lysotracker Red. 


\section{Results}

\subsection{Dct-Ednrb Transgene Rescues the Sox $10^{\mathrm{LacZ} /+}$ and Partially Rescues the Pax ${ }^{\mathrm{Sp} /+}$ Hypopigmentation Phenotypes}

The transgenic delivery of Ednrb to the melanoblasts of Sox $10^{\mathrm{LacZ} / \mathrm{+}}$ revealed that the hypopigmentation caused by Sox10 heterozygosity can be rescued by additional Ednrb (Figure 1). In fact, while $47 \%(n=83)$ of Sox $10^{L a c Z /+}$ mice did not exhibit ventral hypopigmentation (53\% did; $n=95) ; 100 \%(n=33)$ of the Sox $10^{\text {LacZ/+ }}$ carrying the transgene had fully colored coats (Table 1 ).

In contrast, the $P a x 3^{S p /+}$ hypopigmentation was only partially rescued by the transgene. The hypopigmentation defect of $\mathrm{Pax}^{\mathrm{Sp} / \mathrm{H}}$ is completely penetrant; all Pax3 heterozygous mice have ventral hypopigmentation. $P a x 3^{S p /+}:$ :Dct-Ednrb mice exhibited no hypopigmentation $24 \%(n=5)$ of the time and a partial rescue (considerably smaller area of hypopigmentation) $10 \%(n=2)$ of the time. The other $66 \%$ of the animals displayed typical Pax3 heterozygous hypopigmentation (Figure 2, Table 2).

\subsection{Transgenic Embryos Show Increased Numbers of Melanoblasts}

In situ hybridization using Pmel17 as a marker shows an increased number of melanoblasts in the transgenic embryos when compared to the nontransgenic embryos of the same genotype (Table 3). Easily apparent in E11.5 embryos, counts taken of trunk melanoblasts supports this observation. Comparison of Sox $10^{\mathrm{LacZ} /+}$ embryos to Sox $10^{\mathrm{LacZ} /+}:$ :Dct-Ednrb embryos results in a significant increase in trunk melanoblasts $(p=0.04)$. Unexpectedly, an even more significant increase in trunk melanoblasts $(p=0.01)$ was seen when 
comparing wildtype $\left(\right.$ So $\left.10^{+/+}\right)$embryos to transgenic wildtype $\left(\right.$Sox $10^{+/+}:$DctEdnrb) embryos. Three embryos were counted for each genotype (Figure 3).

\subsection{Increased Numbers of Melanoblasts in Transgenic Embryos Cannot Be Accounted for by an Effect on their Survival}

Double staining with LysoTracker Red and LacZ indicate that the increased numbers of melanoblasts observed in transgenic embryos is not due to a putative role of the transgene in preventing the apoptosis of melanoblasts in Sox $10^{\text {LacZ/+ }}$ embryos at E11.5 and E12.5. LacZ+ cells traveling along the dorsolateral pathway that were morphologically identified as melanoblasts were counted and then checked to see if they were double labeled with LysoTracker Red (Tables 4 and 5). While cell death was seen throughout the embryo in a characteristic pattern, there were very few LacZ+ cells that also stained positive for LysoTracker Red (figures 4 and 5). In fact, in E11.5 embryos it was very rare that a cell was double stained for LacZ and LysoTracker Red (Table 4). 11.5 day old homozygous Sox10 embryos rarely had a LacZ+ cell while the transgenic Sox10 homozygous embryo did have a few (between 4 and 16) LacZ+ cells but there was no significant difference $(p=0.26)$. Sox10 heterozygous embryos had LacZ+ $38-67$ cells but the transgenic Sox10 heterozygous embryos had significantly more LacZ+ cells (135-180 cells; $\mathrm{p}=0.003)$

Rapid increase in the amount of these LacZ+ (presumptive melanocytic) cells was seen when comparing numbers obtained from E11.5 (Table 4) and E12.5 (Table 5) embryos. Interestingly, not only do the numbers increase tremendously in the Sox $10^{\mathrm{LacZ} /+}$ embryos from E11.5 to E12.5 (with or without 
the transgene), but the number of cells increased somewhat in the homozygous embryos as well. In the E12.5 Sox $10^{\mathrm{LacZ} /+}$ embryos, the number of LacZ+ cells increased significantly in the transgenic heterozygous embryos $(p=0.012)$ when compared to the heterozygous embryos without the transgene; while in the homozygous embryos there was no significant difference in the number of

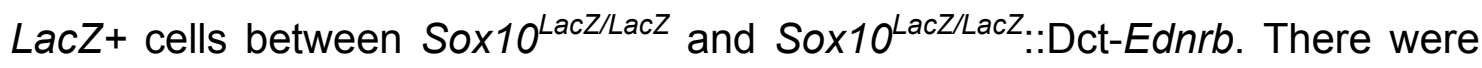
several more double stained cells $(0-20)$ at this age in the heterozygous embryos but this seemed to be relative to the total number of LacZ+ cells observed. Sox10 homozygous mutants were difficult to obtain at E12.5 as they often disintegrated during dissection or during the staining process.

\section{Discussion}

In vivo analysis of coat color and embryonic melanoblasts indicated that the Sox10 hypopigmentation phenotype was consistently rescued by the transgenic addition of Ednrb; in the case of Pax3 hypopigmentation phenotype the additional Ednrb conferred a partial rescue on coat color. Sox10, which is colocalized with Ednrb, may be required as premigratory melanoblasts emerge to ensure melanoblast survival and differentiation (Potterf et al., 2001). Dct, a well known melanocyte marker (Hornyak et al., 2001; Zhao and Overbeek, 1999), is partially regulated by Sox10 (Jiao et al., 2004; Ludwig et al., 2004;

Potterf et al., 2000) so that in Sox10 heterozygous mice the level of Dct expression is less than it would normally be in melanoblasts of wildtype mice. Sox10 is known to activate Mitf, a major melanocyte-specific transcriptional regulator and Mitf in turn regulates Dct expression (Bondurand et al., 2000; 
Yokoyama et al., 2006). In the case of Sox10 heterozygosity, Mitf activation is diminished as is Dct expression with Dct expression being affected by decreased levels of both Sox10 and Mitf. In Sox $10^{\text {Dom/t }}$ embryos, Dct expression is greatly reduced but melanoblasts still populate the embryo in a temporally and spatially correct manner with a dramatic increase in Dct expression at E13.5 and normal melanoblast population by E14.5 (Potterf et al., 2001). Melanoblasts in Sox $10^{\mathrm{LacZ} /+}$ embryos also appear to migrate in a temporally and spatially correct manner at E11.5 and E12.5. Sox10 haploinsufficiency must provide sufficient Ednrb activation so that melanoblasts migrate normally and populate most of the embryo, except for the ventral aspect. Trunk melanoblasts migrate at a later time than do other melanoblast populations (Serbedzija et al., 1990; Yoshida et al., 1996) and therefore may have a later requirement for Ednrb. Since the critical window for Ednrb expression in melanoblasts lasts through E12.5, the use of a Dct promoter, whose expression begins at E11.5, appears to act early enough to compensate for the decreased amount of Sox10 activity and rescue the melanoblasts.

While a Dct-Sox10 transgene could not rescue the hypopigmentation phenotype of $E d n r b^{S-/ /+}$ (Hakami et al., 2006), the Dct-Ednrb transgene consistently rescued the hypopigmentation phenotype of the Sox $10^{L a c Z /+}$ mice. Dct-Sox10 adds more Sox10 to a system with limited Ednrb. It may be that once the limited amount of functional Ednrb has been fully activated by Sox10 the addition of more Sox10 does nothing because there are no more binding sites available on Ednrb. Conversely, the transgenic addition of Ednrb to a 
Sox $10^{\text {LacZ/+ }}$ does what Sox 10 would have normally done - provide sufficient levels of Ednrb signaling to promote proper melanoblast dispersal and thereby rescues the hypopigmentation phenotype of the Sox10 heterozygous mutant.

$\mathrm{Pax}^{\mathrm{Sp} /+}$ mutants, which exhibit a completely penetrant ventral hypopigmentation phenotype, experienced a partial rescue with the Dct-Ednrb transgene. Present by E8.5 (Goulding et al., 1991), Pax3 is important in the initiation of the melanogenic pathway while simultaneously acting in the prevention of terminal differentiation (Lang et al., 2005). Similar to Sox10, Pax3 activates Mitf (which then activates Dct) but unlike Sox10, Pax3 competes with Mitf for binding sites on Dct (Fuchs et al., 2004; Potterf et al., 2000; Yasumoto et al., 2002). Dct expression is normal in $\mathrm{Pax}^{\mathrm{Sp} / \mathrm{t}}$ embryos at $\mathrm{E} 11.5$ indicating that Dct expression is not affected by Pax3 haploinsufficiency (Potterf et al., 2001). Prior to Mitf activation of Dct, Mitf is present in the dorsal aspect of the neural tube and is important in the survival of premigratory melanoblasts shortly before they reach the MSA and for a short while after they start migrating (Hornyak et al., 2001). It is possible therefore, that $P a x 3$ may exert influence over the expression of Mitf at this early stage (E8.5-E10.0) as well and that the hypopigmentation phenotype seen in Pax3 heterozygous mice is at least partially due to this early insult on Mitf. If melanoblasts are more severely affected by decreased levels of $P a x 3$ at the premigratory phase rather than later once Dct is expressed, then the transgenic expression of Ednrb may be too late to rescue coat color in the Pax3 mutant. 
In order to elucidate the timing of the rescue in Sox $10^{\mathrm{LacZ} /+}$ embryos, in situ hybridization with Pmel17 was performed on E11.5 as this is the first time melanoblasts are migrating throughout the length of the embryo. Pmel17 hybridizes to a larger number of murine melanoblasts than does Dct and at an earlier age (E10.5 vs. E11.5), as presumptive melanoblasts are starting to emerge (Baxter and Pavan, 2003). Initially identified in human and murine DNA (Kwon et al., 1991), Pmel17 is now used in a variety of animals including horses (Brunberg et al., 2006), dogs (Clark et al., 2006) and chickens (Kerje et al., 2004) to study pigmentation genetics. Sensitivity of Pmel17 to identify melanoblasts may be due to the fact that it is the only melanosomal component that has membrane bound and soluble forms (Valencia et al., 2006), possibly making detection easier.

The Pmel17 promoter is not regulated by Sox10 (Loftus et al., 2009) implying that expression of Pmel17 is not influenced by Sox10 haploinsufficiency. In addition to its early expression, being Sox10-independent makes Pmel17 an excellent candidate for identifying whether or not the transgenic addition of Ednrb into a Sox10 heterozygote increases the number of melanoblasts. By E11.5, significant differences in the number of melanoblasts were seen between Sox $10^{\mathrm{LacZ} /+}$ and Sox $10^{\mathrm{LacZ} /+}:$ :Dct-Ednrb embryos and interestingly, between wildtype and wildtype transgenic embryos. It appears that increasing the amount of Ednrb in the melanocyte lineage allows for greater expansion of migrating precursors. 
Since the LacZ reporter gene has been knocked into the Sox10 locus, migrating melanoblasts (and other Sox10 positive cells) can be easily identified. Double staining of embryos was employed to explore whether the melanoblast density difference between transgenic and non-transgenic embryos was due to increased apoptosis in the non-transgenic embryos. As this was not the case, the increased numbers of melanoblasts in transgenic embryos may be due to a variety of reasons. The Dct-Ednrb transgene may have compensated for the lack of Sox10 activation by saturating the system with Ednrb thereby increasing any survival component that Ednrb bestows on melanoblasts as they emerge from the MSA. Since Ednrb appears to be required for the migration of emerging melanoblasts (Shin et al., 1999), the additional Ednrb may have compensated for the haploinsufficient Sox10 activation of Ednrb and may ensure proper melanoblast migration. And finally, given that $E d n 3$, the preferred ligand for Ednrb, is a known proliferative agent for this lineage (Lahav et al., 1996) perhaps the increase in functional receptor allowed for an increase in Edn3 proliferative action resulting in an even larger number of melanoblasts at E11.5 and E12.5. Taken together, these results support the direct interaction of Sox 10 and Ednrb because it is the Sox 10 activation of Ednrb which enables the receptor to promote survival, migration and subsequently the proliferation of emerging melanoblasts needed to rescue the pigmentation phenotype.

While Sox10 and Pax3 work together to transactivate Mitf in the melanocyte lineage, it appears that the relationship of Pax3 to Ednrb is more complex than that of Sox10 and Ednrb. As shown earlier, mice harboring both $\mathrm{Pax}^{\mathrm{Sp} /+}$ and 
$E d n r b^{S-1 /+}$ mutations exhibited aggravated pigmentation phenotypes (Chapter 2), yet there is only a small partial rescue of the coat color with the transgenic addition of Ednrb in the $\mathrm{Pax}^{\mathrm{Sp} /+}$ mutant. Perhaps an interaction between Pax3 and Ednrb does exist but in a much more indirect fashion with one or more intermediate transcription factors or signaling pathways in the genetic cascade. Or perhaps the insult of $P a x 3$ haploinsufficiency on neural crest specification is too great for Ednrb to rescue. And finally, it is possible that the Dct promoter used to deliver the Ednrb becomes active too late to completely rescue melanoblasts from their Pax3 deficiency. Any of these possibilities would explain the increased hypopigmentation of the double mutant and the lack of rescue using the Dct transgene.

In conclusion, the complete rescue of hypopigmentation in the Sox10 heterozygote supports an interaction between Sox10 and Ednrb in the melanocyte lineage. Still unclear is the mode of rescue although there may be a putative survival effect of the transgene by E11.5. Future experiments should include looking earlier in development to evaluate whether or not cell death is occurring prior to E11.5 in Sox10 heterozygous mice. Proliferation assays (such as labeling with P-Histone3) from the time that premigratory melanoblasts emerge from the MSA until E12.5 when melanoblasts have populated the entire length of the embryo may help illuminate the mode of rescue as well. In regards to the Pax3 heterozygous condition, the possible interaction between Pax3 and Ednrb remains elusive. Evaluating possible effects of Pax3 haploinsufficiency on neural crest specification and on Mitf expression prior to and during the time 
premigratory melanoblasts begin their journey may help elucidate any interaction, albeit indirect, between Pax3 and Ednrb in the melanocyte lineage.

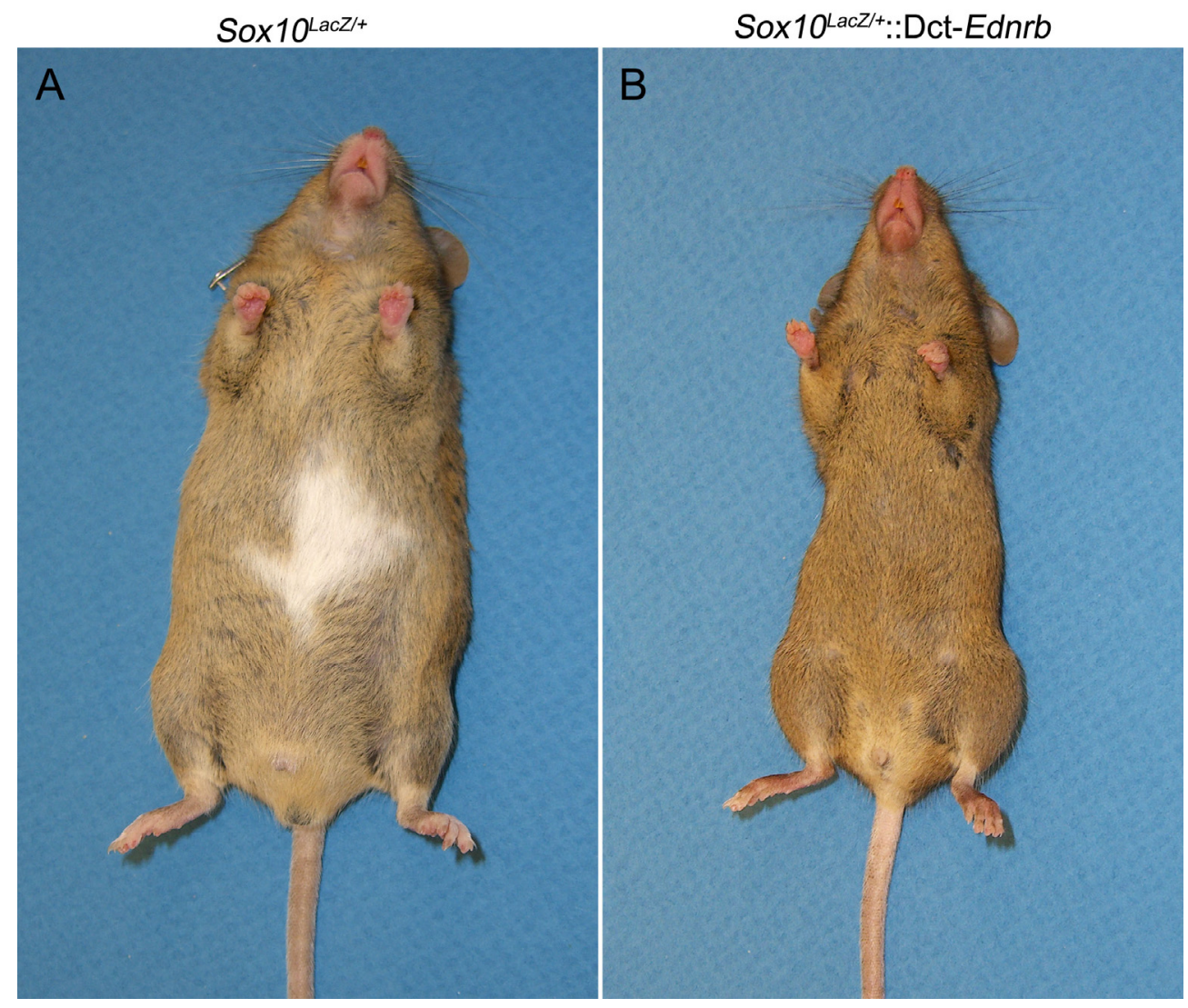

Figure 3.1 Transgenic rescue of the Sox $10^{L a c Z /+}$ pigmentation phenotype. (A)Typical hypopigmentation of Sox $10^{\mathrm{LacZ} /+}$ mice. (B)The targeted addition of Ednrb to the melanocyte precursors consistently rescued the hypopigmentation phenotype of Sox $10^{L a c Z /+}$ mice. 


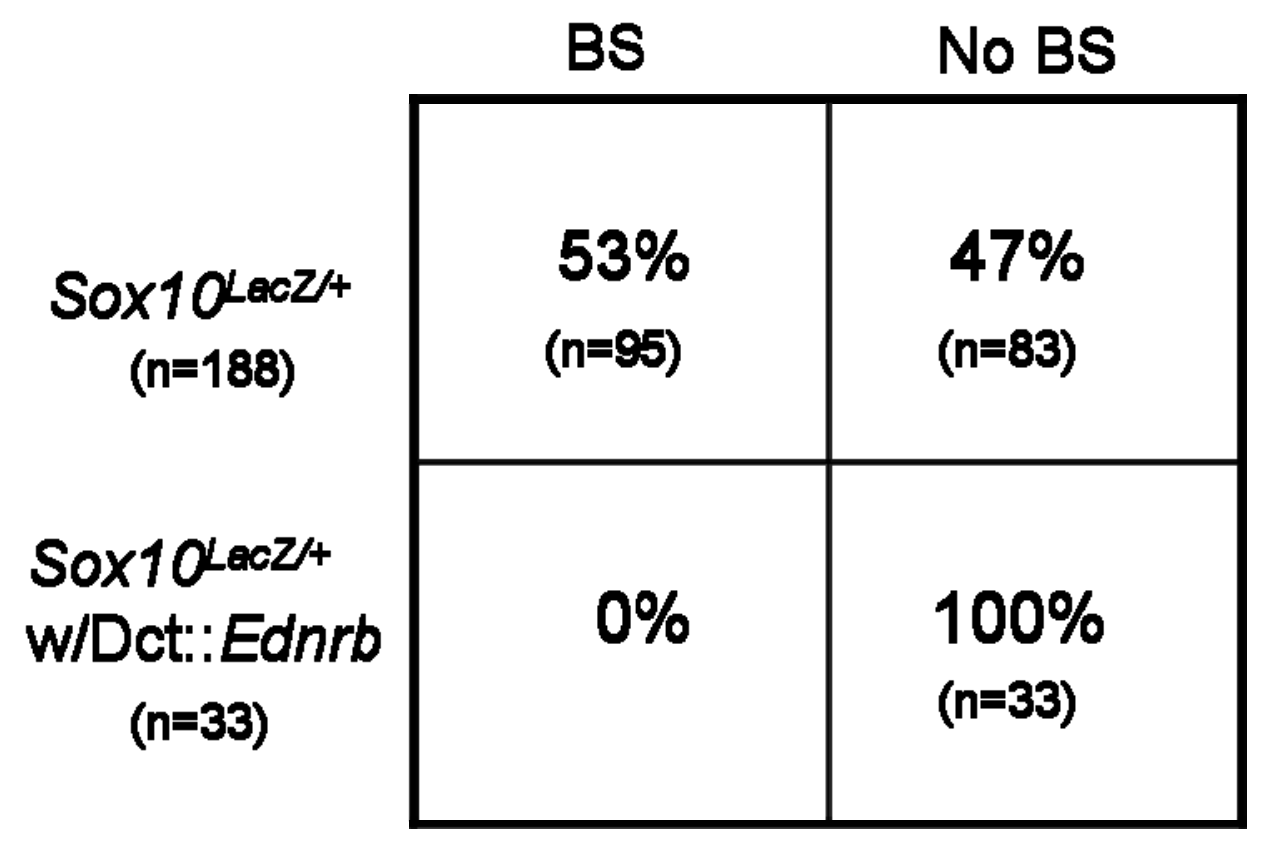

Table 3.1 Complete rescue of Sox $10^{\mathrm{LacZ} /+}$ pigmentation phenotype by DctEdnrb transgene. Targeted addition of Ednrb to melanoblasts rescues the pigmentation phenotype in Sox10 heterozygous mice $100 \%$ of the time. Homozygous Sox10 embryos did not have rescued melanoblasts and were still embryonic lethal, possibly due to the more serious developmental anomalies incurred by the near complete absence of Sox10. BS = Belly Spot.
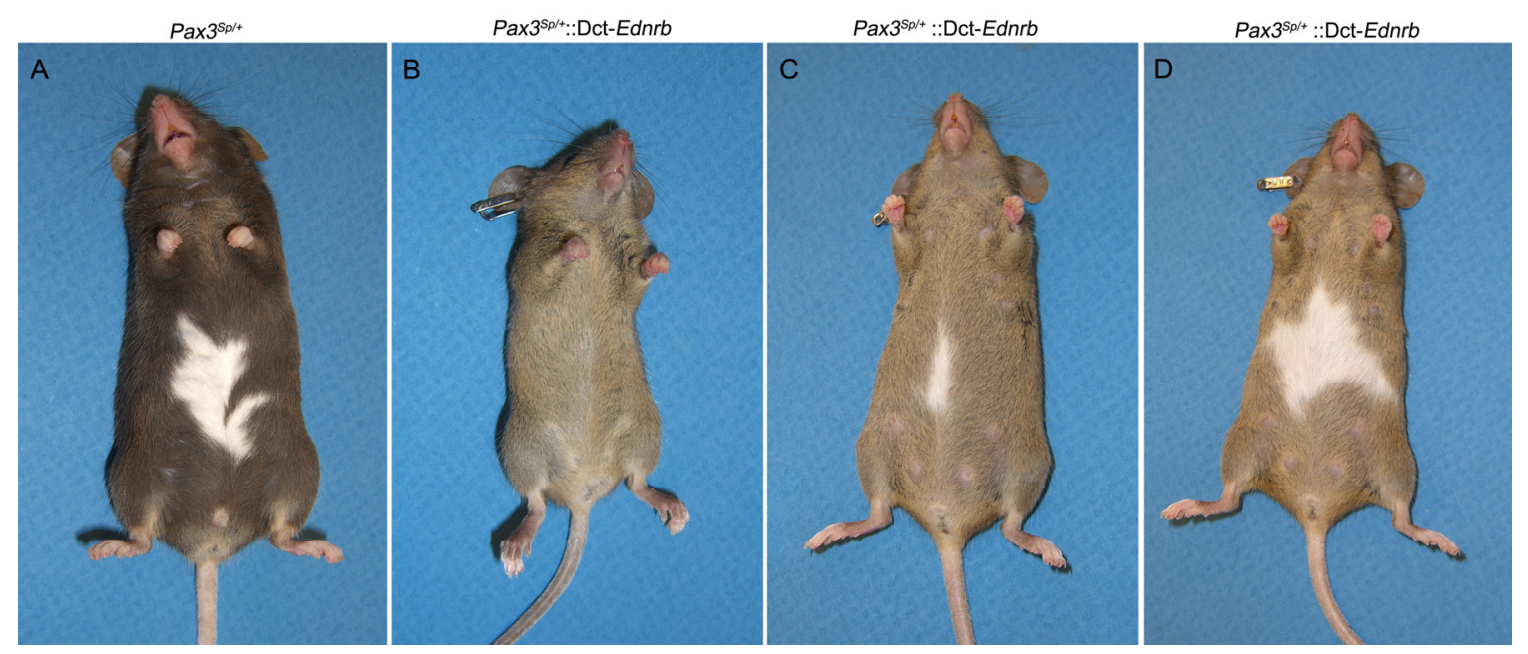

Figure 3.2 Dct-Ednrb transgene partially rescues the $P a x 3^{S p /+}$ pigmentation phenotype. (A) Mice who did inherit the transgene have the characteristic $P a x 3^{S p /+}$ pigmentation; transgenic delivery of Ednrb (B) completely rescues the $\mathrm{Pax}^{\mathrm{Sp} / \mathrm{+}}$ pigmentation phenotype $24 \%$ of the time and (C) partially rescues $10 \%$ of the time. (D) The transgene was not able to rescue $66 \%$ of the time. 


\begin{tabular}{|c|c|c|c|}
\hline & BS & Reduced BS & No BS \\
\hline $\begin{array}{c}P a \times 3^{S p /+} \\
(n=120)\end{array}$ & $\begin{array}{l}100 \% \\
(n=120)\end{array}$ & $0 \%$ & $0 \%$ \\
\hline $\begin{array}{c}P a \times 3^{S p /+} \\
\text { w/Dct::Ednrb } \\
(\mathrm{n}=21)\end{array}$ & $\begin{array}{l}66 \% \\
(n=14)\end{array}$ & $\begin{array}{l}10 \% \\
(n=2)\end{array}$ & $\begin{array}{l}24 \% \\
(n=5)\end{array}$ \\
\hline
\end{tabular}

Table 3.2 Transgenic expression of Ednrb partially rescues the $P a x 3^{S p /+}$ phenotype. Targeted addition of Ednrb to melanoblasts rescues the pigmentation phenotype in Pax3 heterozygous mice nearly a quarter of the time and partially rescues $10 \%$ of the time. The transgene was not able to rescue melanoblasts in homozygous embryos, possibly due to the more serious developmental anomalies caused by the absence of Pax3, such as the lack of structures and tissues necessary to support life. BS = Belly Spot. 


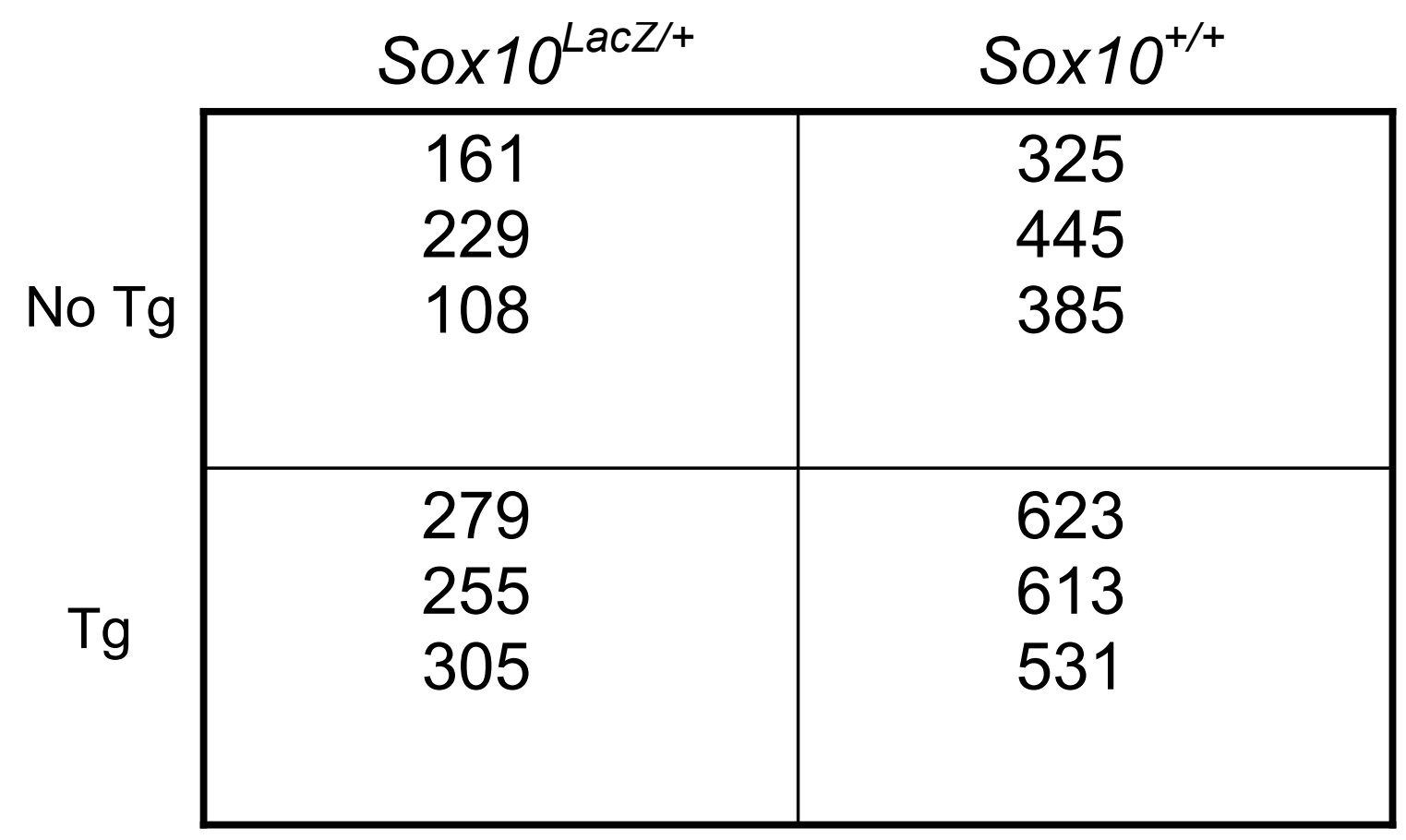

Table 3.3 Pmel17 labeled trunk melanoblasts. Cell counts for each of the embryos in which trunk melanoblasts were counted show an increase in the number of melanoblasts in the transgenic counterpart for each genotype: Sox $10^{\mathrm{LacZ} /+}$ vs. Sox $10^{\mathrm{LacZ} /+}::$ Dct-Ednrb and Sox $10^{+/+}$vs. Sox $10^{+/+}:$:Dct-Ednrb. $\mathrm{Tg}=$ Transgene. 


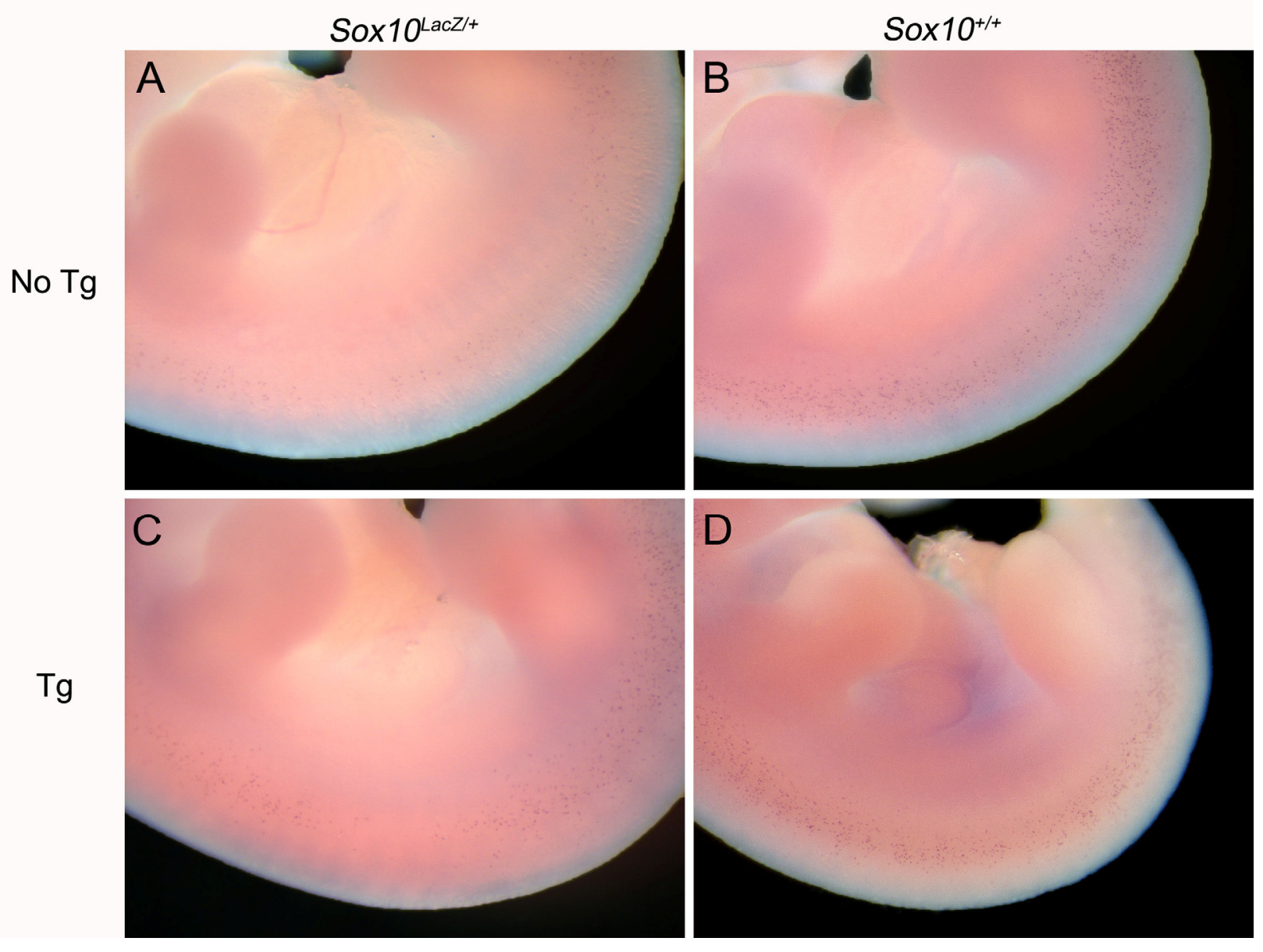


E

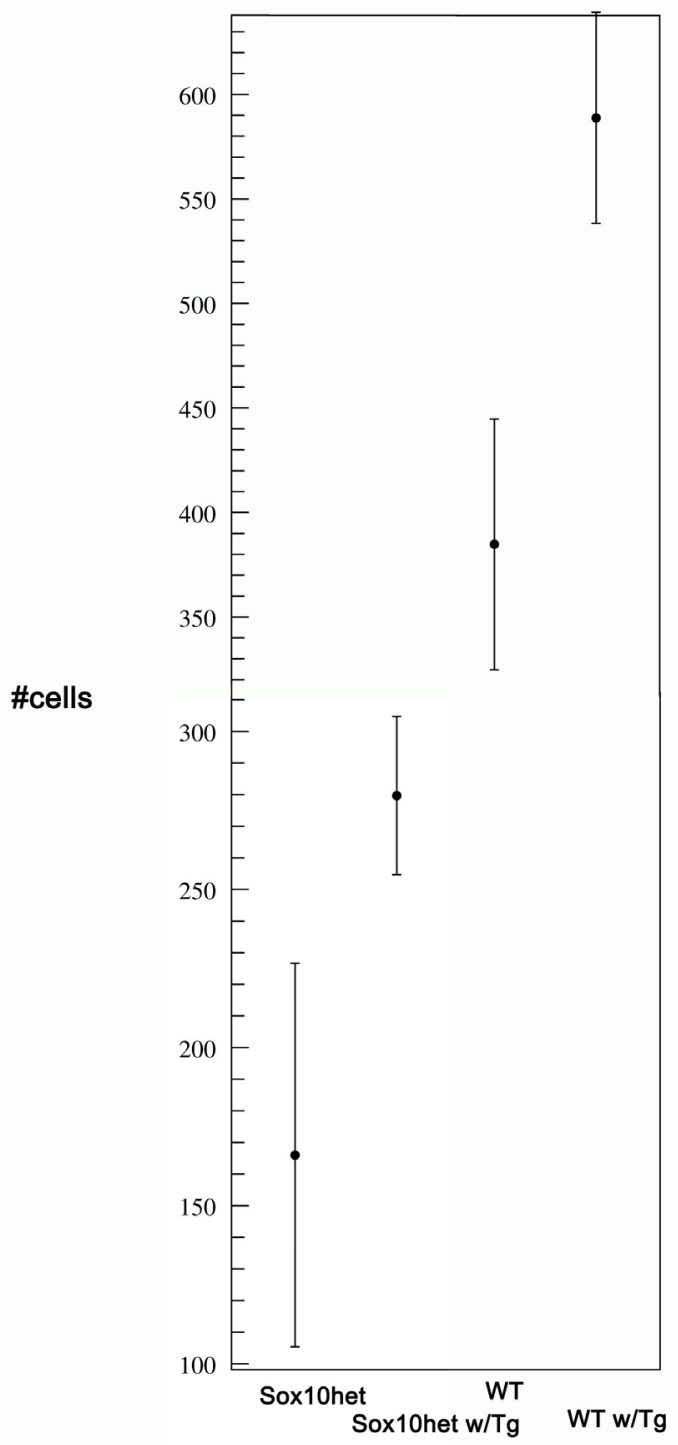

Figure 3.3 In situ hybridization with Pmel17 riboprobe shows increased numbers of truck melanoblasts in transgenic embryos at E11.5. Nontransgenic embryos of both (A) Sox 10 $0^{\mathrm{LacZ} /+}$ and (B) wildtype embryos have fewer melanoblasts than their $(C, D)$ transgenic counterparts. (E) Pmel17 labeled cell count shows transgene increases number of melanoblasts in Sox $10^{\mathrm{LacZ} /+}$ and in wildtype embryos. In each condition, the presence of Dct-Ednrb significantly increased the number of melanoblasts. Sox $10^{\mathrm{LacZ} /+}$ vs. Transgenic Sox $10^{\mathrm{LacZ} /+}, p=0.04$;

wildtype vs. transgenic wildtype $p=0.01$. Three embryos were counted for each condition. No $\mathrm{Tg}=$ No Transgene; $\mathrm{Tg}=$ Transgene. 


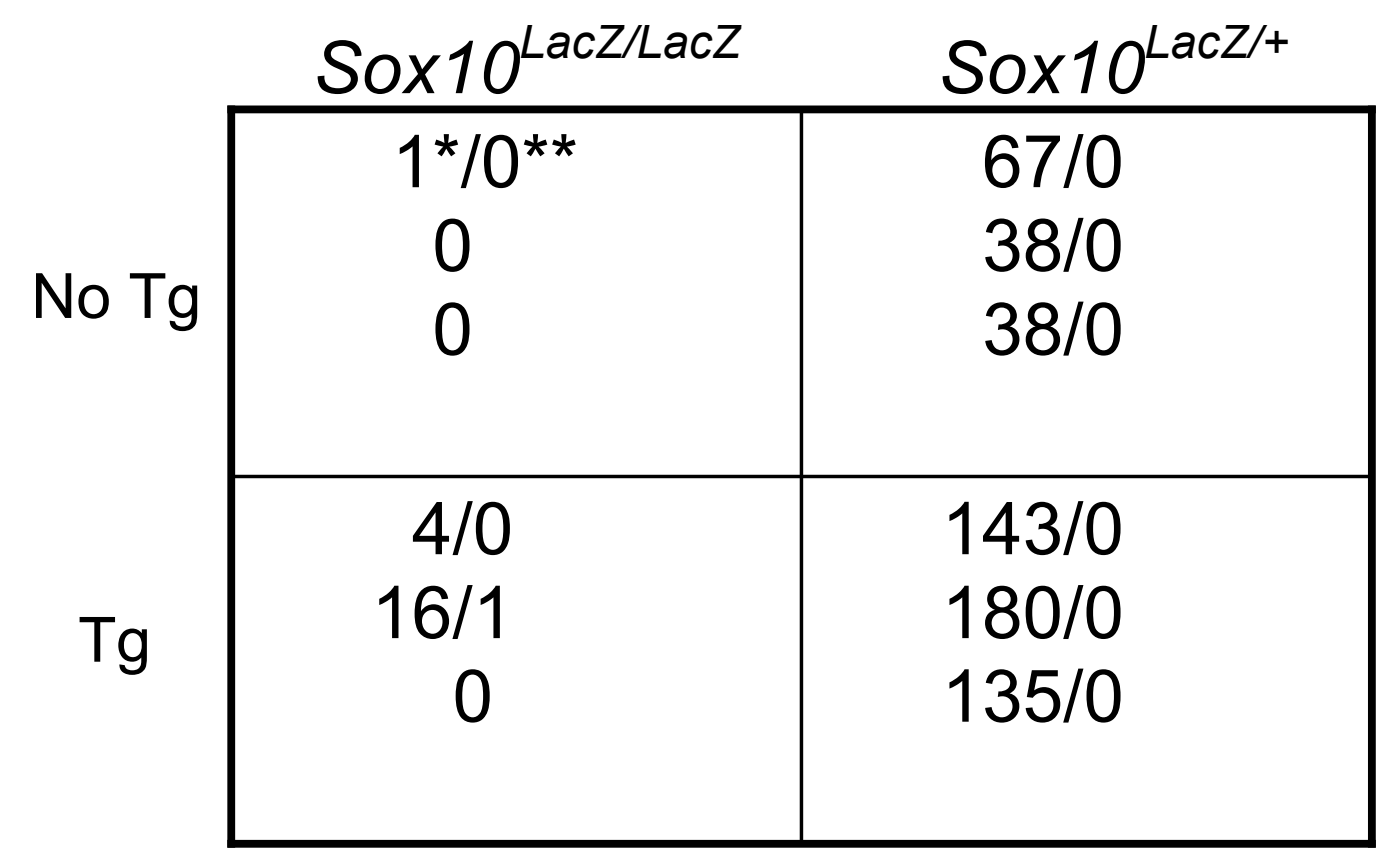

Table 3.4 Transgenic rescue of Sox10 haploinsufficient cells is not due to an effect on melanoblast survival at E11.5. LacZ and LysoTracker Red double stained Sox10 positive cells indicate that apoptosis is not the cause of decreased melanoblasts in E11.5 embryos. It is a rare cell in E11.5 embryos that is stained by LacZ and also stained by Lysotracker Red, even though ample cell death is seen throughout the embryo. *Number of LacZ+ cells; ${ }^{* *}$ Number of LysoTracker Red + cells. No Tg = No Transgene; $\mathrm{Tg}=$ Transgene. 

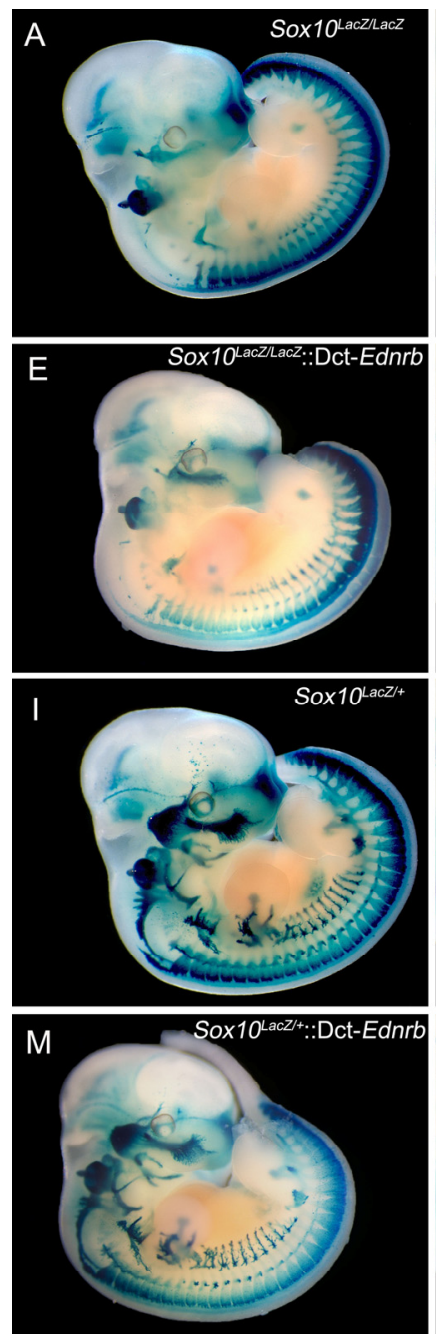
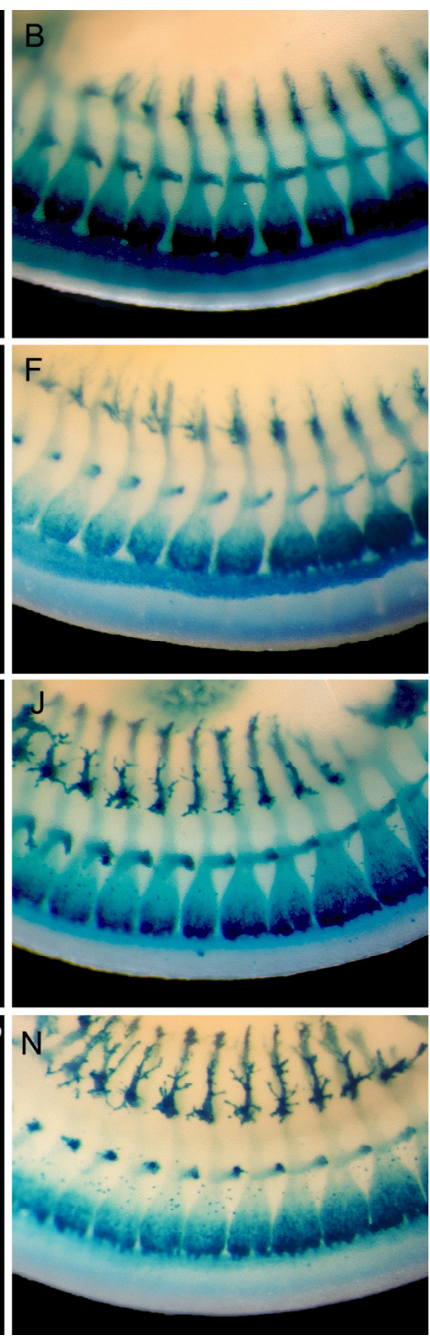

C

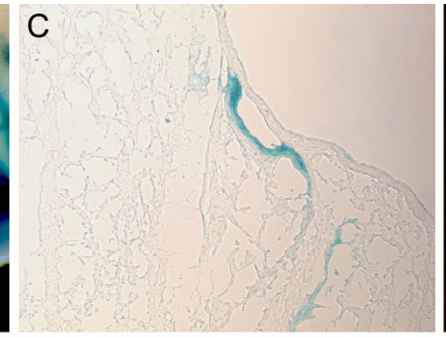

G

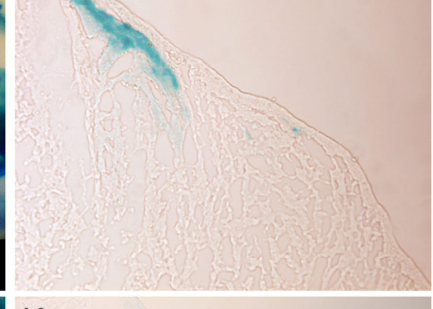

K

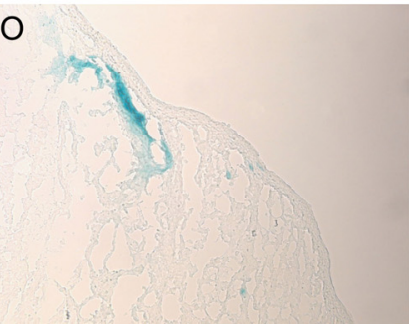

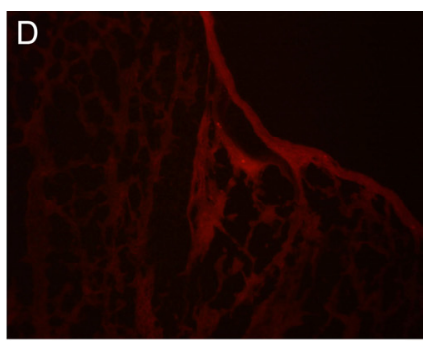

$\mathrm{H}$
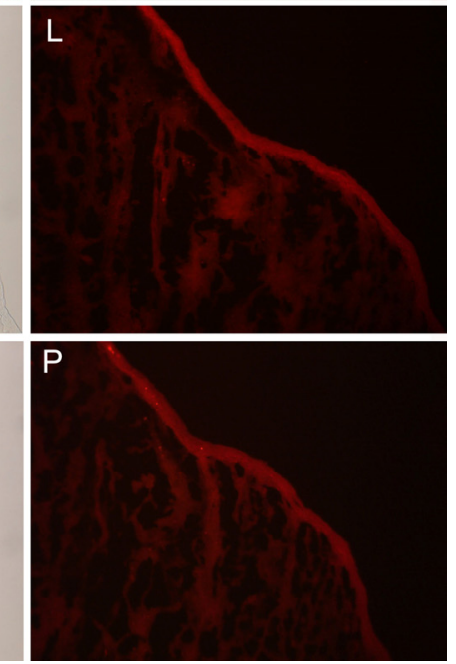

Figure 3.4 LacZ staining of E11.5 Sox10 embryos shows transgenic rescue of melanoblasts in Sox10 heterozygotes. (A,B) Sox10 homozygous embryos appear void of melanoblasts in the truck region, $(E, F)$ regardless of transgenic expression of Ednrb. $(C, D, G, H)$ In reality, homozygous embryos with or without the transgene have very few if any melanoblasts, none of which stained positive for LysoTracker Red. Melanoblasts are seen populating the trunk region in $(\mathrm{I}, \mathrm{J})$ Sox $10^{\mathrm{LacZ} /+}$ embryos; $(\mathrm{M}, \mathrm{N})$ Sox10 heterozygous embryos exhibit a large increase in the number of melanoblasts in transgenic animals. (K,L,O,P) Again, none of the melanoblasts were double labeled with LysoTracker Red implying that the difference in melanoblast numbers is not due to increased cell death at E11.5. 


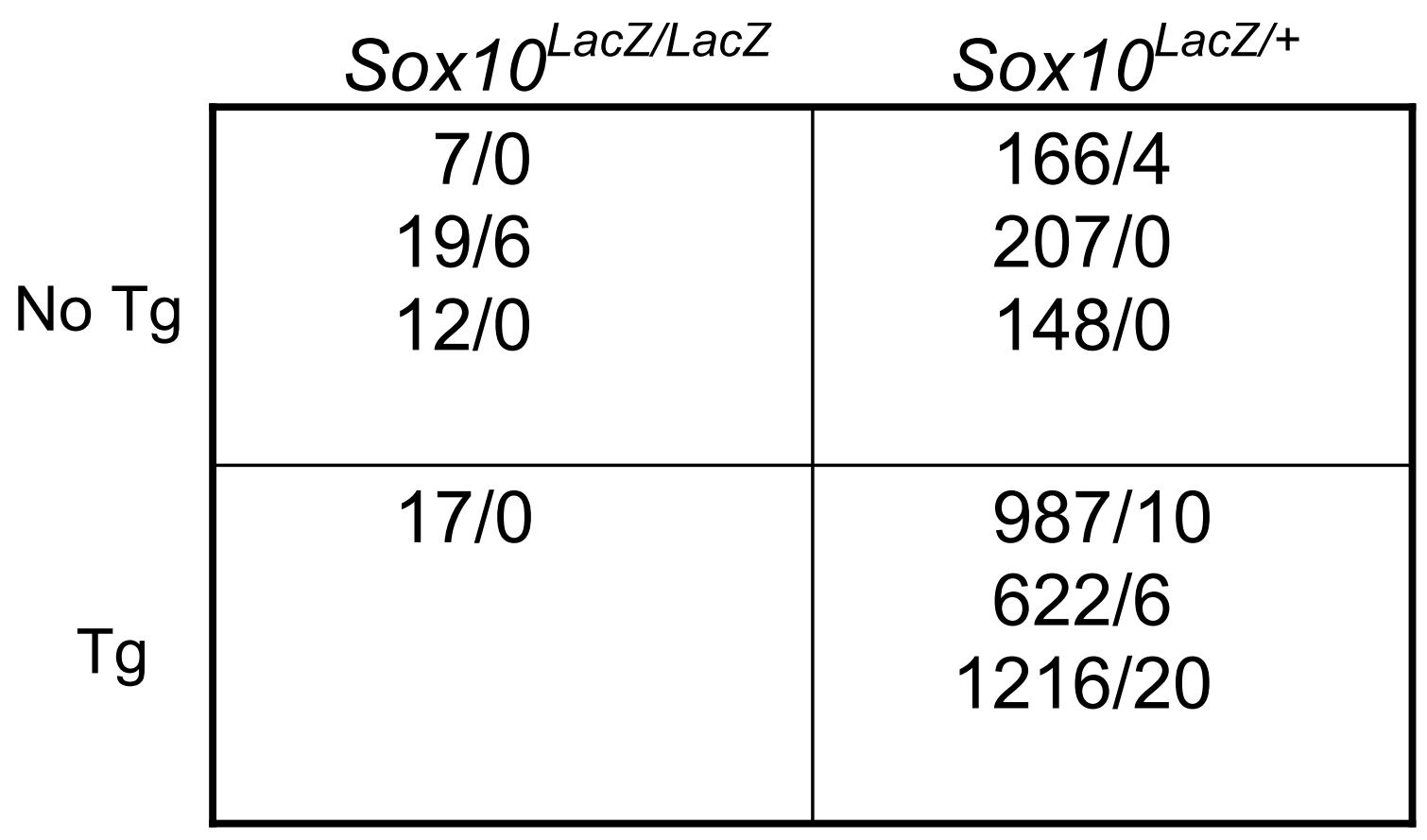

Table 3.5 Transgenic rescue of Sox10 haploinsufficient cells is not due to an effect on melanoblast survival at E12.5. LacZ and LysoTracker Red double stained Sox10 positive cells indicate that apoptosis is not the cause of decreased melanoblasts in E12.5 embryos. Very few cells in E12.5 embryos that are stained by $L a c Z$ are also stained by Lysotracker Red, even though ample cell death is seen throughout the embryo. *Number of LacZ+ cells; ${ }^{* *}$ Number of LysoTracker Red+ cells. No Tg $=$ No Transgene; Tg = Transgene. 

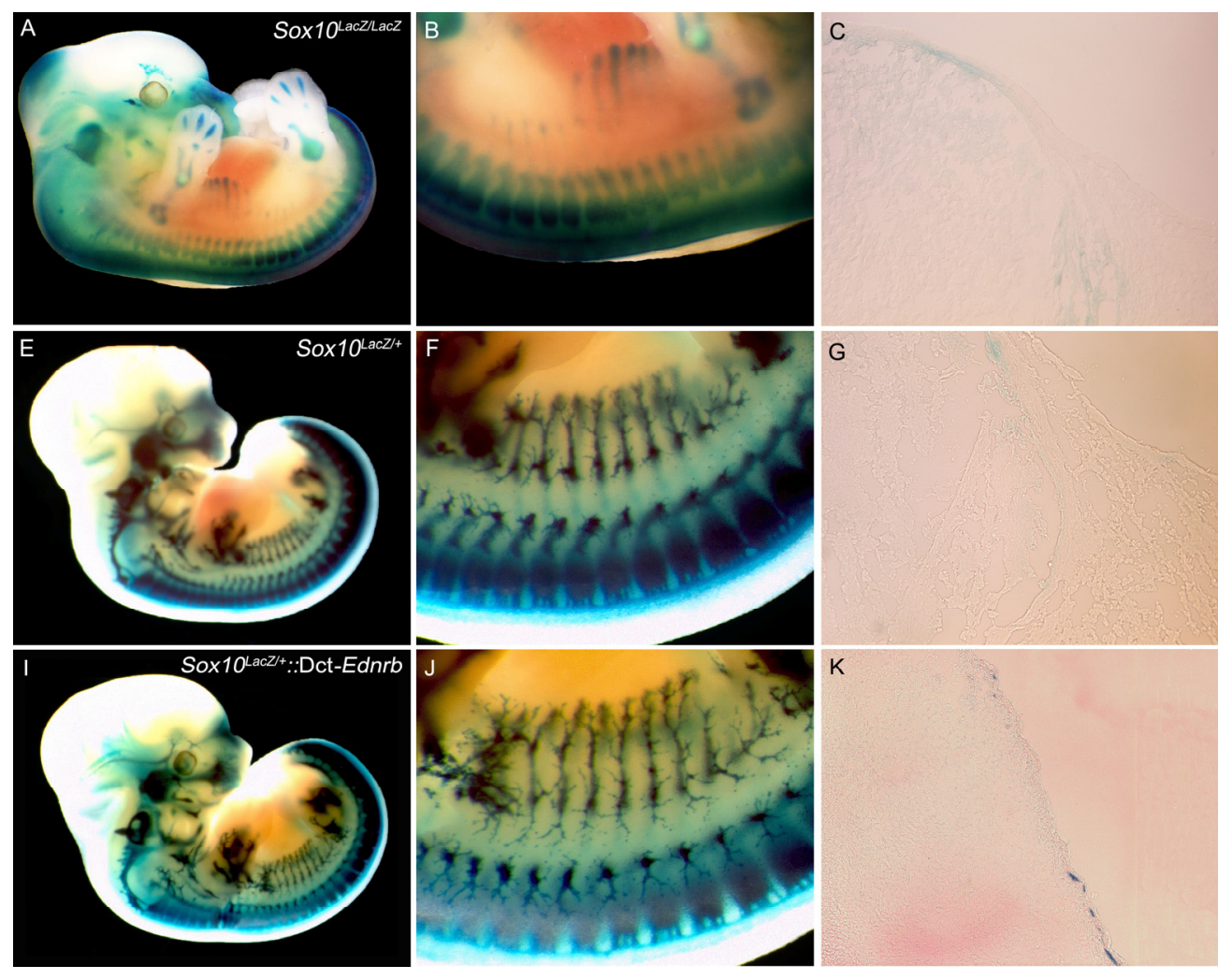

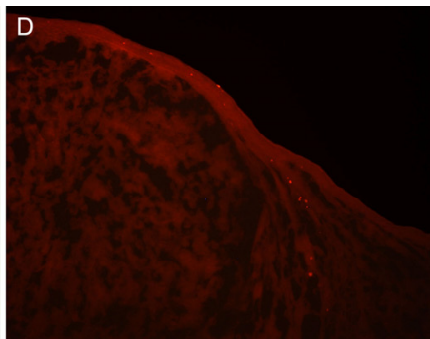

H
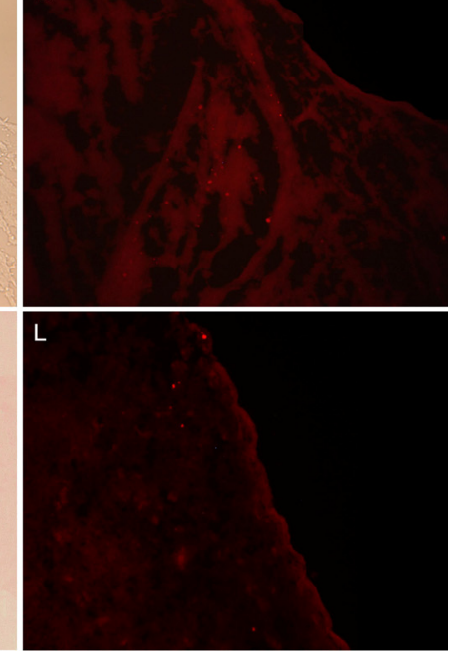

Figure 3.5 LacZ staining of E12.5 Sox10 embryos shows transgenic rescue of melanoblasts in Sox10 heterozygotes. $(A, B)$ Homozygous Sox10 embryos have relatively few melanoblasts that can be seen in (C) cryosections. (E,F) Sox10 heterozygous embryos had visible melanoblasts that were also better visualized in $(\mathrm{G})$ cryosections. $(\mathrm{I}, \mathrm{J}, \mathrm{K})$ Transgenic Sox10 heterozygous embryos had significantly more melanoblasts than non-transgenic heterozygous embryos. $(\mathrm{D}, \mathrm{H}, \mathrm{L})$ No significant cell death was seen in any of the embryos regardless of genotype. 


\section{References:}

Baxter, L. L. and Pavan, W. J. (2003). Pmel17 expression is Mitf-dependent and reveals cranial melanoblast migration during murine development. Gene Expr Patterns 3, 703-7.

Bondurand, N., Pingault, V., Goerich, D. E., Lemort, N., Sock, E., Caignec, C. L., Wegner, M. and Goossens, M. (2000). Interaction among SOX10, PAX3 and MITF, three genes altered in Waardenburg syndrome. Hum Mol Genet 9, 1907-17.

Brunberg, E., Andersson, L., Cothran, G., Sandberg, K., Mikko, S. And Lindgren, G. (2006). A missense mutation in PMEL17 is associated with the Silver coat color in the horse. BMC Genet 7, 46.

Cantrell, V. A., Owens, S. E., Chandler, R. L., Airey, D. C., Bradley, K. M., Smith, J. R. and Southard-Smith, E. M. (2004). Interactions between Sox 10 and EdnrB modulate penetrance and severity of aganglionosis in the Sox10Dom mouse model of Hirschsprung disease. Hum Mol Genet 13, 2289-301.

Clark, L. A., Wahl, J. M., Rees, C. A. and Murphy, K. E. (2006).

Retrotransposon insertion in SILV is responsible for merle patterning of the domestic dog. Proc Natl Acad Sci U S A 103, 1376-81.

Edery, P., Lyonnet, S., Mulligan, L. M., Pelet, A., Dow, E., Abel, L., Holder, S., Nihoul-Fekete, C., Ponder, B. A. and Munnich, A. (1994). Mutations of the RET proto-oncogene in Hirschsprung's disease. Nature 367, 378-80.

Fuchs, E., Tumbar, T. and Guasch, G. (2004). Socializing with the neighbors: stem cells and their niche. Cell 116, 769-78.

Goulding, M. D., Chalepakis, G., Deutsch, U., Erselius, J. R. and Gruss, P. (1991). Pax-3, a novel murine DNA binding protein expressed during early neurogenesis. Embo J 10, 1135-47.

Hakami, R. M., Hou, L., Baxter, L. L., Loftus, S. K., Southard-Smith, E. M., Incao, A., Cheng, J. and Pavan, W. J. (2006). Genetic evidence does not support direct regulation of EDNRB by SOX10 in migratory neural crest and the melanocyte lineage. Mech Dev 123, 124-34.

Hornyak, T. J., Hayes, D. J., Chiu, L. Y. and Ziff, E. B. (2001). Transcription factors in melanocyte development: distinct roles for Pax-3 and Mitf. Mech Dev 101, 47-59. 
Ittah, A. (2005). Transgenic Expression of Endothelin Receptor B Rescues Hypopigmentation, Cochlear Dysfunction and Enteric Aganglionosis of Piebald Lethal Mice. In Dissertation, (ed. Miami, FL: Florida International University.

Jiao, Z., Mollaaghababa, R., Pavan, W. J., Antonellis, A., Green, E. D. and Hornyak, T. J. (2004). Direct interaction of Sox10 with the promoter of murine Dopachrome Tautomerase (Dct) and synergistic activation of Dct expression with Mitf. Pigment Cell Res 17, 352-62.

Kerje, S., Sharma, P., Gunnarsson, U., Kim, H., Bagchi, S., Fredriksson, R., Schutz, K., Jensen, P., von Heijne, G., Okimoto, R. et al. (2004). The Dominant white, Dun and Smoky color variants in chicken are associated with insertion/deletion polymorphisms in the PMEL17 gene. Genetics 168, 1507-18.

Kwon, B. S., Chintamaneni, C., Kozak, C. A., Copeland, N. G., Gilbert, D. J., Jenkins, N., Barton, D., Francke, U., Kobayashi, Y. and Kim, K. K. (1991). A melanocyte-specific gene, Pmel 17, maps near the silver coat color locus on mouse chromosome 10 and is in a syntenic region on human chromosome 12. Proc Natl Acad Sci U S A 88, 9228-32.

Lahav, R., Ziller, C., Dupin, E. and Le Douarin, N. M. (1996). Endothelin 3 promotes neural crest cell proliferation and mediates a vast increase in melanocyte number in culture. Proc Natl Acad Sci U S A 93, 3892-7.

Lang, D., Lu, M. M., Huang, L., Engleka, K. A., Zhang, M., Chu, E. Y., Lipner, S., Skoultchi, A., Millar, S. E. and Epstein, J. A. (2005). Pax3 functions at a nodal point in melanocyte stem cell differentiation. Nature 433, 884-7.

Loftus, S. K., Baxter, L. L., Buac, K., Watkins-Chow, D. E., Larson, D. M. and Pavan, W. J. (2009). Comparison of melanoblast expression patterns identifies distinct classes of genes. Pigment Cell Melanoma Res, 119: 108091.

Ludwig, A., Rehberg, S. and Wegner, M. (2004). Melanocyte-specific expression of dopachrome tautomerase is dependent on synergistic gene activation by the Sox10 and Mitf transcription factors. FEBS Lett 556, 23644.

Mackenzie, M. A., Jordan, S. A., Budd, P. S. and Jackson, I. J. (1997). Activation of the receptor tyrosine kinase Kit is required for the proliferation of melanoblasts in the mouse embryo. Dev Biol 192, 99-107. 
Palmiter, R. D. and Brinster, R. L. (1985). Transgenic mice. Cell 41, 343-5.

Potterf, S. B., Furumura, M., Dunn, K. J., Arnheiter, H. and Pavan, W. J. (2000). Transcription factor hierarchy in Waardenburg syndrome: regulation of MITF expression by SOX10 and PAX3. Hum Genet 107, 1-6.

Potterf, S. B., Mollaaghababa, R., Hou, L., Southard-Smith, E. M., Hornyak, T. J., Arnheiter, H. and Pavan, W. J. (2001). Analysis of SOX10 function in neural crest-derived melanocyte development: SOX10-dependent transcriptional control of dopachrome tautomerase. Dev Biol 237, 245-57.

Puffenberger, E. G., Hosoda, K., Washington, S. S., Nakao, K., deWit, D., Yanagisawa, M. and Chakravart, A. (1994). A missense mutation of the endothelin-B receptor gene in multigenic Hirschsprung's disease. Cell 79 , 1257-66.

Serbedzija, G. N., Fraser, S. E. and Bronner-Fraser, M. (1990). Pathways of trunk neural crest cell migration in the mouse embryo as revealed by vital dye labelling. Development 108, 605-12.

Shin, M. K., Levorse, J. M., Ingram, R. S. and Tilghman, S. M. (1999). The temporal requirement for endothelin receptor-B signalling during neural crest development. Nature 402, 496-501.

Silver, D. L., Hou, L., Somerville, R., Young, M. E., Apte, S. S. and Pavan, W. J. (2008). The secreted metalloprotease ADAMTS20 is required for melanoblast survival. PLoS Genet 4, e1000003.

Steel, K. P., Davidson, D. R. and Jackson, I. J. (1992). TRP-2/DT, a new early melanoblast marker, shows that steel growth factor (c-kit ligand) is a survival factor. Development 115, 1111-9.

Stolt, C. C., Lommes, P., Hillgartner, S. and Wegner, M. (2008). The transcription factor Sox 5 modulates Sox 10 function during melanocyte development. Nucleic Acids Res 36, 5427-40.

Valencia, J. C., Watabe, H., Chi, A., Rouzaud, F., Chen, K. G., Vieira, W. D., Takahashi, K., Yamaguchi, Y., Berens, W., Nagashima, K. et al. (2006). Sorting of Pmel17 to melanosomes through the plasma membrane by AP1 and AP2: evidence for the polarized nature of melanocytes. J Cell Sci 119, 1080-91.

Yasumoto, K., Takeda, K., Saito, H., Watanabe, K., Takahashi, K. And Shibahara, S. (2002). Microphthalmia-associated transcription factor interacts with LEF-1, a mediator of Wnt signaling. Embo J 21, 2703-14. 
Yokoyama, S., Takeda, K. and Shibahara, S. (2006). SOX10, in combination with $S p 1$, regulates the endothelin receptor type B gene in human melanocyte lineage cells. Febs $J$ 273, 1805-20.

Yoshida, H., Kunisada, T., Kusakabe, M., Nishikawa, S. and Nishikawa, S.I. (1996). Distinct stages of melanocyte differentiation revealed by anlaysis of nonuniform pigmentation patterns. Development 122, 1207-14.

Zhao, S. and Overbeek, P. A. (1999). Tyrosinase-related protein 2 promoter targets transgene expression to ocular and neural crest-derived tissues. Dev Biol 216, 154-63.

Zhu, L., Lee, H. O., Jordan, C. S., Cantrell, V. A., Southard-Smith, E. M. and Shin, M. K. (2004). Spatiotemporal regulation of endothelin receptor-B by SOX10 in neural crest-derived enteric neuron precursors. Nat Genet 36, 732-7. 
Chapter IV.

CROSS BETWEEN Ednr $b^{S-1}$ AND Pax $3^{\text {So }}$ RESULTS IN A NOVEL PHENOTYPE: HYDRCEPHALUS AND INTERRMITTENT SKELETAL DEFORMITIES 
IV. CROSS BETWEEN Ednrb ${ }^{S-I}$ AND Pax3 ${ }^{S P}$ RESULTS IN A NOVEL PHENOTYYPE: HYDROCEPHALUS AND INTERMITTENT SKELETAL DEFORMITIES

\section{Abstract}

A novel phenotype arose when studying the potential interaction between Ednrb and Pax3. All pups were born normal in appearance and behavior but by 3 to 3.5 weeks of age, the affected pups were smaller than their normal littermates and developed a dome-shaped head; some also developed distinct thoracic kyphosis. All affected pups were dead by 4 weeks of age except one which survived until the $8^{\text {th }}$ week of life. The goal of this study was to describe the basic characteristics seen in affected pups. Seventy-five percent of affected pups were female although there was no gender bias based on genotype or generation. Of the affected animals, $80 \%$ were heterozygous for Pax3. Upon histologic examination, brains of affected mice had an enlarged $4^{\text {th }}$ ventricle and increased glial processes when compared to brains of normal littermates. Skeletal staining showed kyphosis and rounded wide rib cages in those animals which developed skeletal abnormalities. An epistatic interaction resulting from the mixing of genetic backgrounds that is potentially exacerbated in the presence of Pax3 heterozygosity is suspected.

\section{Introduction}

Endothelin receptor $b$ and Pax3 are involved in early NC development and mutations in either one result in similar phenotypes, such as a decrease in melanocytes or the presence of variant forms of Waardenburg's Syndrome (WS) (2001; Read and Newton, 1997; Tassabehji et al., 1994). Pax3 
heterozygous mice have a completely penetrant ventral hypopigmentation phenotype; Ednrb heterozygous mice often have hypopigmentation while the homozygous mutants are almost completely white (Hornyak et al., 2001; Pavan and Tilghman, 1994). As detailed in chapter one (Figure 1), Pax3 and the Ednrb/Edn3 signaling pathway are both involved in the proliferation of melanocyte progenitors.

Melanocyte numbers are dramatically reduced in mice that are Ednrb homozygotes (Hosoda et al., 1994; Hou et al., 2004). In addition to the reduction of skin melanocytes, these animals are often deaf due to the absence of melanocytes in the stria vascularis of the inner ear (Matsushima et al., 2002) and typically die in the neonatal period due to aganglionosis which arises as a consequence of improper innervation of the gut by enteric neuronal precursors (Lee et al., 2003; Shin et al., 1999). Endothelin receptor $b$ has been suggested to be an essential migration factor for the emerging neural crest cells from E10.5-12.5 (Shin et al., 1999). Expressed by a variety of cells along the migratory path of the increasingly committed NC progenitor cells, Ednrb must be functional in a cell autonomous fashion for melanoblasts to eventually become pigmented and for correct spatial distribution of enteric neurons to occur (Druckenbrod et al., 2008; Hou et al., 2004). Neither of these NC derivatives can successfully reach terminal differentiation in the absence of intrinsic Ednrb.

Pax3 is a critically important transcription factor during early embryonic development with a temporally and spatially restricted expression pattern. Pax3 
expression begins in the mouse embryo at E8.5 and is essential for patterning of the vertebrate nervous system, melanocyte development and skeletal muscle formation (Bajard et al., 2006; Goulding et al., 1991; Hornyak et al., 2001). While Pax3 is known to be a necessary proliferative factor for emerging melanoblasts, it also transactivates (along with Sox10) the major melanocyte regulatory transcription factor Mitf (Bondurand et al., 2000; Hornyak et al., 2001; Potterf et al., 2000). One of the most interesting features of Pax3 is that as it activates Mitf it also serves as an inhibitor to Dct, a downstream target of Mitf, thereby promoting the melanogenic cascade while at the same time preventing terminal differentiation (Lang et al., 2005).

Development is the complex interaction of genes selectively being activated and deactivated in a spatially and temporally restricted fashion in order to dictate cell fate and specification. While Ednrb and Pax3 have several distinct roles in embryonic development, in the melanocyte lineage they are expressed at similar times and in similar locations, and indeed mutants have similar pigmentation and disease phenotypes. This was the original impetus for examining whether or not a genetic interaction existed between Ednrb and Pax3 in the melanocyte lineage. In the previous study detailed in chapter 2, I crossed $E d n r b^{S-/ /+}$ mice with $P a x 3^{S p /+}$ mice to see if double heterozygosity would affect the hypopigmentation phenotype. The hypopigmentation was significantly aggravated in double heterozygous progeny in generations two and three. While collecting data for this first study, a novel phenotype arose. These mice were born looking normal but by $3.5-4$ weeks of age appeared to 
have large dome-shaped heads, were hunched over and smaller than their normal looking littermates. All affected animals died shortly after the appearance of the domed head.

In this study, I wanted to examine the changes occurring both in the head and skeletal structure of these animals. My aim was to provide a descriptive account, in morphologic terms, of the alterations leading up to the certain death of these animals. None of the affected animals survived.

\section{Materials and Methods}

\subsection{Animals and Genotyping}

Heterozygous Ednrb ${ }^{s-l}$ on SSL/Le background and $P a x 3^{S p}$ on C57BL/6J background were originally obtained from Jackson Laboratory and maintained in the FIU Animal Care Facility. Heterozygous Ednrb ${ }^{s-l}$ mice display small to medium areas of ventral hypopigmentation while homozygous animals are almost completely white, with small areas of pigmentation around the pinna and base of the tail. Tail biopsies were used as sources of genomic DNA for PCR genotyping (Appendix I.A). To detect the Ednrb ${ }^{s-l}$ allele, the tightly linked D14Mit7 microsatelite polimorphic marker (Metallinos et al., 1994) was used to distinguish between $E d n r b^{s-1}$ and $C 57 \mathrm{~B} / 6 \mathrm{~J}$ mice using conditions previously described (Pavan and Tilghman, 1994; and Appendix I.B). Pax ${ }^{S p}$ animals carry a point mutation within intron 3 of the paired homeobox 3 (Pax3) gene on mouse Chromosome 1. The mutation interferes with normal splicing of intron 3 and leads to at least 4 aberrantly spliced mRNAs with exon 4 deleted. Pax3 ${ }^{S p}$ heterozygotes consistently display ventral hypopigmentation; mice homozygous 
for this mutation are embryonic lethal by E13.5. To genotype $P a x 3^{S p}$ mice, the intron 3/exon 4 boundary of Pax3 was amplified with primers: P3in3F (5'GAGAGGGTTGAGTACGTTAGCTGG-3') and P3ex4 CTCGCTCACTCAGGATGCC-3'). Products were visualized on a $15 \%$ polyacrylamide gel resulting in a single band around 230bp for a wildtype and a heteroduplex band at this same site for the heterozygote (Appendix I.B).The PCRs were performed for 30 cycles under the following conditions: $94^{\circ} \mathrm{C}$ for 30 $\mathrm{s}, 58^{\circ} \mathrm{C}$ for $30 \mathrm{~s}, 72^{\circ} \mathrm{C}$ for $30 \mathrm{~s}$.

All animals used in this study were housed in the Animal Care Facility at Florida International University (Miami, FL). Water and murine chow were fed ad libitum and light/dark was cycled every 12 hours. All animal work was performed according to institutional guidelines established by $\mathrm{NIH}$.

\subsection{Crosses and Phenotype Analysis}

Crossing of $E d n r b^{S-1 /+}$ mice with $P a x 3^{S p /+}$ mice resulted in mice of all possible genotypes: $E d n r b^{S-1 /+}, P a x 3^{S p /+}$, double heterozygous mutants $\left(E d n r b^{S-/ /+}:: P a x 3^{S p /+}\right)$ and wildtype for these mutations. While genotyping of all animals was done, only characterization of progeny that exhibited the overt phenotype in tandem with one normal littermate was undertaken. These animals were euthanized shortly before the natural death of the affected sibling, typically at 3.5-4 weeks of age and either used for skeletal analysis or for brain antibody staining. These animals were progeny from the first experiment (Chapter 2). 


\subsection{Skeletal Staining}

Animals were euthanized once hydrocephaly was visible and death was imminent, typically between 3.5 and 4 weeks of age. They were immediately skinned, eviscerated and placed in a $95^{\circ} \mathrm{C}$ water bath for 90 seconds to loosen fat and muscle, which was then peeled off the bones. The skeletal specimens were fixed overnight in $4 \%$ paraformaldehyde (Fisher Scientific) at $4^{\circ} \mathrm{C}$, briefly rinsed with deionized water and placed in acetone (Fisher Scientific) overnight. They were then washed 3 times with deionized water, covered with Alcian Blue (Acros) solution and placed in total darkness overnight. The next day, specimens were washed 3 times with $70 \%$ ethanol (Florida Distillers, Co.) changing the solution every 2.5 hours and left overnight in a $1 \% \mathrm{KOH}$ (Acros) solution. $\mathrm{KOH}$ was removed and Alizarin Red (Ricca Chemical Co.) solution added to cover specimens and left again in complete darkness overnight. Specimens were then placed in a $20 \%$ glycerol (Fisher Scientific) in $1 \% \mathrm{KOH}$ for 2 days and then stored in a 1:1 glycerol:ethanol solution. Adapted from Nagy et al. (2003).

\subsection{Brain Dissection}

Animals used for brain studies were also euthanized once hydrocephaly was visible and death was imminent, typically at 3.5 to 4 weeks of age. Animals were anesthetized and perfused initially with $0.1 \mathrm{M}$ PBS, pH 7.4 (Fisher Scientific) and immediately followed with $4 \%$ paraformaldehyde. Animals were decapitated, the head skinned and the skull chipped away using rongeurs. Brains were rinsed in PBS, measured and put in 4\% paraformaldehyde, gently 
rocking at $4^{\circ} \mathrm{C}$ overnight. The following sequence was followed over subsequent days and solutions were changed when the brains had sunk to the bottom of the $50 \mathrm{ml}$ tube: $10 \%$ sucrose; $20 \%$ sucrose; $30 \%$ sucrose and finally a $1: 1$ solution of $60 \%$ sucrose:Tissue-Tek Freezing Medium (Sakura). Brains were then embedded in pure Tissue-Tek Freezing Medium and stored at $-80^{\circ} \mathrm{C}$. Later, transverse cryosections of $10 \mu \mathrm{m}$ were taken of the frozen brains and used for antibody staining.

\subsection{Antibody Staining}

Selected slides were placed on a slide warmer for 2 hours at $37^{\circ} \mathrm{C}$. Slides were washed 3 times in PBS pH7.4 for 15 minutes each time. A blocking solution of $10 \%$ goat serum (Fisher Scientific) in PBT (PBS plus $0.1 \%$ Tween20; Fisher Scientific) was added in two intervals, once for 15 minutes and then for 1.25 hours. The primary antibody in $5 \%$ goat serum in PBT was added to slides and left in a humidity chamber overnight at $4^{\circ} \mathrm{C}$ : $200 \mu$ of Glial fibrillary acidic protein (GFAP; Sigma) at 1:50. In the morning, the primary antibody were neutralized using PBS and the secondary antibody (Alexa Fluor 488; Invitrogen) was diluted 1:100 in 5\% goat serum in PBT and left on slides for 2 hours. Slides were washed with PBS and mounted.

\section{Results}

\subsection{Realization of Novel Phenotype}

As data was being collected to examine whether or not an interaction exists between Ednrb and Pax3 in the melanocytic lineage (previously described in Chapter 2), a number of animals were born that exhibited the same 
developmental anomalies with complete lethality. All pups appeared normal at birth; at approximately 3 weeks of age a number of the progeny appeared smaller than their littermates and their heads became unusually dome shaped. The heads of the affected pups seemed to grow larger as the week went on, especially in the frontal areas. By 4 weeks of age, all pups were dead except for one which lived to approximately 8 weeks of age. Some of the affected pups also appeared to develop kyphotic curvatures of the thoracic spine (Figure 1).

\subsection{Sample Size and Demographics}

A total of 23 affected pups were among the 428 animals born from the $E d n r b^{S-l /+} \times \mathrm{Pax}^{\mathrm{S} / /+}$ cross signifying that $5.4 \%$ of all progeny born in the study developed this lethal phenotype. Of these 23,3 died prior to the realization that a trend was emerging and because genotyping is done at 4 weeks of age, no genetic data is available on these 3 pups other that they were born in the second generation. The remaining 20 pups were genotyped and examined for brain and skeletal abnormalities.

Fifteen of the 20 affected pups (75\%) evaluated were female. Although the total was skewed toward female gender, the distribution among genotypes does not seem to be favored by one gender or the other, at least within this small sample. Males and females appear in all genotype categories: 8 females and 2 males were $P a x 3^{S p /+}, 4$ females and 2 males were $E d n r b^{S-/ /+}:: P a x 3^{S p /+}$ and 3 females and 1 male were wildtype at these two loci (Table 1). Initially there appeared to be generational bias (favoring generations 2 and 3 ) but one mutant pup was a first generation progeny. Generation 2 produced 11 mutant 
pups and generation 3, 8 mutant pups. Twenty-two of the 23 mutant animals died between 3.5 and 4 weeks of age; one mutant mouse, who was not a runt, did not develop hydrocephaly until the $7^{\text {th }}$ week of life and was dead by the $8^{\text {th }}$ week. Of interest, several of the affected mice had microphthalmia.

\subsection{Skeletal Abnormalities Seen in Mutant Mice}

All affected mice developed hydrocephaly and were smaller than their littermates; the only affected mouse that was not smaller than his littermates was the one mouse that didn't develop hydrocephaly until the $7^{\text {th }}$ week of life and survived until the $8^{\text {th }}$ week. Upon examination of the affected progeny, several of them had a curvature of the spine equivalent to thoracic kyphosis, their rib cages appeared wider and their organs were tucked further up into their rib cages than their unaffected littermates (Figure 2). Note the difference in head shape between the normal (Figure 2A) and the affected (Figure 2B) littermates. The abnormal shape of the head is seen again in the affected (Figure $3 \mathrm{~A}$ ) versus the normal (Figure 3B) littermates. The dorsal view seen in the bottom of figure 3 exemplifies the difference in size seen between affected (C) and non-affected (D) mice. The difference in the density and development of the pelvic area is striking.

\subsection{Differences in Brain Morphology}

The brains of the affected mice were always larger than the brains of their normal littermates in all dimensions measured: length, width and depth (Table 2). Often times the skulls of affected mice were soft and the meninges thick. During dissections, a clear liquid commonly leaked out of brains of affected 
mice and often times during the fixation process these brains would deflate somewhat. Brains of affected mice often had blood in the skull cavity, the cortical area of the olfactory nucleus and between the two hemispheres. During cryosectioning along the coronal plane, blood was often seen in the outer cortical layer and would diminish as sectioning progressed towards the caudal aspect of the brain.

The most striking difference between the brains of the affected and unaffected mice was the size of the ventricles. In particular, the $4^{\text {th }}$ ventricle was typically huge when comparing the affected brain to the normal brain. An increase in glial cells and processes was clear when comparing the brains of the affected mice to the brains of the normal mice (Figure 4).

\section{Discussion}

Expansion of the cranial cavity from a normal sloping forehead to a domedshaped head during the neonatal period suggested the development of hydrocephaly, and upon further evaluation, morphological studies supported this initial hypothesis. Approximately $5 \%$ of the progeny born from an Ednrb $b^{S-1 /+}$ and $\mathrm{Pax}^{\mathrm{Sp} /+}$ cross developed this abnormal phenotype which resulted in $100 \%$ lethality. Presence of this novel phenotype was more prevalent in second and third generation progeny but one pup born in the first generation developed hydrocephaly.

Hydrocephaly literally means water ("hydro") on the brain ("cephaly"); the water being cerebrospinal fluid (CSF). Cerebrospinal fluid bathes the brain and spinal column and then is reabsorbed back into the bloodstream all the while 
serving as a protective cushion, and nutrient supplier and waste removal system for the brain. A blockage of any type can trap CSF within the confines of the ventricular system causing pressure on sensitive brain tissue, subsequent swelling and tissue damage (Rekate, 2009). Reactive gliosis, the generation of astroglia, is seen as a measure of stress and tissue damage in the central nervous system (Aoyama et al., 2006; Miller and McAllister, 2007). It has been estimated that 1 in 500 children are affected with hydrocephaly (National Institute of Neurological Disorders and Stroke, 2009) and a quick search on PubMed reveals a plethora of research activity (over 22,000 articles). Yet little is known about the mechanisms of development or truly adequate treatment of hydrocephaly.

Hydrocephaly appears to be a complicated, multigenetic disorder (Takahashi et al., 2008; Town et al., 2008; Zador et al., 2007) often with the coconcurrence of polycystic kidney disease (Liebau et al., 2007; Town et al., 2008). Stumpy, a recently characterized highly conserved gene required for mammalian ciliogenesis, results in complete penetrance of hydrocephalus and polycystic kidney disease in mice with the homozygous null condition (Town et al., 2008). Interestingly, several observable development trends seen in my mice are similar to theirs in that both our mutant pups were born with normally shaped heads which became domed shaped during the neonatal period and these pups were smaller than normal littermates yet had larger brains. Two of their control pups $(<1 \%)$ manifested the condition which they concluded may represent spontaneous development of hydrocephaly in C57BL/6J mice. The 
"wildtype" animals in my population that manifested hydrocephaly may have an allele of a yet unidentified gene that has low causative influence on the development of hydrocephalus. Perhaps in the presence of Pax3 haploinsufficiency, this unidentified gene is modified and there is a dramatic increase in the expressivity and penetrance of this defect ( $80 \%$ of affected pups were Pax 3 heterozygotes compared to $20 \%$ with two normal Pax3 alleles). In addition, it is possible that a mutation in Pax 3 exacerbates the expression of the phenotype in the presence of a homozygous-null modifier. In other words, background strains mixed as generations of progeny were born could increase incidence of this unidentified allele occurring in the homozygous-null state and perhaps it is under these circumstances that a Pax3 mutation modifies its expression. This would explain the preponderance of affected mice in generations 2 and 3 while there was only one affected mouse in generation one. It would be interesting to investigate whether or not these affected mice had abnormal renal morphology, and whether or not their expression of Stumpy is normal.

The skeletal abnormalities seen in some of the affected animals insinuate that the genetic network underlying this phenotype may be dependent on the allelic variations present at the locus. In the case of piebald, the varying lengths of deletions of the piebald gene affected gene expression and dictated whether the mice displayed hydrocephaly, skeletal defects, cartilage malformations of the head or a combination of these defects (O'Brien et al., 1996). The possibility 
remains open that the presentation of allelic variance will manifest in similar but varying phenotypes in our mutant mice as well.

The complexity of elucidating genetic networks is magnified further by the possibility of subunits of a modifier gene having substantially different effects on gene expression. In the case of the Reelin signaling pathway, the Pafah $1 \mathrm{~b}$ Alpha subunits have profoundly different effects on brain development (Assadi et al., 2008). Appropriate Pafah1b1 association with genes in the Reelin pathway is necessary for proper layering of the brain and defects in this interaction results in layering defects and hydrocephaly. Mutations in Pafah1b3 aggravate the layering defects while mutations in Pafah $1 \mathrm{~b} 2$ strongly suppress the development of hydrocephaly in mutant mice destined to develop this condition.

Background strains also have tremendous impact on gene penetrance and expressivity. To establish whether mice of five commonly used inbred background strains were born with similar ventricular size and volume capacity, Hino and colleagues (2009) examined ventricles in newborn mice on MRL/Mp, $\mathrm{C} 57 \mathrm{BL} / 6, \mathrm{C} 3 \mathrm{H} / \mathrm{He}, \mathrm{DBA} / 2$ and BALB/c background strains. The MRL/Mp strain had the largest ventricles and the lipid droplets lining the ventricles were fewer in number and smaller than those present in other backgrounds. The authors concluded that the initial increased volume of CSF and the decreased number of lipid molecules (which supply nutrients) may increase the risk of developing hydrocephaly. Other studies have also shown that the C57BL/6J background decreases the incidence of hydrocephaly in mice (Takahashi et al., 2008; 
Tapanes-Castillo et al., 2009) just as it decreases the hypopigmentation phenotype. However, while severity of hypopigmentation decreases on a C57BL/6J background, the incidence and severity of aganglionosis increases (Cantrell et al., 2004) implying that background modifiers can exacerbate or diminish gene expression. It is possible that the incidence of hydrocephaly in my population is only $5.4 \%$ due to the effect of C57BL/6J background modifiers and that an interaction between Ednrb and Pax3, or a modifier of one or both of these, is minimized because of the background strain. The Ednrb mice were originally on an LLE background, and although there have been several years of generations on a C57BL/6J background, it is possible that a modifier of Pax3 (although dilute) exists in the Ednrb background. And as in the case of Stumpy, perhaps until that modifier had the opportunity to exist in a homozygous state in the presence of a Pax3 mutation it went along relatively undetected.

Much work needs to be done in order to characterize the etiology of the hydrocephaly and skeletal deformities seen here. Determining candidate genes, single polymorphisms, types of mutations involved and microarray analysis may begin to illuminate the genetic interaction underlying the development of hydrocephaly in this particular population. 


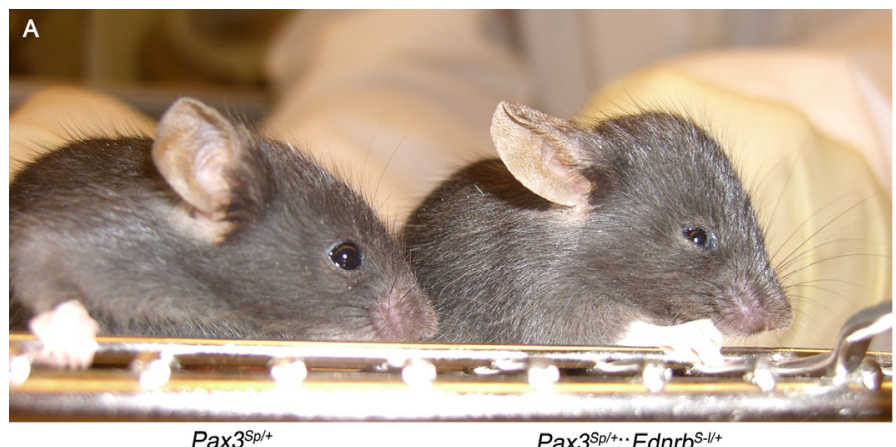

$\operatorname{Pax}^{\mathrm{Sp} /+}$

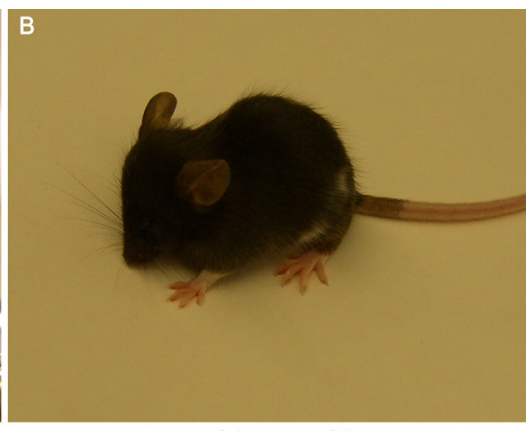

Pax3 ${ }^{S p /+.: E d n r b}{ }^{S-1 /+}$

Figure 4.1 Normal and affected littermates. (A) Littermates at 4 weeks minus a day, the mouse on the left appears normal while the mouse on the right is developing a domed-shaped head and eyes appear smaller than its sibling's eyes. (B) is the same affected mouse from panel (A). The body shape is more hunched and rounder than those of its littermate. Both animals are female.

\begin{tabular}{|c|c|c|c|}
\hline & $P a x 3^{S p /+}$ & $\mathrm{Pax}^{S p /+}:: E d n r b^{S-1 /+}$ & Wildtype \\
\hline $\mathrm{F}_{1}$ & & q & \\
\hline $\mathrm{F}_{2}^{*}$ & 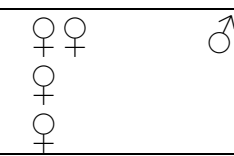 & $\begin{array}{l}\text { q } \\
\text { q } \\
+\end{array}$ & $\begin{array}{ll}9 & \hat{0} \\
9 & 0 \\
+ & \end{array}$ \\
\hline $\mathrm{F}_{3}$ & $\begin{array}{ll}\text { 우우 } & \hat{0} \\
\text { o } & \\
+9 & \\
\text { 9 } & \end{array}$ & q & P \\
\hline
\end{tabular}

*Three animals died prior to genotyping or recognition of novel phenotype.

Table 4.1 Distribution of affected progeny according to generation, genotype and gender. Animals are classified by generation according to their genotype and gender. Of the 20 animals genotyped, 10 were $\mathrm{Pax} 3^{\mathrm{Sp} / \mathrm{H}}, 4$ were $P a x 3^{S p /+}:: E d n r b^{S-1 /+}$ and 4 were wildtype for both these genes. While no gender pattern emerged via genotype or generation there were a predominance of females (15 females out of 20 animals). Three animals $\left(F_{2}\right)$ died prior to genotyping or recognition of novel phenotype. $F_{2}=2^{\text {nd }}$ generation. 

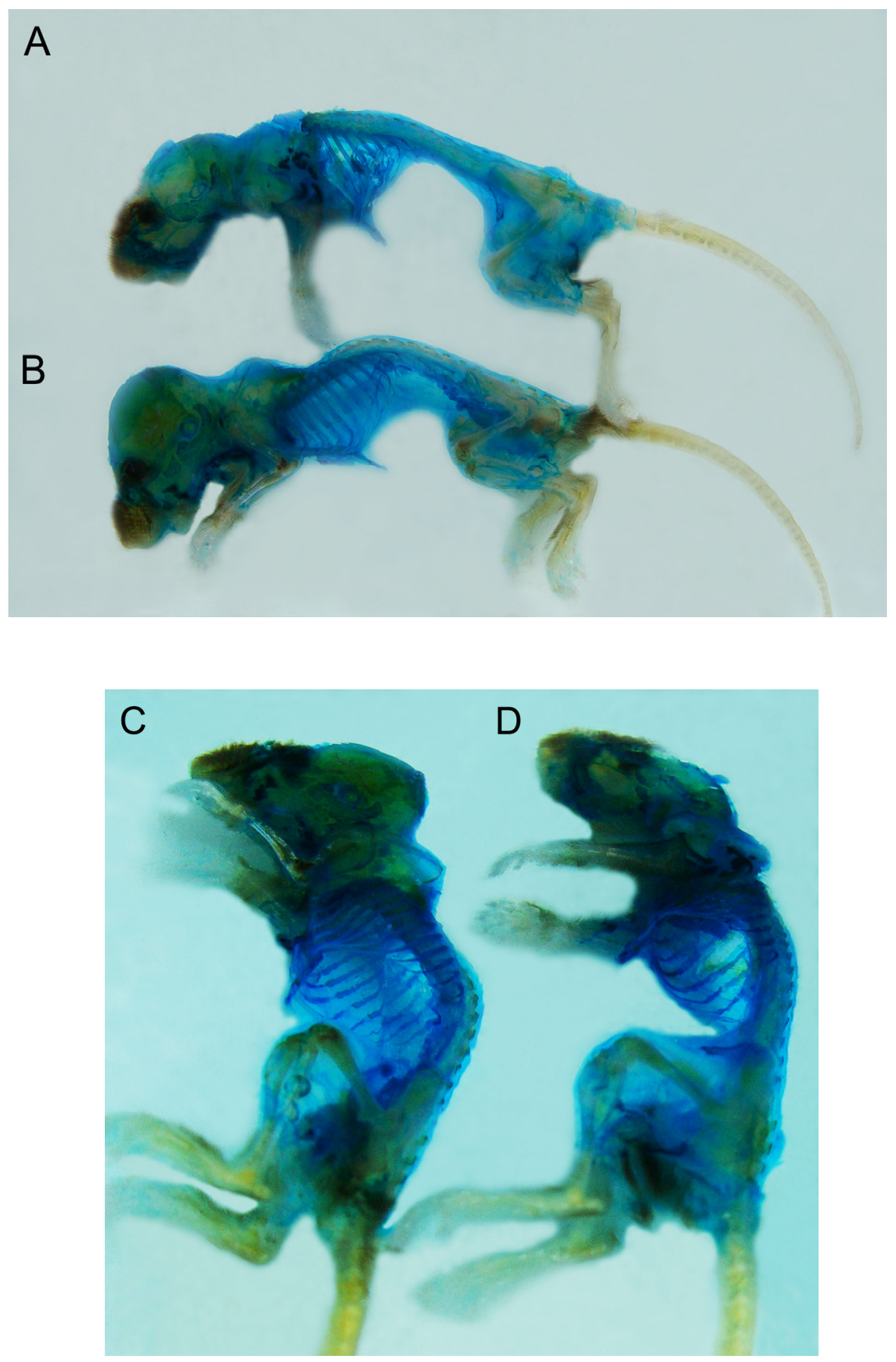

Figure 4.2 Skeletal staining showing curvature of the spine, rib cage expansion and hydrocephalic head. (A) Normal curvature of the mouse spine in the normal mouse as compared to (B) kyphotic curve of the thoracic part of the spine seen in the affected mouse. (C) Rib cage had normal number of ribs but has rounded and wider when compared to (D) the unaffected littermate. Both specimens are female, age 4 weeks old. These mice were depicted in Figure 1; the affected mouse is $P a x 3^{S p /+}:: E d n r b^{S-l /+}$ and the normal littermate is $P a \times 3^{S p /+}$. 

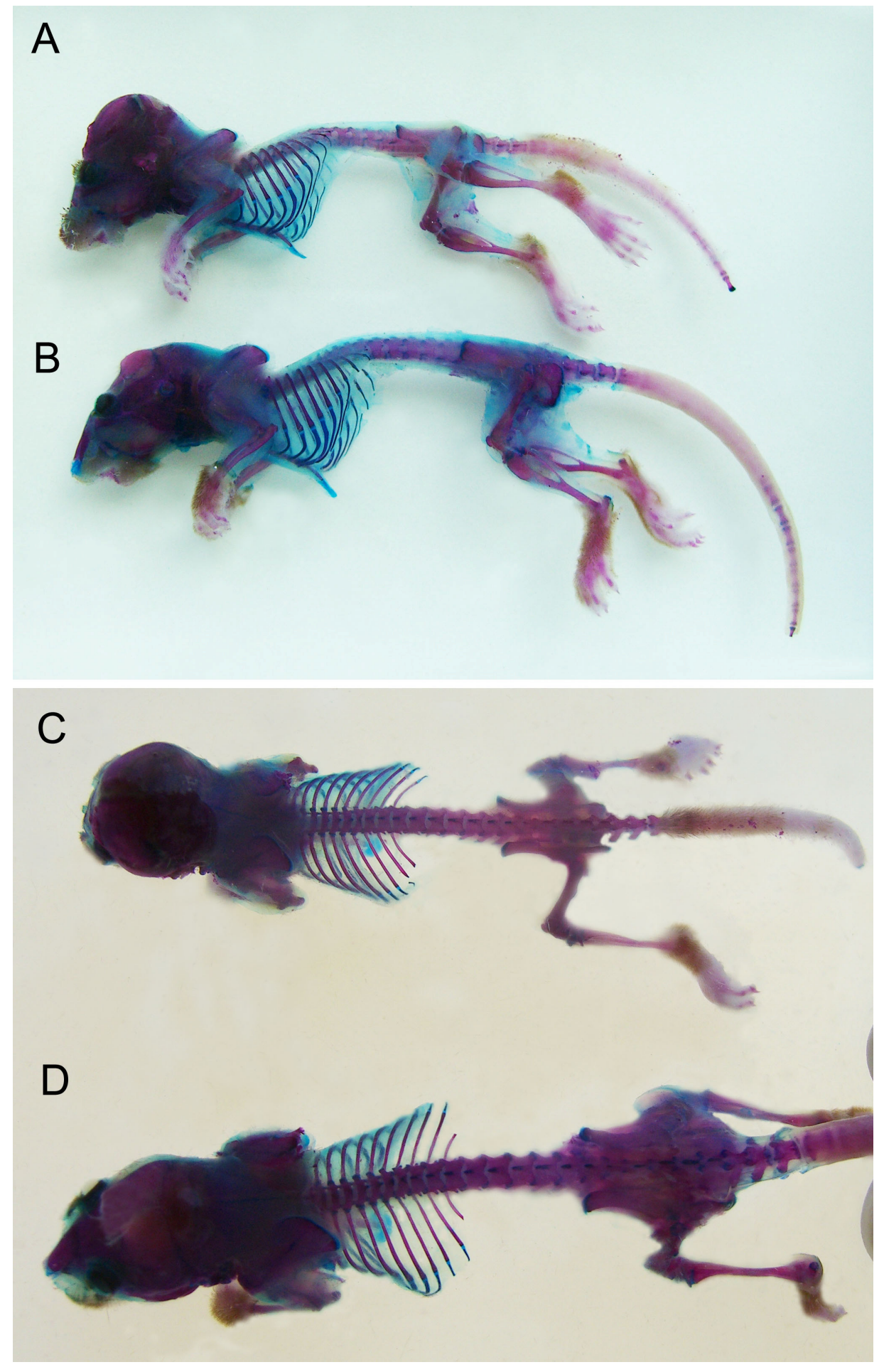

Figure 4.3 Skull and pelvic differences. (A) Affected mouse exhibits misshapen head secondary to hydrocephaly as compared to (B) unaffected littermate. (C) Affected mouse is much smaller in overall size and also has considerably less bone in the pelvic region as compared to (D) its littermate. Specimens are female, 4 weeks old and Pax3 heterozygotes. 


\begin{tabular}{|c|c|c|}
\hline & Normal Brain & Mutant Brain \\
\hline Length & $15 \mathrm{~cm}$ & $17.1 \mathrm{~cm}$ \\
\hline Width & $10 \mathrm{~cm}$ & $11.5 \mathrm{~cm}$ \\
\hline Depth & $5 \mathrm{~cm}$ & $6.5 \mathrm{~cm}$ \\
\hline
\end{tabular}

Table 4.2 Dimensions of two brains. The brain from the affected mouse is larger than the brain of its unaffected littermate in all dimensions. All affected and unaffected brains followed this pattern; this example was chosen as it was an average example of the difference in one pair of littermate brains. Brains come from female littermates who were 3.5 weeks old and both were Pax3 heterozygotes.

Normal Brain
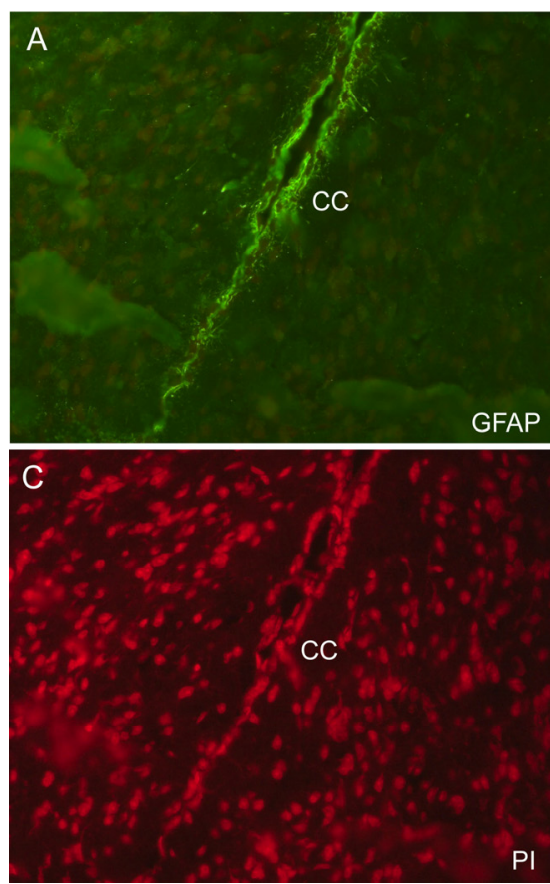

Hydrocephalic Brain

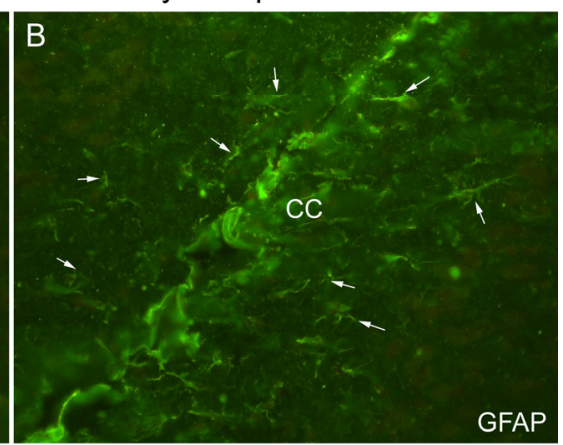

D

Figure 4.4 Brain morphology differences. Antibody staining of 4-week old female murine brains with GFAP shows an increase in glia in the (B) affected brain when compared to $(A)$ a normal brain. In addition, there are fewer cells in (D) the brain tissue of the hydrocephalic brain than in (C) the normal brain. CC = corpus callosum, Magnification: 40X; arrows indicate glia. 


\section{References:}

Aoyama, Y., Kinoshita, Y., Yokota, A. and Hamada, T. (2006). Neuronal damage in hydrocephalus and its restoration by shunt insertion in experimental hydrocephalus: a study involving the neurofilamentimmunostaining method. J Neurosurg 104, 332-9.

Assadi, A. H., Zhang, G., McNeil, R., Clark, G. D. and D'Arcangelo, G. (2008). Pafah1b2 mutations suppress the development of hydrocephalus in compound Pafah1b1; Reln and Pafah1b1; Dab1 mutant mice. Neurosci Lett 439, 100-5.

Bajard, L., Relaix, F., Lagha, M., Rocancourt, D., Daubas, P. and Buckingham, M. E. (2006). A novel genetic hierarchy functions during hypaxial myogenesis: Pax3 directly activates Myf5 in muscle progenitor cells in the limb. Genes Dev 20, 2450-64.

Bondurand, N., Pingault, V., Goerich, D. E., Lemort, N., Sock, E., Caignec, C. L., Wegner, M. and Goossens, M. (2000). Interaction among SOX10, PAX3 and MITF, three genes altered in Waardenburg syndrome. Hum Mol Genet 9, 1907-17.

Cantrell, V. A., Owens, S. E., Chandler, R. L., Airey, D. C., Bradley, K. M., Smith, J. R. and Southard-Smith, E. M. (2004). Interactions between Sox10 and EdnrB modulate penetrance and severity of aganglionosis in the Sox10Dom mouse model of Hirschsprung disease. Hum Mol Genet 13, 2289-301.

Druckenbrod, N. R., Powers, P. A., Bartley, C. R., Walker, J. W. and Epstein, M. L. (2008). Targeting of endothelin receptor-B to the neural crest. Genesis 46, 396-400.

Goulding, M. D., Chalepakis, G., Deutsch, U., Erselius, J. R. and Gruss, P. (1991). Pax-3, a novel murine DNA binding protein expressed during early neurogenesis. Embo J 10, 1135-47.

Hino, K., Otsuka, S., Ichii, O., Hashimoto, Y. and Kon, Y. (2009). Strain differences of cerebral ventricles in mice: can the MRL/MpJ mouse be a model for hydrocephalus? Jpn J Vet Res 57, 3-11.

Hornyak, T. J., Hayes, D. J., Chiu, L. Y. and Ziff, E. B. (2001). Transcription factors in melanocyte development: distinct roles for Pax-3 and Mitf. Mech Dev 101, 47-59.

Hosoda, K., Hammer, R. E., Richardson, J. A., Baynash, A. G., Cheung, J. C., Giaid, A. and Yanagisawa, M. (1994). Targeted and natural (piebald- 
lethal) mutations of endothelin-B receptor gene produce megacolon associated with spotted coat color in mice. Cell 79, 1267-76.

Hou, L., Pavan, W. J., Shin, M. K. and Arnheiter, H. (2004). Cell-autonomous and cell non-autonomous signaling through endothelin receptor $B$ during melanocyte development. Development 131, 3239-47.

Lang, D., Lu, M. M., Huang, L., Engleka, K. A., Zhang, M., Chu, E. Y., Lipner, S., Skoultchi, A., Millar, S. E. and Epstein, J. A. (2005). Pax3 functions at a nodal point in melanocyte stem cell differentiation. Nature 433, 884-7.

Lee, H. O., Levorse, J. M. and Shin, M. K. (2003). The endothelin receptor-B is required for the migration of neural crest-derived melanocyte and enteric neuron precursors. Dev Biol 259, 162-75.

Liebau, M. C., Gal, A., Superti-Furga, A., Omran, H. and Pohl, M. (2007). L1CAM mutation in a boy with hydrocephalus and duplex kidneys. Pediatr Nephrol 22, 1058-61.

Matsushima, Y., Shinkai, Y., Kobayashi, Y., Sakamoto, M., Kunieda, T. and Tachibana, M. (2002). A mouse model of Waardenburg syndrome type 4 with a new spontaneous mutation of the endothelin-B receptor gene. Mamm Genome 13, 30-5.

Metallinos, D. L., Oppenheimer, A. J., Rinchik, E. M., Russell, L. B., Dietrich, W. and Tilghman, S. M. (1994). Fine structure mapping and deletion analysis of the murine piebald locus. Genetics 136, 217-23.

Miller, J. M. and McAllister, J. P., 2nd. (2007). Reduction of astrogliosis and microgliosis by cerebrospinal fluid shunting in experimental hydrocephalus. Cerebrospinal Fluid Res 4, 5.

Nagy, A., Gertsenstein, M., Vintersten, K. and Behringer, R. (2003). Manipulating the Mouse Embryo: A Laboratory Manual. Cold Spring Harbor, NY: Cold Spring Harbor Press.

National Institute of Neurological Disorders and Stroke. (2009). Hydrocephalus Fact Sheet, (ed.: National Institutes of Health.

O'Brien, T. P., Metallinos, D. L., Chen, H., Shin, M. K. and Tilghman, S. M. (1996). Complementation mapping of skeletal and central nervous system abnormalities in mice of the piebald deletion complex. Genetics 143, 44761.

Pavan, W. J. and Tilghman, S. M. (1994). Piebald lethal (sl) acts early to 
disrupt the development of neural crest-derived melanocytes. Proc Natl Acad Sci U S A 91, 7159-63.

Potterf, S. B., Furumura, M., Dunn, K. J., Arnheiter, H. and Pavan, W. J. (2000). Transcription factor hierarchy in Waardenburg syndrome: regulation of MITF expression by SOX10 and PAX3. Hum Genet 107, 1-6.

Read, A. P. and Newton, V. E. (1997). Waardenburg syndrome. J Med Genet 34, 656-65.

Rekate, H. L. (2009). A contemporary definition and classification of hydrocephalus. Semin Pediatr Neurol 16, 9-15.

Shin, M. K., Levorse, J. M., Ingram, R. S. and Tilghman, S. M. (1999). The temporal requirement for endothelin receptor-B signalling during neural crest development. Nature 402, 496-501.

Takahashi, A., Shiroishi, T. and Koide, T. (2008). Multigenic factors associated with a hydrocephalus-like phenotype found in inter-subspecific consomic mouse strains. Mamm Genome 19, 333-8.

Tapanes-Castillo, A., Weaver, E. J., Smith, R. P., Kamei, Y., Caspary, T., Hamilton-Nelson, K. L., Slifer, S. H., Martin, E. R., Bixby, J. L. and Lemmon, V. P. (2009). A modifier locus on chromosome 5 contributes to L1 cell adhesion molecule X-linked hydrocephalus in mice. Neurogenetics, [Epub ahead of print].

Tassabehji, M., Newton, V. E., Leverton, K., Turnbull, K., Seemanova, E., Kunze, J., Sperling, K., Strachan, T. and Read, A. P. (1994). PAX3 gene structure and mutations: close analogies between Waardenburg syndrome and the Splotch mouse. Hum Mol Genet 3, 1069-74.

Town, T., Breunig, J. J., Sarkisian, M. R., Spilianakis, C., Ayoub, A. E., Liu, X., Ferrandino, A. F., Gallagher, A. R., Li, M. O., Rakic, P. et al. (2008). The stumpy gene is required for mammalian ciliogenesis. Proc Natl Acad Sci U S A 105, 2853-8.

Zador, Z., Bloch, O., Yao, X. and Manley, G. T. (2007). Aquaporins: role in cerebral edema and brain water balance. Prog Brain Res 161, 185-94. 
Chapter V.

CONCLUSIONS, FUTURE DIRECTIONS AND IMPLICATIONS 


\section{Conclusions, Future Directions and Implications}

\section{Conclusions and Future Directions}

Genetic interactions provide a complicated network of signals that modulate penetrance and expressivity of gene expression. To elucidate some of the most basic mechanisms of development is to unravel the process of multipotent progenitor cells determining cell fate and subsequently differentiating into highly specialized cells. Neural crest cells emerge as a population of multipotent cells that generate a diverse array of cells and tissues, among them the pigment cells. Melanogenic genes have been described and major melanogenic transcription factors identified but the study of the genetic interactions between the genes that modulate the differentiation of these cells is underway. To that regard, I have determined that interactions between Sox10 and Ednrb, and Pax3 and Ednrb do exist.

Mouse pigmentation phenotypes were used as they are an excellent system in which to elucidate the underpinnings of genetic interactions due to their high homology with the human genome and their short generation time. In chapter 2, I showed that progeny harboring double heterozygous mutations in Sox $10^{\text {LacZ }}$ and $E d n r b^{S-I}$ displayed significantly aggravated pigmentation phenotype in generations two and three of the crosses: in other words, animals who were double heterozygotes had areas of hypopigmentation significantly larger that the sum of the hypopigmentation of Sox $10^{L a c Z /+}$ and Ednrb ${ }^{S-1 /+}$ areas. This suggests that rather than there being an additive effect of the mutations, a synergistic effect occurred indicating that Sox10 and Ednrb do interact in the 
melanocyte lineage. A similar outcome was seen in the $P a x 3^{S p /+}$ cross with $E d n r b^{S-/ /+}$ in which double heterozygote progeny in generations two and three exhibited significantly larger areas of hypopigmentation than the progeny harboring only one of the two mutations.

Melanocytes are derived from the NC. Given that NC cells provide progenitor cells for diverse tissues and organ systems throughout the vertebrate body, it is of no surprise that when a mutation affects NC development early on other cells may be compromised as well. In the case of Sox10 mutations, haploinsufficient mice can also develop aganglionosis or hearing phenotypes in addition to hypopigmentation. Other studies have shown an interaction between Sox10 and Ednrb but with varying results. Stanchina and colleagues (2006) showed aggravated phenotypes (pigmentation and aganglionosis) when using an Ednrb hypomorph crossed with Sox $10^{D o m}$ or Sox $10^{\text {LacZ }}$ while two other studies showed no effect of double heterozygosity on pigmentation phenotype (Cantrell et al., 2004; Hakami et al., 2006). Differences between these results may lie in some yet unidentified background modifier that is present in higher levels in some of these in-bred strains than in other in-bred strains. If no genetic interaction existed between Sox10 and Ednrb then all studies would have produced negative results; in addition, in human melanocytes two Sox10 binding sites have been identified on Ednrb (Yokoyama et al., 2006). I do not believe that these mixed results are due to stochastic events but rather that gene expression and penetrance may be dependent on modifiers of which we are not yet aware. A clear analysis of 
phenotypic expression and the background in which it is expressed will help elucidate the myriad of interactions that comprise the signals necessary for the process of cell fate determination and differentiation. It is this process of discovery that will enable us to unravel and understand how diseases vary in their onset and severity.

In chapter 3,1 showed that when using a transgene to deliver additional Ednrb to the melanoblasts of Sox10 deficient animals, the hypopigmentation phenotype was rescued in all progeny. Sox10 heterozygous mice display a hypopigmented ventral spot approximately half of the time, yet when crossed with a transgenic mouse that was created to deliver additional Ednrb to melanocyte precursors there was a complete rescue of coat color. If Sox10 activates the expression of Ednrb as I suspect it does, then Sox10 heterozygous mice may have a larger belly spot than the Ednrb heterozygous mice due to the initial effect of Sox10 haploinsufficiency on the premigratory and early migratory melanoblasts in addition to the insufficient activation of Ednrb. Sox10 heterozygous mice survive with few, if any side effects, implying that the level of Sox10 in these mice is still adequate to sustain overall cellular function. The delivery of additional Ednrb to melanoblasts that have survived Sox10 haploinsufficiency appears to compensate for the lower level of Ednrb activation thereby rescuing the pigmentation phenotype. Interestingly, the transgenic addition of Sox10 to Ednrb heterozygotes did not rescue the hypopigmentation phenotype (Hakami et al., 2006). The delivery of additional Sox10 to a system with limited Ednrb provides no additional Ednrb to 
compensate for heterozygosity. In other words, once the limited amount of functional Ednrb has been fully activated by Sox10 the addition of more Sox10 does nothing because there is no more Ednrb available to be activated by Sox10. Conversely, the addition of Ednrb to a Sox10 limited system does what Sox10 would have normally done - provide sufficient levels of Ednrb signaling to promote proper melanoblast dispersal and thereby rescues the hypopigmentation phenotype of the Sox10 heterozygous mutant.

Pax3 and Ednrb have a more complicated relationship. Pax3 heterozygous mice exhibit a completely penetrant hypopigmentation phenotype and the transgenic delivery of Ednrb produced a partial rescue. Double heterozygous animals also displayed a significantly larger area of hypopigmentation as discussed above and in chapter 2. However, the transgene rescued the hypopigmentation in only $24 \%$ of the progeny and in another $10 \%$ there was a partial rescue. The ability of the transgene to rescue the pigmentation phenotype may differ due to the temporal expression of Sox10 and Pax3. Sox10 and Ednrb are co-expressed temporally while Pax3 expression is downregulated at the time when Ednrb is being upregulated. If this is the case, then Ednrb may be activated too late to rescue melanocyte progenitors in the $P a x 3^{S p /+}$. It is also possible that the insult of $P a x 3$ haploinsufficiency is more devastating to the premigratory melanoblast precursors and that the additional Ednrb is insufficient to rescue more of the cells. 
In order to establish the timing of the rescue in the Sox10 heterozygous mice, Sox $10^{\mathrm{LacZ} /+}$ embryos with and without the transgene were evaluated at E11.5 (the age at which melanoblasts have first populated the entire length of the embryo). In situ hybridization using a Pme/17 riboprobe showed that the transgenic expression of Ednrb rescued the Sox10 deficient melanoblasts by E11.5. Pmel17 was used as its expression is not regulated by Sox10 and it is among the most sensitive of melanoblast markers (Loftus et al., 2009; Valencia et al., 2006). Once the rescue was established, the mechanism of this rescue came into question. Cell survival assays in E11.5 and E12.5 embryos indicate that the rescue is not due to the effect of the transgene on melanoblast survival. Proliferation and migration studies at E11.5 or earlier will help elucidate the answer to this question.

During the $\mathrm{Pax}^{\mathrm{Sp} /+}$ and $E d n r b^{S-/ /+}$ study, a novel phenotype in the progeny became apparent. Approximately $5 \%$ of pups born in this experiment developed hydrocephaly and died by 4 weeks of age. In addition to the hydrocephaly, some pups also exhibited skeletal abnormalities that included kyphosis of the thoracic region and smaller pelvic regions that appeared less ossified than the pelvic regions of their unaffected littermates. All affected pups except one were much smaller than their littermates. Interesting characteristics of this population include that $80 \%$ of all affected animals were $\mathrm{Pax}^{\mathrm{Sp} / \mathrm{+}}$ and $75 \%$ were female. All except one of the affected animals were born in the second or third generation of the cross. 
All affected progeny developed severe hydrocephaly (which became apparent in the $4^{\text {th }}$ week of life) from which they died. Brain morphology studies showed enlarged brains and bilaterally distended $4^{\text {th }}$ ventricles in all animals. Many of the skulls of these animals were softer than those of their unaffected littermates. In addition, all affected animals were smaller than their normal littermates (except one) and skeletal studies confirmed that their skeletons were indeed smaller than usual. Also of interest was that some of the affected animals had kyphosis, a curvature of the spine in the thoracic region, and had a much smaller pelvis than normal littermates.

The founders used to create this $P a x 3^{S p /+}:: E d n r b^{S-/ /+}$ population originally came on different backgrounds and were backcrossed (independently) for several years prior to being used in this study. The Pax3 mutant mice came on a C57BL/6J background and the Ednrb mutant mice were originally on an LLE background and were later transitioned to a C57BL/6J background. We have many different lines of mice on the C57BL/6J background and on other backgrounds as well, and we have created double and triple mutants of some of these lines and have never seen hydrocephaly develop in any of these progeny. In this study however, it was apparent early on that some unknown interaction was occurring inducing hydrocephalus and intermittently inducing skeletal deformities. This was the first time in the history of our lab that the $\mathrm{Pax}^{\mathrm{Sp} / \mathrm{+}}$ animals were crossed with $E d n r b^{\mathrm{S}-1 /+}$ animals and this tangential finding was intriguing. Eighty percent of the affected animals were Pax3 heterozygotes while $20 \%$ were not. So the question remains as to what kind of 
modifier lies in the Ednrb background that, when in the presence of Pax3 haploinsufficiency, increases the incidence of hydrocephaly and skeletal deformities?

The complexity of illuminating genetic cascades and networks is a monumental task that will undoubtedly take years of research. DNA analyses to determine candidate genes, single polymorphisms and microarray analyses could be used to begin to identify potential genes that are being modified by a mutation in Pax3.

\section{Implications}

One of the mysteries of medical science is that individuals who harbor the same mutations can vary tremendously in the course of the disease and in how much they suffer. Gene expression and penetrance varies according to the presence or absence of other genes, or to background modifiers that were previously undetected. The four types of Waardenburg's syndrome bring to light some of the difficulties of studying genetic interactions: (1) similarity of signs and symptoms despite defects in different genes; and, (2) differences in severity and penetrance of the disease between families as well as within families. These complexities arise from the myriad of genes involved in every transaction that occurs along the developmental path. To make matters even more difficult, genes typically function in a nonlinear fashion and may be affecting expression of more than one gene at any given time.

It should be of no surprise that genetic networks contain a level of unprecedented complexity given the intricate and delicate balance of 
developmental pathways, biochemical cycles, immunological responses and the many other highly sophisticated systems that integrate to become a living organism. Phenotypic expression is anchored in gene expression and it is a matter of time and patience until the underlying connections and mechanisms are uncovered. Elucidation of genetic interactions will help us understand how the mutated gene is modulated, with the intention of one day being able to provide gene therapy to individuals in need.

\section{References:}

Cantrell, V. A., Owens, S. E., Chandler, R. L., Airey, D. C., Bradley, K. M., Smith, J. R. and Southard-Smith, E. M. (2004). Interactions between Sox 10 and EdnrB modulate penetrance and severity of aganglionosis in the Sox10Dom mouse model of Hirschsprung disease. Hum Mol Genet 13, 2289-301.

Hakami, R. M., Hou, L., Baxter, L. L., Loftus, S. K., Southard-Smith, E. M., Incao, A., Cheng, J. and Pavan, W. J. (2006). Genetic evidence does not support direct regulation of EDNRB by SOX10 in migratory neural crest and the melanocyte lineage. Mech Dev 123, 124-34

Loftus, S. K., Baxter, L. L., Buac, K., Watkins-Chow, D. E., Larson, D. M. and Pavan, W. J. (2009). Comparison of melanoblast expression patterns identifies distinct classes of genes. Pigment Cell Melanoma Res, 119: 108091.

Stanchina, L., Baral, V., Robert, F., Pingault, V., Lemort, N., Pachnis, V., Goossens, M. and Bondurand, N. (2006). Interactions between Sox10, Edn3 and Ednrb during enteric nervous system and melanocyte development. Dev Biol 295, 232-49.

Valencia, J. C., Watabe, H., Chi, A., Rouzaud, F., Chen, K. G., Vieira, W. D., Takahashi, K., Yamaguchi, Y., Berens, W., Nagashima, K. et al. (2006). Sorting of Pmel17 to melanosomes through the plasma membrane by AP1 and AP2: evidence for the polarized nature of melanocytes. J Cell Sci 119, 1080-91.

Yokoyama, S., Takeda, K. and Shibahara, S. (2006). SOX10, in combination with $S p 1$, regulates the endothelin receptor type B gene in human melanocyte lineage cells. Febs $J$ 273, 1805-20. 
APPENDICES 


\section{APPENDIX I.}

\section{A. Isolation of DNA from Tail Biopsies}

Animal is briefly anesthetized using a few drops of Isoflurane (Abbott). Working quickly, a numbered ear tag is placed in the right ear and the tip of the tail is clipped $(0.5 \mathrm{~cm})$. The tail is briefly cauterized to prevent bleeding. Each tail is placed in $500 \mu \mathrm{l}$ of tail lysis buffer $(100 \mathrm{mM}$ Tris-Cl pH 8.0, $5 \mathrm{mM}$ EDTA pH 8.0, $200 \mathrm{mM} \mathrm{NaCl}, 0.2 \%$ SDS; Fisher Scientific) and $5 \mu \mathrm{l}$ of proteinase $\mathrm{K}(10 \mathrm{mg} / \mathrm{ml}$; Promega) and placed in a $55-60^{\circ} \mathrm{C}$ water bath overnight.

Digested tails were cooled with $167 \mu \mathrm{l} 5 \mathrm{M} \mathrm{NaCl}$ (Fisher Scientific) for 10 minutes. Samples were then centrifuged for $10 \mathrm{~min}$ at $4^{\circ} \mathrm{C}$; supernatant transferred to clean microcentrifuge tubes and 1 volume of cold $100 \% \mathrm{EtOH}$ (Florida Distillers Co.) added. Solution was shaken vigorously (DNA strands became visible) and centrifuged for $10 \mathrm{~min}$ at $4^{\circ} \mathrm{C}$. Supernatant was poured off and the remaining pellet was dissolved in $1 \mathrm{X}$ TE $(100 \mathrm{mM}$ Tris-Cl $\mathrm{pH} 8.0$, 10mM EDTA pH 8.0; Fisher Scientific) (Miller et al., 1988).

\section{B. Genotyping of Mouse Mutants}

DNA extracted from tails was used to genotype mice. Individual PCR reactions $(10 \mu \mathrm{l}$ total volume/reaction) were set up for each of the genes being tested.

PCR reaction for Ednrb consisted of $1 \mu \mathrm{M}$ of each primer (Ednrbf: 5'AATGTATGGGCATGTGCGTG-3'; and Ednrbr: 5'GAGATAGTCAACCAAAACAA-3'; Invitrogen), 1X buffer, $1.5 \mathrm{mM} \mathrm{MgCl}, 1$ unit of Taq (Promega), 2.5mM of each of the four deoxynucleotides (dNTPs; Invitrogen). Reactions were cycled 30 times at $94^{\circ} \mathrm{C}$ for $30 \mathrm{~s}, 58^{\circ} \mathrm{C}$ for $30 \mathrm{~s}$ and $72^{\circ} \mathrm{C}$ for $30 \mathrm{~s}$. Amplified DNA was visualized on a $15 \%$ polyacrylamide gel made from $30 \%$ acrylamide/bis-acrylamide with $10 \%$ of $5 \mathrm{X}$ TBE, $1 \%$ ammonium persulfate (Fisher Scientific) and 0.1\% TEMED (Sigma). All gels were run at 350 volts for 3.5 hours at $4^{\circ} \mathrm{C}$. Ethidium bromide (Fisher Biotech) was used to visualize DNA.

To genotype $P a x 3^{S p}$ mice, the point mutation was amplified with primers: P3in3F (5'-GAGAGGGTTGAGTACGTTAGCTGG-3') and P3ex4 (5'CTCGCTCACTCAGGATGCC-3'; Invitrogen). The reaction protocol and thermocycler program are identical to that of Ednrb (listed above). Products are visualized on a $15 \%$ polyacrylamide gel resulting in a single band around $230 \mathrm{bp}$ for a wildtype and a heteroduplex band at this same site for the heterozygote.

Sox $10^{\mathrm{LacZ} /+}$ is a knock-in mutant and requires 3 primers: 5' Sox10 (5'CAGGTGGGCGTTGGGCTC-3'); 3' Sox10 (5'-CAGAGCTTGCCTAGTGTCTT3'); and 3' LacZ (5'-TAAAAATGCGCTCAGGTCAA-3'). In addition to the $1 \mu \mathrm{M}$ of 
each primer (Invitrogen), 1X buffer, $2 \mathrm{mM} \mathrm{MgCl}, 1$ unit Taq (Promega), 5\% DMSO (Fisher Scientific), $2.5 \mathrm{mM}$ of each dNTP (Invitrogen) and $1 \mu$ LNA. Thermocycler conditions were $94^{\circ} \mathrm{C}$ for $30 \mathrm{~s}, 55^{\circ} \mathrm{C}$ for $30 \mathrm{~s}$, and $72^{\circ} \mathrm{C}$ for $30 \mathrm{~s}$ for 32 cycles. Products were visualized on a $2 \%$ agarose (Fisher Scientific) gel resulting in a $500 \mathrm{bp}$ band for wildtype and a $600 \mathrm{bp}$ for the mutated allele. Animals homozygous for Sox10 are embryonic lethal, typically by E13.5.

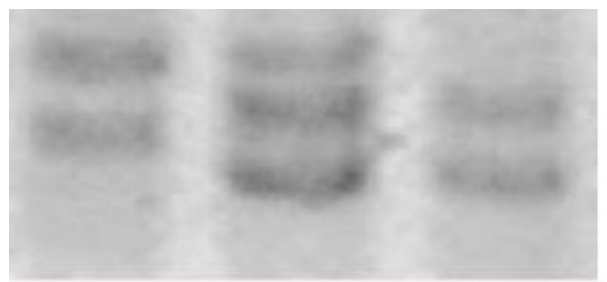

$E d n r b^{2 / / 21} \quad E d n r b^{21 /+} \quad$ WT

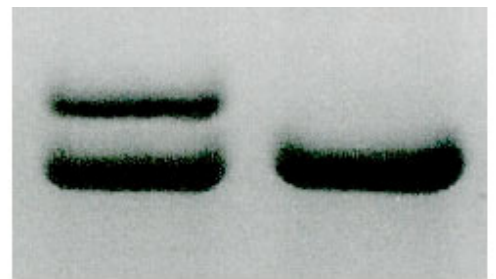

$\operatorname{Sox} 10^{\operatorname{Lrc} Z /+}$

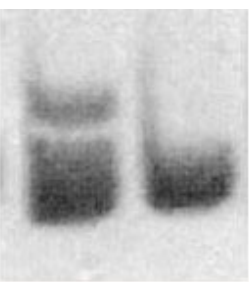

$\operatorname{Pax}^{S_{\text {F/t }}}$ WT

Figure A.1 Possible results of gel electrophoresis of mice tail DNA genotyping. Ednrb genotyping of tail DNA can result in either homozygous (Ednr $b^{s-1 / s-1}$ ), heterozygous (Ednrb $\left.{ }^{s-1 /+}\right)$ or wildtype identification of animals. Sox10 and Pax3 genotyping of tail DNA results in either heterozygous (Sox $10^{\mathrm{LacZ} /+}$ or $\mathrm{Pax} 3^{\mathrm{Sp} /+}$ ) or wildtype animals. Both Sox10 and Pax3 null mutants are embryonic lethal by E13.5-14.5).

\section{Buffers}

Tris Acetate EDTA (TAE) (typically made as 50X solution)

40mM Tris-acetate

$1 \mathrm{mM}$ EDTA

(24.2g Tris, $5.7 \mathrm{ml}$ Glacial Acetic acid, 10.0ml 0.5M EDTA pH 8.0, bring volume up to $100 \mathrm{ml}$ with $\mathrm{dH}_{2} \mathrm{O}$ and autoclave.)

Tris Borate EDTA (TBE) (typically made as a $5 \mathrm{X}$ solution)

45mM Tris-borate

$1 \mathrm{mM}$ EDTA

(54g Tris, $27.5 \mathrm{~g}$ Boric acid, 20ml 0.5M EDTA pH8.0, bring volume up to 1 liter with $\mathrm{dH}_{2} \mathrm{O}$ and autoclave.)

Tris EDTA (TE) (typically made as a $10 \mathrm{X}$ solution)

10mMTris, $\mathrm{pH} 7.5$

$1 \mathrm{mM}$ EDTA pH8.0

$(10 \mathrm{ml} 1.0 \mathrm{M}$ Tris, $2 \mathrm{ml} 0.5 \mathrm{M}$ EDTA pH 8.0 , bring volume up to $100 \mathrm{ml}$ with $\mathrm{dH}_{2} \mathrm{O}$. Adjust $\mathrm{pH}$ to 8.0 and autoclave.) 


\section{APPENDIX II.}

\section{A. Staging and Harvesting of Embryos}

Mice were mated overnight and staged embryos were dated as $0.5 \mathrm{~d}$ noon the day the vaginal plug was observed. Embryos were harvested at E11.5 and E12.5 by euthanizing the pregnant dam via cervical dislocation and dissecting embryos through a transverse abdominal incision. Embryos were immediately placed in PBS (the $\mathrm{pH}$ of which was determined by the subsequent procedure, see Appendices II.D and II.H) and yolk sacs were saved for DNA extraction (Appendix II.B). Those destined for double staining with LysoTracker Red and LacZ, were immediately started on that protocol (Appendix II.I). Embryos for in situ hybridization were dehydrated through a methanol $(\mathrm{MeOH}$; Fisher Scientific) series (25\%:75\% MeOH:PBS; 50\%:50\%; 75\%:25\% MeOH:PBS for 5 min each) and stored in $100 \% \mathrm{MeOH}$ at $-20^{\circ} \mathrm{C}$.

\section{B. Isolation of DNA from Tail Biopsies or Embryonic Yolk Sacs}

Isolation of DNA from tail biopsies was achieved using the protocol listed in Appendix I.A. To genotype embryos, yolk sacs were harvested by taking the innermost of the 3 embryonic membranes surrounding the developing embryo. This membrane was placed in $250 \mu \mathrm{l}$ of yolk sac buffer $(10 \mathrm{mM}$ Tris-Cl $\mathrm{pH} 8.0$, $10 \mathrm{mM}$ EDTA pH $8.0,100 \mathrm{mM} \mathrm{NaCl}, 0.5 \%$ SDS; Fisher Scientific) plus $10 \mu \mathrm{l}$ of Proteinase K $\left(10 \mathrm{mg} / \mathrm{ml}\right.$; Promega) and placed in a $55-60^{\circ} \mathrm{C}$ water bath overnight.

Digested yolk sacs were cooled with $200 \mu \mathrm{l} 5 \mathrm{M} \mathrm{NaCl}$ (Fisher Scientific) for 10 minutes. Samples were then centrifuged for $10 \mathrm{~min}$ at $4^{\circ} \mathrm{C}$; supernatant transferred to clean microcentrifuge tubes and 1 volume of cold $100 \% \mathrm{EtOH}$ (Florida Distillers Co.) added. Solution was shaken vigorously (DNA strands became visible) and centrifuged for $10 \mathrm{~min}$ at $4^{\circ} \mathrm{C}$. Supernatant was poured off and the remaining pellet was dissolved in $1 \mathrm{X}$ TE $(100 \mathrm{mM}$ Tris- $\mathrm{Cl} \mathrm{pH} 8.0$, 10mM EDTA pH 8.0; Fisher Scientific) (adapted from Miller et al., 1988).

\section{Genotyping of Mouse Mutants}

Sox10, Pax3 and Ednrb mutant animals were genotyped as described in the materials and methods section of Chapter 2 and Appendix I.B. Sox $10^{\text {LacZ/LacZ }}$ are embryonic lethal at approximately E13.5, hence Sox10 embryos were harvested at E11.5 and E12.5 enabling the possibility of examining developmental changes in the Sox10 homozygous condition. DNA amplification of embryos homozygous for Sox10 generates a 600bp band while wildtype embryos generate a 500bp band; heterozygous embryos produce both bands. 
Dct-Ednrb transgenic animals were generated in our laboratory (Avner Ittah, FIU dissertation 2005). The full length Ednrb cDNA (1958bp, genbank accession \# U32329) obtained from pmET-B (Hosoda et al., 1994) was inserted into the vector pmDct that contains $3431 \mathrm{bp}$ of the mouse Dct promoter and the BGH poly adenylation signal (Hornyak et al., 2000). Dct-Ednrb transgenic mice were generated by microinjection of the transgene into FVB $F_{1}$ zygotes. The studies presented here were carried out with a line that initially had 150 copies of the transgene. This line was crossed for over 10 generations with C57BL/6J mice from our colony. Mice were genotyped using $1 \mu \mathrm{M}$ of each primer DctEdnrbf (5'-ACAAGGAAGACTGGCGAGAA-3'); and, Dct-Ednrbr (5'TCCTCCCCCTTGCTGTCCTGC-3'; Invitrogen), 1X buffer, 2mM MgCl, 1 unit Taq (Bioline), $5 \%$ DMSO (Fisher Scientific), $2.5 \mathrm{mM}$ of each dNTP (Invitrogen) and $1 \mu \mathrm{L}$ DNA. The amplified DNA was visualized on a $1 \%$ agarose gel resulting in a $2217 \mathrm{bp}$ band (Appendix I). The PCRs were performed for 35 cycles under the following conditions: $94^{\circ} \mathrm{C}$ for $30 \mathrm{~s}, 57^{\circ} \mathrm{C}$ for $30 \mathrm{~s}$, and $72^{\circ} \mathrm{C}$ for $2 \mathrm{~min}$.

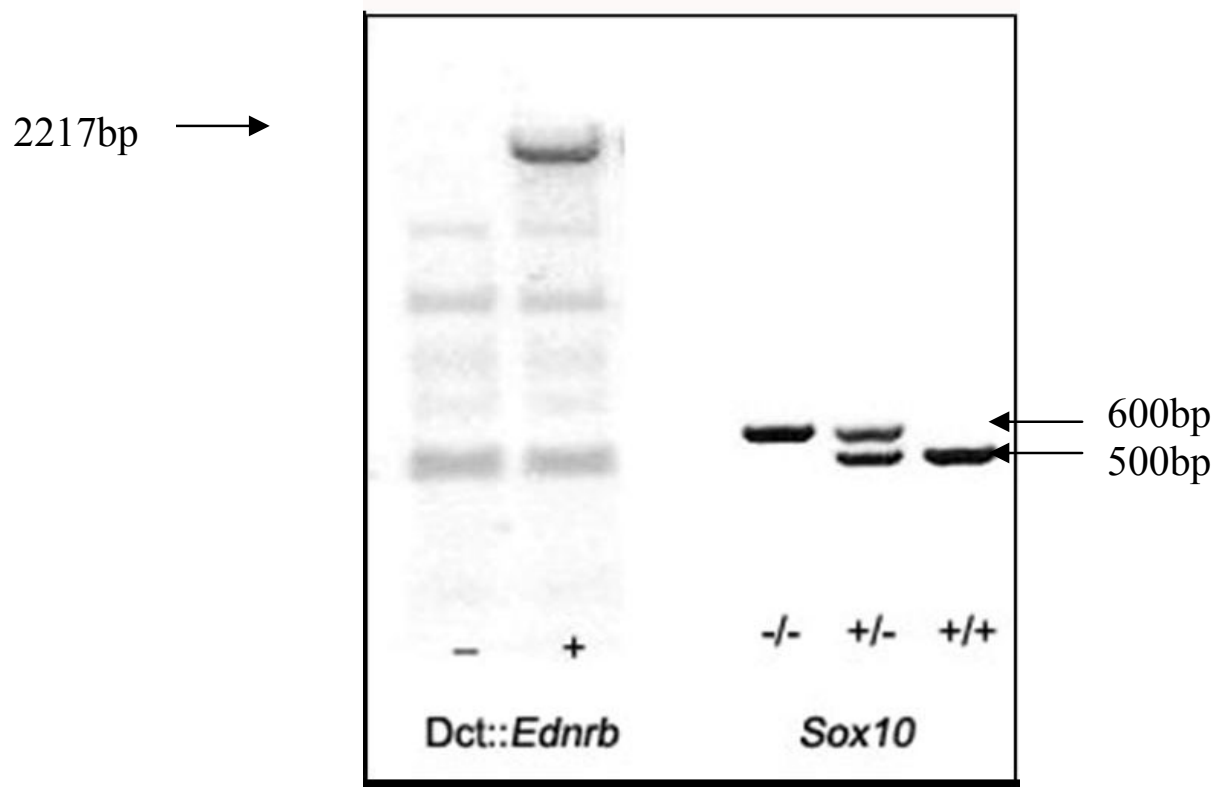

Figure A.2 Possible results of gel electrophoresis of mice tail or yolk sac DNA genotyping. Dct-Ednrb results either in a positive 2217bp band indicating presence of the transgene, or no band at this level indicating that the transgene was not transmitted. Other bands are non-specific. Sox10 gel shows a $600 \mathrm{bp}$ band for Sox $10^{\mathrm{LacZ} / \mathrm{LacZ}}(-/-), 600 \mathrm{bp}$ and $500 \mathrm{bp}$ bands for Sox $10^{\mathrm{LaCZ} /+}(+/-)$ and a $500 \mathrm{bp}$ band for the wildtype $(+/+)$.

\section{In Situ Hybridization of Mouse Embryos}

In situ hybridization took 4 days to complete. Day 1 (pretreatment and hybridization): Embryos were rehydrated via a $\mathrm{MeOH}$ series using $\mathrm{PBT}^{*}\left(\mathrm{PBS}^{* *}\right.$ plus $0.1 \%$ Tween-20 Fisher Scientific) $5 \mathrm{~min}$ for each of the following steps: 75\%:25\% MeOH:PBT; 50\%50\%; 25\%:75\% MeOH:PBT and two washes in 
$100 \%$ PBT. Embryos were then bleached in $6 \% \mathrm{H}_{2} \mathrm{O}_{2}$ (Fisher Scientific) in PBT for $1 \mathrm{hr}$ at RT and then permeabilized using $10 \mu \mathrm{g} / \mathrm{ml}$ proteinase $\mathrm{K}$ (Promega) in PBT (15min for E11.5 and 18min for E12.5). To neutralize this reaction, $2 \mathrm{mg} / \mathrm{ml}$ glycine (Fisher Scientific) in PBT was added for $10 \mathrm{~min}$ at RT and then washed twice with PBT. Embryos were postfixed with 4\% paraformaldehyde (Fisher Scientific), $0.2 \%$ gluteraldehyde (Sigma) in PBT for 20min. Pre-hybridization was accomplished by adding $1 \mathrm{ml}$ hybridization solution (50\% formamide, $5 \times S S C$ pH4.5 1\% SDS, Fisher Scientific; $50 \mu \mathrm{g} / \mathrm{ml}$ yeast tRNA, Sigma; $50 \mu \mathrm{g} / \mathrm{ml}$ heparin, Sigma) and incubated in a $70^{\circ} \mathrm{C}$ water bath for $1 \mathrm{hr}$. The prehybridization solution was removed and fresh hybridization solution containing $2 \mu \mathrm{l}$ pel17 riboprobe per $\mathrm{ml}$ of hybridization solution added and left overnight in the $70^{\circ} \mathrm{C}$ water bath.

Day 2 (washing and antibody addition): Embryos briefly rinsed in solution 1 ( $50 \%$ formamide, $5 \times$ SSC and $1 \%$ SDS; Fisher Scientific) and then washed 3 times more with solution 1 (30min each time in a $70^{\circ} \mathrm{C}$ water bath). Washing was continued, 3 more times, using solution 2 (50\% formamide and 2xSSC; Fisher Scientific) and placed in a $65^{\circ} \mathrm{C}$ water bath for $30 \mathrm{~min}$ each time, followed by washing with TBS plus $0.1 \%$ Tween-20 (TBST) 3 times for 5 min each time. Blocking of embryos in $10 \%$ goat serum (Fisher Scientific) in TBST for $2 \mathrm{hrs}$, rocking at RT, during which time the preabsorb anti-digoxigenin antibody was prepared by adding a pinch of embryo powder to microcentrifuge tubes containing $0.5 \mathrm{ml}$ TBST (1 microcentrifuge tube/embryo) and placed in $70^{\circ} \mathrm{C}$ water bath for $30 \mathrm{~min}$. Microcentrifuge tubes were removed from water bath, vortexed and cooled prior to the addition of $5 \mu \mathrm{l}$ of $100 \%$ goat serum and $1 \mu \mathrm{l}$ anti-digoxigenin antibody (Roche) and rocked at $4^{\circ} \mathrm{C}$ for $1 \mathrm{hr}$. After centrifuging for $5 \mathrm{~min}$, the supernatant was collected and $1.5 \mathrm{ml}$ of $1 \%$ goat serum in TBST per microcentrifuge tube was added. When embryos were ready, the blocking solution was removed, the antibody solution added and embryos were left rocking overnight at $4^{\circ} \mathrm{C}$.

Day 3 (washing the antibody): Embryos were briefly rinsed in TBST and then washed 4 times in TBST for $1 \mathrm{hr}$ each time at RT. Levamisole $(2 \mathrm{mM}$; Sigma) was added to a $5^{\text {th }}$ TBST wash and left overnight, rocking at $4^{\circ} \mathrm{C}$.

Day 4 (detection): Embryos were washed in NTMT $(100 \mathrm{mM} \mathrm{NaCl}, 100 \mathrm{mM}$ Tris pH9.5, 50mM MgCl2, 0.1\% Tween-20; Fisher Scientific; $2 \mathrm{mM}$ levamisole; Sigma) 3 times for $10 \mathrm{~min}$ each time. While protecting from light, $45 \mu$ l 4-Nitro

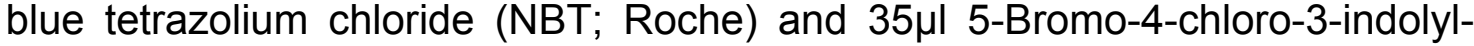
phosphate (BCIP; Roche) were added to $10 \mathrm{ml}$ NTMT and added to each embryo. Still protected from light, embryos were monitored every 30min to control the level of antibody development (Wilkinson 1998).

*All water used for solutions was Diethylpyrocarbonate (DePC; Sigma) treated water and therefore RNase-free.

${ }^{* * *}$ All PBS used in this protocol was $0.05 \mathrm{M}, \mathrm{pH} 7.4$. 


\section{E. Pmel17 Template and Riboprobe Preparation}

Bacterial Transformation: $2.5 \mu$ of Pmel17 plasmid was added to $50 \mu$ of DH5a competent Escherichia coli and incubated on ice for $30 \mathrm{~min}$, heat shocked for $20 \mathrm{sec}$ at $37^{\circ} \mathrm{C}$ and then immediately placed in ice for $1 \mathrm{~min}$. 950 $\mu \mathrm{l}$ Luria Broth (LB) was added and mixture was incubated for $1 \mathrm{hr}$ at $37^{\circ} \mathrm{C}(30 \mathrm{~min}$ into the hour $30 \mu$ Ampicillin was added). An LB plate containing Ampicillin was inoculated and left to incubate overnight at $37^{\circ} \mathrm{C}$.

Glycerol Stock of Pmel17 Plasmid: Inoculated 5ml LB with isolated colonies from LB plate and incubated overnight at $37^{\circ} \mathrm{C}$ shaking at $250 \mathrm{rpm}$. $750 \mu \mathrm{l}$ of freshly grown transformed bacteria was added to $750 \mu \mathrm{l}$ sterile glycerol stock and stored at $-80^{\circ} \mathrm{C}$.

DNA Isolation and Purification: $5 \mathrm{ml}$ LB was inoculated with glycerol stock of Pmel17 plasmid (stored in $-80^{\circ} \mathrm{C}$ ) and incubated overnight at $37^{\circ} \mathrm{C}$ at $250 \mathrm{rpm}$. Wizard Plus SV Mini Prep: DNA Purification System (Promega catalog \#A1460) was used for the following steps. $2 \mathrm{ml}$ of fresh culture was centrifuged and pellet was resuspended in $250 \mu \mathrm{l}$ Resuspension Solution. To this, $250 \mu \mathrm{l}$ Cell Lysis Solution was added, inverted 4 times followed by the addition of $10 \mu$ l Alkaline Protease Solution and again inverted 4 times to mix gently, then incubated at room temperature for $5 \mathrm{~min}$. $350 \mu \mathrm{l}$ Neutralization Solution was added, centrifuged for $10 \mathrm{~min}$ and the clear lysate was decanted into the spin column and centrifuged again for $1 \mathrm{~min}$. Flowthrough was discarded and $750 \mu \mathrm{l}$ Wash Solution added, centrifuged for $1 \mathrm{~min}, 250 \mu \mathrm{l}$ Wash Solution, centrifuged for $2 \mathrm{~min}$ and transferred to spin column to remove Wash Solution. Finally, 50 $\mu$ l of nuclease free $\mathrm{H}_{2} \mathrm{O}$ was added and stored at $-20^{\circ} \mathrm{C}$.

Template Preparation: $10 \mu \mathrm{l}$ of Pme/17 plasmid was digested with $2 \mu \mathrm{l}$ of the restriction enzyme KPN1 (Promega), $2 \mu \mathrm{l}$ buffer $\mathrm{J}$ and $6 \mu \mathrm{UV} \mathrm{UH}_{2} \mathrm{O}$ at $37^{\circ} \mathrm{C}$ for $2 \mathrm{hrs}$. Linearized template was then cleaned via phenol-chloroform (Fisher Scientific) extraction and ethanol (Florida Distillers Co.) precipitation and resuspended in $\mathrm{H}_{2} \mathrm{O}$ to a concentration of approximately $1 \mu \mathrm{g} / \mu \mathrm{l}$.

Riboprobe Synthesis: $5 \mu \mathrm{l}$ template was added to $4 \mu \mathrm{l} 5 \mathrm{x}$ transcription buffer (Roche), $2 \mu \mathrm{l}$ nucleotide tri-phosphate (NTP) labeling mix (Roche), $2 \mu \mathrm{l} \mathrm{T}_{3}$ polymerase (Promega), $1 \mu \mathrm{l}$ RNase inhibitor (Promega) and $6 \mu \mathrm{l} \mathrm{DePC} \mathrm{H}_{2} \mathrm{O}$ and incubated at $37^{\circ} \mathrm{C}$ for $2 \mathrm{hrs}$. At this point, $2 \mu \mathrm{l} 0.2 \mathrm{M}$ EDTA, $2.5 \mu \mathrm{l} 4 \mathrm{M} \mathrm{LiCl}$ and $75 \mu \mathrm{l} \mathrm{EtOH}$ were added to precipitate riboprobe; pellet was then washed in $70 \%$ $\mathrm{EtOH}$, resuspended in $22.5 \mu \mathrm{l} \mathrm{DePC} \mathrm{H}_{2} \mathrm{O}, 2.5 \mu \mathrm{l} 4 \mathrm{M} \mathrm{LiCl}$ and $75 \mu \mathrm{l} \mathrm{EtOH}$ to precipitate again and a final wash in $70 \% \mathrm{EtOH}$. This pellet was dissolved in $20 \mu \mathrm{l} \mathrm{DePC} \mathrm{H}_{2} \mathrm{O}$ and $80 \mu \mathrm{l}$ hybridization solution and stored at $-20^{\circ} \mathrm{C}$. 


\section{F. Embryo Powder}

12.5-14.5 day old embryos were homogenized in cold PBS pH7.4. Four volumes of acetone were added and mixture was incubated on ice for $30 \mathrm{~min}$, then centrifuged for $10 \mathrm{~min}$ at $4^{\circ} \mathrm{C}$. Supernatant was discarded, the pellet washed again in cold acetone and spun down for another $10 \mathrm{~min}$. Supernatant was again discarded and pellet was macerated into a fine powder and air-dried. Embryo powder was stored at $4^{\circ} \mathrm{C}$.

\section{G. Cell Counts of Pmel17 labeled Melanoblasts}

Cells labeled with Pmel17 that were located in the torso from the fore limb to the hind limb were counted from a picture taken of the area at $3.2 x$ magnification. The angle of lines drawn to define the area, lighting and magnification were kept constant for all pictures taken.

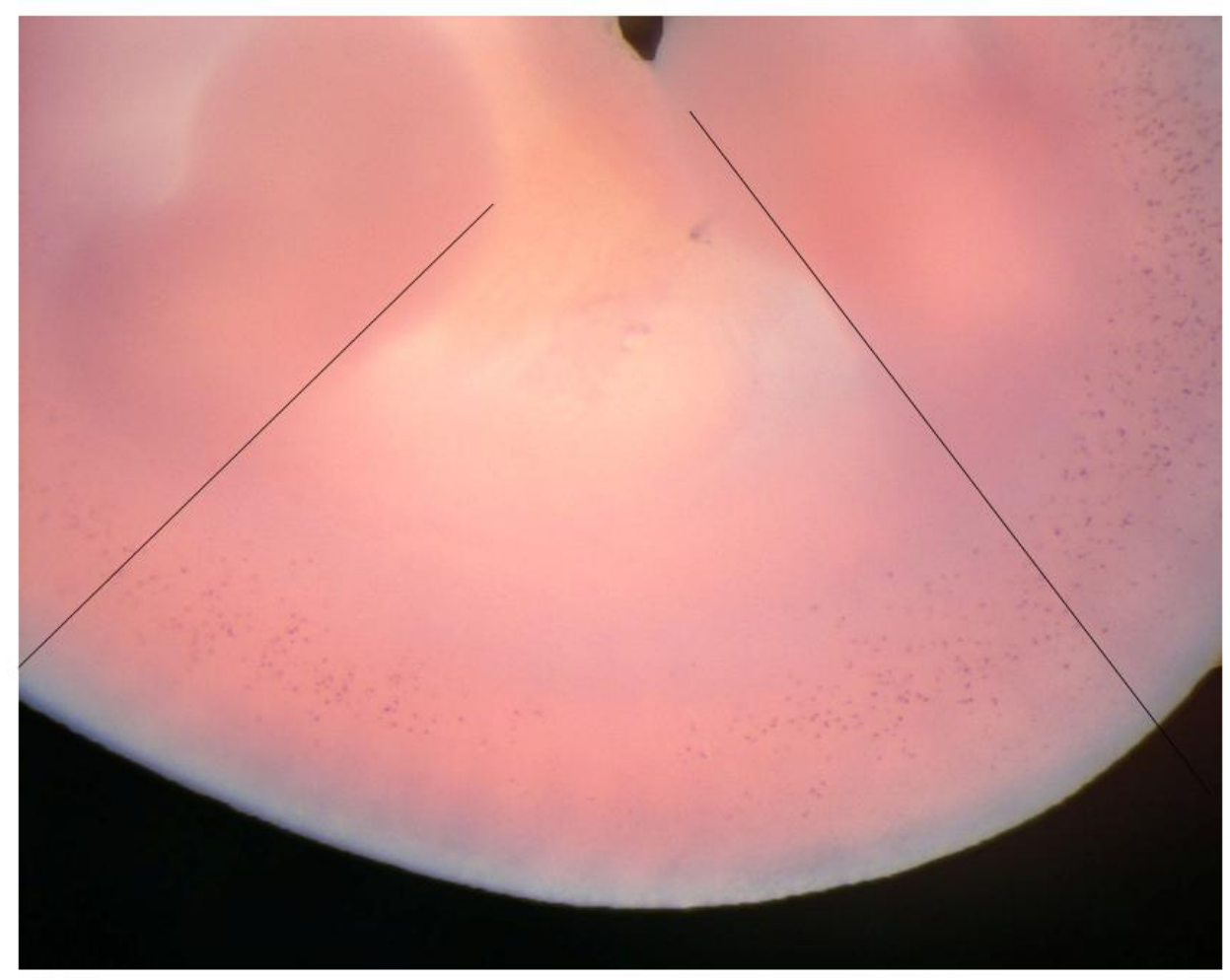

Figure A.3 Defining the area for cell counts of Pmel17 positive cells. Lines were drawn that intersect the posterior most aspect of the forelimb and the anterior most aspect of the hindlimb. E11.5 Sox10 heterozygote. 


\section{H. Lysotracker Red and LacZ Double Staining of Mouse Embryos}

Embryos were dissected and rinsed in cold $0.05 \mathrm{M} \mathrm{PBS}^{*}$ and placed in $5 \mu \mathrm{M}$ LysoTracker Red DND-99** (Invitrogen) at $37^{\circ} \mathrm{C}$ for $30 \mathrm{~min}$. Embryos were washed twice in PBS, $2 \%$ paraformaldehyde (PF; Fisher Scientific) for $1 \mathrm{hr}$ at room temperature (RT), washed twice more with PBS and then left overnight at $30^{\circ} \mathrm{C}$ in $\mathrm{LacZ}$ solution $(5 \mu \mathrm{M}$ ferricyannide, $5 \mu \mathrm{M}$ ferrocyannide, $2 \mathrm{mM} \mathrm{MgCl}$, $0.01 \%$ sodium deoxycholate (Fisher Scientific), $0.02 \%$ nonidate p-40 (Roche) and $1 \mathrm{mg} / \mathrm{ml} \mathrm{X-gal} \mathrm{(Invitrogen).} \mathrm{Rinsed} \mathrm{twice} \mathrm{in} \mathrm{PBS} \mathrm{to} \mathrm{stop} \mathrm{reaction} \mathrm{and} \mathrm{a} \mathrm{10 \%}$ sucrose (Fisher Scientific) solution was added to embryos for overnight incubation at $4^{\circ} \mathrm{C}$, rocking gently. Finally, embryos were placed in $20 \%$ sucrose solution for 4-6hrs and embedded in Tissue-Tek Tissue Freezing Medium (Sakura). Embryos were stored at $-80^{\circ} \mathrm{C}$.

*All PBS used in this protocol was pH7.2.

${ }^{* *}$ From this point on, all embryos and solutions were protected from light at all times.

\section{Counts of Lysotracker Red and LacZ+ Cells}

Transverse cryosections of $10 \mu \mathrm{m}$ were taken of embryos from the brachial nerves to the sciatic nerve. Every third section was kept in E11.5 embryos while every $4^{\text {th }}$ section was kept in E12.5 embryos. Of these sections, 30 equally spaced sections (e.g. every other section) were selected for counting. Cells that were blue $(\mathrm{LacZ}+)$, elongated and appeared to be traveling along the dorsolateral pathway were counted and checked for double labeling with Lysotracker Red.

\section{J. Buffers and Solutions}

$\mathrm{DePC} \mathrm{H}_{2} \mathrm{O}$

$0.1 \% \mathrm{DePC}$ in 1 liter $\mathrm{dH}_{2} \mathrm{O}$ mixed for a minimum of $2 \mathrm{hrs}$ on the stir plate in the hood with an open top; autoclaved and left venting in hood with loose cap.

\section{Glycerol Stock}

$100 \%$ glycerol was added in equal volumes to $\mathrm{dH}_{2} \mathrm{O}$ and autoclaved.

Luria Broth (done in hood)

$1 \%$ Tryptone powder

$0.5 \%$ Yeast Extract powder

$1 \% \mathrm{NaCl}$

Brought up to $100 \mathrm{ml}$ with $\mathrm{dH}_{2} \mathrm{O}$, calibrated to $\mathrm{pH} 7.0$, autoclaved, cooled and added $50 \mu \mathrm{l}$ of $100 \mu \mathrm{g} / \mathrm{ml}$ Ampicillin. Stored at $4^{\circ} \mathrm{C}$. 
Luria Broth Agar Plates (done in hood)

$10 \mathrm{~g}$ Tryptone powder

$5 \mathrm{~g}$ Yeast Extract

$10 \mathrm{~g} \mathrm{NaCl}$

$15 \mathrm{~g} \mathrm{Agar}$

Brought up to 1 liter with $\mathrm{dH}_{2} \mathrm{O}$, autoclaved, cooled slightly to add $250 \mu \mathrm{l}$ of $100 \mu \mathrm{g} / \mathrm{ml}$ Ampicillin and poured plates. Once set, stored at $4^{\circ} \mathrm{C}$.

Phosphate Buffered Saline (PBS) (typically made in a 10X solution)

For $\mathrm{pH} 7.4$ : $\quad 11.2 \mathrm{ml}$ of $1 \mathrm{M}$ Potassium Phosphate Monobasic $\left(\mathrm{KH}_{2} \mathrm{PO} 4\right)$ $38.8 \mathrm{ml}$ of $1 \mathrm{M}$ Potassium Phosphate Dibasic $\left(\mathrm{K}_{2} \mathrm{HPO} 4\right)$

Brought up to $100 \mathrm{ml}$ with $\mathrm{dH}_{2} \mathrm{O}$ and autoclaved

For $\mathrm{pH} 7.2: \quad 16.8 \mathrm{ml}$ of $1 \mathrm{M}$ Potassium Phosphate Monobasic $\left(\mathrm{KH}_{2} \mathrm{PO} 4\right)$

$34.2 \mathrm{ml}$ of $1 \mathrm{M}$ Potassium Phosphate Dibasic $\left(\mathrm{K}_{2} \mathrm{HPO} 4\right)$

Brought up to $100 \mathrm{ml}$ with $\mathrm{dH}_{2} \mathrm{O}$ and autoclaved

Phosphate Buffer Saline with 0.1\% Tween-20 (PBT; made fresh)

$1 \mu \mathrm{l}$ of $100 \%$ Tween-20 added for each $\mathrm{ml}$ of PBS

Tris Buffered Saline with $0.1 \%$ Tween-20 (TBST; made fresh)

$1 \mu \mathrm{l}$ of $100 \%$ Tween-20 added for each $\mathrm{ml}$ of TBS

$\underline{\mathrm{SSC}}$

20xSSC: $175.3 \mathrm{gNaCl}$ and $88.2 \mathrm{~g} \mathrm{NaCitrate}$, volume brought up to 1 liter; $\mathrm{pH}$ adjusted to 7.0 .

10xSSC, pH4.5: $250 \mathrm{ml} 20 x S S C+30 \mathrm{ml}$ citric acid $+220 \mathrm{ml} \mathrm{DePC} \mathrm{H}_{2} \mathrm{O}$

\section{References:}

Miller, S. A., Dykes, D. D, and Polesky, H. F. 1988. A simple salting out procedure for extracting DNA from human nucleated cells. Nucleic Acids Res. 16, 1215.

Sambrook, J., Russell, D.W. 2001. Molecular Cloning: A laboratory manual, $3^{\text {rd }}$ ed. Cold Spring Harbor Press, NY.

Wilkinson, D. 1998. In Situ Hybridization: a Practical Approach, $2^{\text {nd }}$ ed. IRL Press, Oxford. 
MARCIA K. LOWENSTEIN

\section{EDUCATION:}

2009

Doctoral Candidate in Biology

Florida International University, Miami, FL

1992

Intensive Course in Maternal Nutrition

Department of Obstetrics and Gynecology

University of Florida, Gainesville, FL

1988

Intensive Course in Pediatric Nutrition

University of lowa Children's Hospital

lowa City, lowa

1984

Masters of Science in Nutrition and Dietetics

Florida International University

Miami, Florida.

1983 Bachelor of Science in Human Nutrition and Food Science University of Florida, Gainesville, Florida.

\section{PRESENTATIONS:}

March 2009. Interaction between the transcription factor Sox10 and Endothelin receptor $B$ in the melanocyte lineage. Poster presentation $10^{\text {th }}$ Annual Biology Symposium, Florida International University, Miami FL.

December 2008. Interaction between the transcription factor Sox10 and Endothelin receptor $B$ in the melanocyte lineage. Poster presentation $48^{\text {th }}$ Annual Meeting American Society for Cell Biology, San Francisco, California.

February 2008. Interaction between the transcription factor, Sox10, and Endothelin receptor $B$ in the melanocyte lineage. Tenth Annual Florida International Biology Symposium, Kampong Gardens, Miami, Florida.

March 2007. Interactions Among Endothelin Receptor B and Transcription Factors, Sox10 and Pax3, in Melanocyte and Glial Lineages. Biological Diversity: Cellular and Molecular Interactions. Biomedical and Comparative Immunology Symposium. Florida International University, Miami, Florida. 
March 2006. Transgenic Expression of Ednrb Rescues the Spotting Phenotype of Sox10 Mutant Mice. Annual Scholarly Forum, Graduate Student Association. Florida International University, Miami, Florida.

October 2005. Transgenic Expression of Ednrb Rescues the Spotting Phenotype of Sox10 Mutant Mice. MBRS-Rise (Minority Biomedical Research Initiative for Scientific Enhancement) Mini-symposium, Florida Internation University, Miami, Florida.

September 2005. Transgenic Expression of Ednrb Rescues the Spotting Phenotype of Sox10 Mutant Mice. Plenary speaker, Developmental Biology 1: Melanoblast/RPE Specification, Development, Survival and Apoptosis. International Pigment Cell Conference, Reston VA.

Fall 2004. The Effect of Endothelin-3 Signaling on Early Schwann Cell Development. MBRS-Rise (Minority Biomedical Research Support Research Initiative for Scientific Enhancement) Mini-symposium, Florida International University, Miami, Florida.

PUBLICATIONS:

Martinez, J., Lowenstein, M. and Munois, W. "Nutrition and Substance Use in The Adolescent Male Football Player". International Pediatrics, Dec. 1993 (vol. 8, no. 4).

Lowenstein, M.K. "How to Help America Eat Right". Miami Medicine, March, 1993.

Lowenstein, M.K. and Field, T. "Maternal Depression Effects on Infants. Analise Psicologica, Jan. - March, no.1, 1992.

Lowenstein, M.K. and Field, T. "Maternal Depression Effects on Infants. Devenir, Sept., no. 3, 1990.

Lowenstein, M.K. "Family Dynamics Profile: Identifying Factors Contributing to Disordered Eating Patterns." Dietitian's Patient Education Manual, ASPEN Publishers; vol.1, 1991.

Lowenstein, M.K. "Weight Reduction Techniques in the Pediatric Population". Topics in Clinical Nutrition, 2:1, 1987.

Lowenstein, M.K., Blackburn, S.A., Curry, K. and Easton, P. "Integrated Diet Therapy and Dietary Counseling: An Alternative Educational Technique". Journal of The American Dietetic Association, 86:44, 1986. 